\title{
A Limpet's Legacy: \\ Carry-Over Effects across Life Stages and Generations \\ Caused by Global Change Stressors
}

by

Gustav Kessel

\author{
A thesis \\ submitted to Victoria University of Wellington \\ in partial fulfilment of the \\ requirements for the degree of \\ Master of Science \\ in Marine Biology
}

Victoria University of Wellington

2015 


\section{Acknowledgements}

I would like to express my gratitude to all those who helped me during the course of my research, especially my supervisor, Dr. Nicole Phillips. Her expertise and the invaluable guidance and advice she imparted on all aspects of my thesis over two years ensured that this project was not only conducted smoothly and efficiently, but also made it a rewarding and enjoyable experience. I consider myself very lucky to have studied under Nicole's supervision.

I also thank Dr. Ken Ryan for his advice and generously supplying UVR-related equipment, as well as John van der Sman for skilfully constructing escape-proof limpet containers and water change siphons. The Phillips lab group was also instrumental in my work. Agnes Rouchon kindly shared her knowledge of marine metal pollution and assisted in the creating of a copper dosage methodology, while Stephanie Marinus contributed significantly to the maintenance of algal cultures.

Special thanks goes to Ushana Jayasuriya, my partner and unceasing source of encouragement, who accompanied me on limpet collection excursions and kind-heartedly donated her ears whenever I felt the need to discuss limpet-related triumphs or hardships.

Finally, I thank the Victoria University Coastal Ecology Laboratory (VUCEL) and the School of Biological Sciences for providing space, facilities, and administrative support.

This research was made possible through funding provided by Victoria University of Wellington in the form of a Master's by Thesis Scholarship, the Allison Morton Scholarship in Ecology and Marine Biology, and the Dr. FG Maskell Prize. 


\begin{abstract}
Global change is increasingly impacting coastal marine systems. Organisms inhabiting the intertidal zone may be especially vulnerable to additional anthropogenic influences, which augment the naturally stressful, highly variable conditions to which they are already subjected and may lead to the manifestation of artificially severe carry-over effects (COEs). In marine invertebrates with complex life histories, COEs can occur between life stages, when the conditions experienced by one stage influence the characteristics or performance of the next, as well as trans-generationally, in which case the environment experienced by a parental generation affects offspring. Most of the existing literature surrounding COEs focuses only on those between life stages or generations, seldom both simultaneously, and do so with the implementation of only a single stressor. In nature however, organisms may be affected by both forms of COE, since the presence of one does not preclude the other, and are invariably subjected to multiple co-occurring stressors that can interact in complex ways. Consequently, how trans-generational COEs might impact the propagation of stress through offspring life stages remains unclear, and how these processes operate in a global change context is little understood. It was here aimed to elucidate the role of COEs under ongoing global change by addressing these common literature imitations and taking the novel approach of examining how the effects of multiple, global change-associated stressors carry-over from a parental generation through their offspring's life stages in order to provide a more realistic representation of the conditions under which COEs manifest in the field.
\end{abstract}

This was done using Siphonaria australis, an intertidal pulmonate limpet that deposits benthic egg masses, from which hatch planktonic veliger larvae. Adult $S$. australis were subjected to one of four treatments for $4 \mathrm{~h} /$ day over four weeks to induce trans-generational COEs: a no-stress control, a pollution treatment with added copper $(5.0 \mu \mathrm{g} / \mathrm{L})$, a "climate change" treatment with elevated temperature $\left(25^{\circ} \mathrm{C}\right)$ and UVR $(1.7 \mathrm{~W} / \mathrm{m} 2)$, and a full global change treatment incorporating all three stressors. At the end of this period, the egg masses laid under each of these adult treatments were subjected to further experimentation for two weeks by being redistributed among the same four treatments again, so as to produce 16 unique treatment histories of adult-to-egg mass stress. Of these, 11 provided successfully hatching larvae, which were reared and observed for COEs between life stages (from egg to larva) under ambient conditions (ie. no added stressors) for 27 days.

In adult $S$. australis survivor size, the size of egg masses laid and the size of individual eggs varied in complex ways over time and across treatments, while the number of survivors was unaffected by stress. Egg masses were unaffected in terms of hatching time but displayed strong responses to parental and developmental stress exposure through hatching success, and the percentage of viable eggs per egg mass, with the latter clearly declining according to adult treatment severity and both showing trans- 
generational COEs. Larval characteristics were extremely varied across treatment histories and highly context-dependent as hatching size, size reached by 27 days, growth rate, and size at death all showed evidence of COEs between generations and life stages, as well as interaction between both types of $\mathrm{COE}$, with the number of survivors again being the only unaffected response variable. Overall, transgenerational COEs were slightly more common than those between life stages.

These results show that both forms of COE, each triggered by exposure to multiple stressors in progenitors and developmental stages, interact to form highly context-dependent legacies of mostly impaired performance in $S$. australis larvae. This implies that COEs may become more prominent with worsening stressors in the future and suggests that the role of COEs in the persistence of marine invertebrates under ongoing global change may so far have been underestimated by the existing literature. 


\section{Table of Contents}

Acknowledgements.

..ii

Abstract .iii

Table of Figures vii

List of Tables viii

Chapter 1: General Introduction. . .1

1.1 Global Change and Coastal Habitats..................................................

1.2 Stress in Rock Pools - A Closer Look at Temperature, UVR and Copper..................2

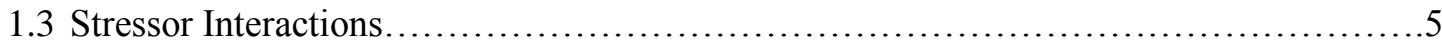

1.4 Carry-Over Effects between Life Stages.............................................6

1.5 Carry-Over Effects between Generations...........................................

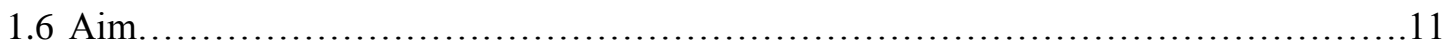

Chapter 2: Trans-Generational Carry-Over Effects Caused by Stress Exposure in Adults and

Egg Masses of Siphonaria australis................................................12

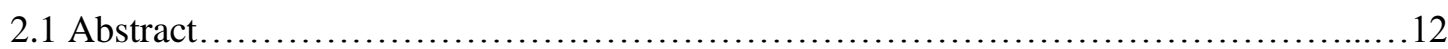

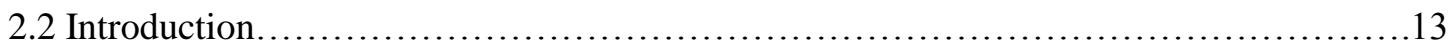

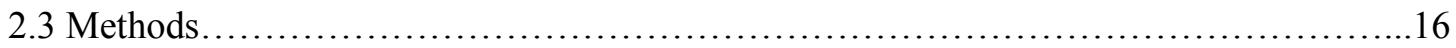

2.3.1 Specimen Collection............................................... 16

2.3.2 Experimental Stress Exposure in Adult S. australis...........................16

2.3.3 Stress Exposure in Egg Masses...........................................18

2.3.4 Data Collection...............................................................

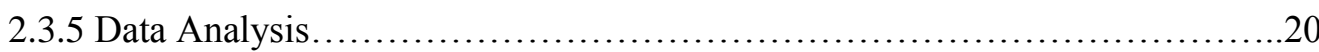

2.3.5.1 Size and Number of Surviving Adult S. australis....................20

2.3.5.2 Number of Egg Masses Laid....................................20

2.3.5.3 Sizes of Egg Masses and Eggs...............................20

2.3.5.4 Hatching Success..........................................20

2.3.5.5 Hatching Times............................................21

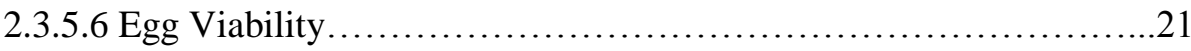

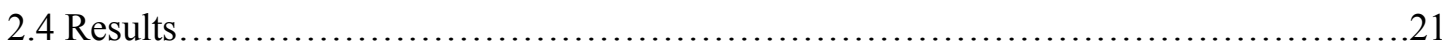

2.4.1 Size and Number of Surviving Adult S. australis............................21

2.4.2 Number of Egg Masses Laid................................................21 


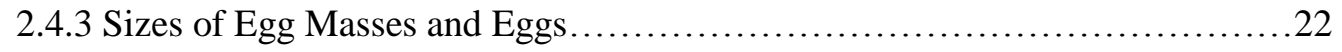

2.4.4 Hatching Success.................................................22

2.4.5 Hatching Times..........................................................

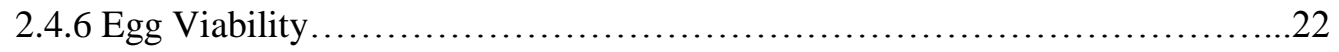

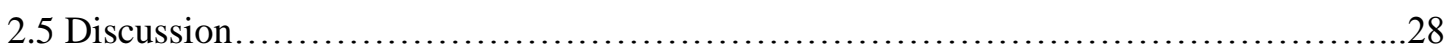

2.5.1 Effects of Stress on Adult Limpets.....................................28

2.5.2 Effects of Stress on Egg Masses............................................30

\section{Chapter 3: Parental and Embryonic Stress Causes Carry-Over Effects in Larvae of Siphonaria}

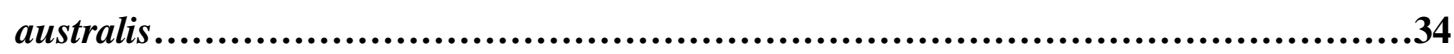

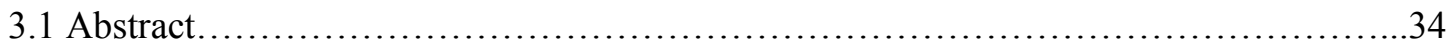

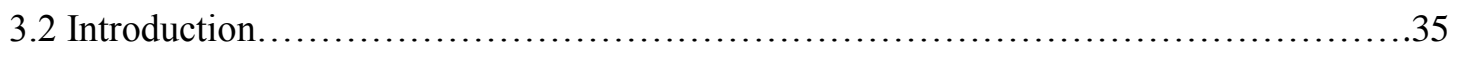

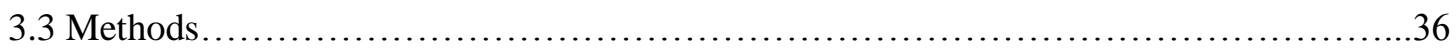

3.3.1 Rearing of Larvae.................................................. 36

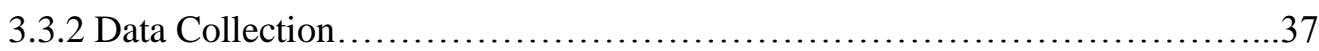

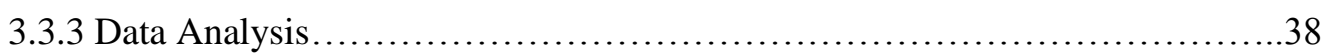

3.3.3.1 Hatching Size ................................................. 38

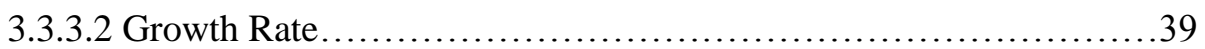

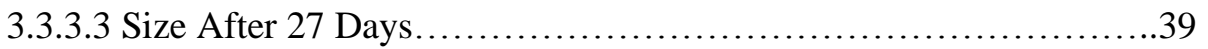

3.3.3.4 Size at Death.................................................

3.3.3.5 Survivorship............................................. 39

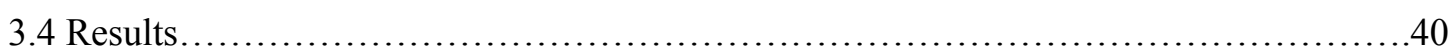

3.4.1 Hatching Size ......................................................40

3.4.2 Growth Rate............................................................... 40

3.4.3 Size After 27 Days....................................................... 41

3.4.4 Size at Death............................................................ 41

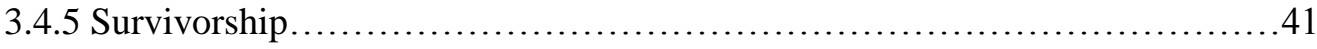

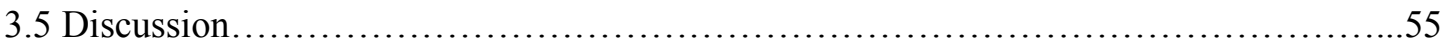

Chapter 4: General Discussion.....................................................60

4.1 Summary of Findings..................................................61

4.2 Further Directions for COE Research...................................63

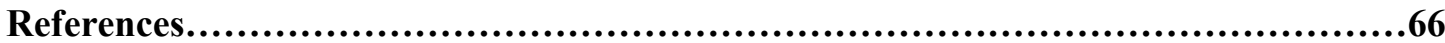




\section{Table of Figures}

Figure 2.1 Siphonaria australis: A) Adult with freshly deposited egg mass at VUCEL; B) side view of adult at VUCEL; C) Egg mass exposed during low tide on Wellington south coast.

Figure 2.2 A) $S$. australis eggs containing viable blastulae; B) Failed eggs containing inviable blastulae. 19

Figure 2.3 A) S. australis eggs containing veliger larvae ready to hatch; B) close-up. .19

Figure 2.4 Mean shell length of adult S. australis before and after 4 weeks of stress exposure.

Figure 2.5 Mean number of surviving adult S. australis out of 10 after 4 weeks of stress exposure.

Figure 2.6 Mean number of egg masses laid by adult $S$. australis during each of the 4 weeks of adult stress across treatments .24

Figure 2.7 Mean sizes of egg masses laid by adult $S$. australis during each of the 4 weeks of adult stress across treatments

Figure 2.8 Mean sizes of individual eggs in egg masses laid by adult $S$. australis during each of the 4 weeks of adult stress across treatments.

Figure 2.9 The $\%$ of successfully hatching egg masses. Each bar represents one of the 16 treatment histories .25

Figure 2.10 Mean hatching time of egg masses .26

Figure 2.11 Mean \% of viable eggs per egg mass

Figure 3.1 Mean shell length at hatching of $S$. australis larvae across treatments .42

Figure 3.2 Mean coefficient of variation for shell length at hatching across treatments. . .42

Figure 3.3 Mean growth rate of $S$. australis larvae from hatching to day 9 of rearing period across treatments. 
Figure 3.4 Mean growth rate of S. australis larvae from day 9 to day 18 across treatments....

Figure 3.5 Mean growth rate of $S$. australis larvae from day 18 to day 27 across treatments.

Figure 3.6 Mean shell length at 27 of $S$. australis larvae across treatments. 44

Figure 3.7 Mean coefficient of variation for shell length of $S$. australis larvae at 27 days across treatments.

Figure 3.8 Mean shell length at death of S. australis larvae across treatments. 45

Figure 3.9 Mean number of surviving $S$. australis larvae at 27 days across treatments. . .46

\section{List of Tables}

Table 2.1 Details of the four experimental treatments

Table 2.2 Survivor size pairwise comparisons.

Table 2.3 Egg viability pairwise comparisons

Table 3.1 Hatching size pairwise comparisons

Table 3.2 Hatching size CV pairwise comparisons.

Table 3.3 Hatching to day 9 growth rate pairwise comparisons

Table 3.4 Day 9 to 18 growth rate pairwise comparisons. .50

Table 3.5 Day 18 to 27 growth rate pairwise comparisons.

Table 3.6 Size at day 27 pairwise comparisons.

Table 3.7 Size at day 27 CV pairwise comparisons. .53

Table 3.8 Size at death pairwise comparisons .54 


\section{CHAPTER 1 \\ General Introduction}

\subsection{Global Change and Coastal Habitats}

"Global change" describes the collective effects of anthropogenic climate change and other compounding disturbances such as pollution. This modern phenomenon threatens not only to compromise the ecological integrity of coastal marine systems but also to undermine their socioeconomic value (Harley et al., 2006). Marine habitats stretching from the intertidal to the continental shelf provide tens of trillions of dollars per year in ecosystem goods and services, such as food and nutrient cycling (Costanza et al., 1997). Consequently, marine environments and their responses to global change are the focus of an extensive literature that began to increase rapidly after a pair of seminal reviews was published in the early 1990s. Fields et al. (1993) and Lubchenco et al. (1993) both focused on increasing temperature as causing widespread shifts in distributions according to the thermal tolerances of organisms. Crucially however, such initially envisioned consequences are now regarded as too simplistic.

Coastal habitats in particular, are under increasing pressure due to the high proportion of human populations living near shorelines, whose activities impinge on these ecosystems directly as well as on broader scale climate drivers (Halpern et al., 2008). In addition to temperature, other stressors now of concern in coastal marine systems include elevated ultraviolet radiation (UVR), decreases in $\mathrm{pH}$, pollution, eutrophication and sedimentation. Such stressors are capable of inducing modifications to innumerable aspects of ecosystem functioning, such as food availability, disease, reproduction, competition, community structure and population connectivity (Munday et al., 2009). These effects will not manifest evenly throughout the marine environment, because some habitats and ecosystems are more vulnerable than others. In particular, the impacts of global change will be magnified in habitats that are already subjected to a relatively high degree of "natural" stress, such as the rocky intertidal zone. This is because although organisms inhabiting this zone are comparatively robust, they lack the propensity to further optimise their physiology to any great extent. As a result, intertidal organisms may suffer from a limited ability to adjust to additional anthropogenic stress (Tomanek \& Somero, 1999; Stillman, 2002).

Generally, organisms of the rocky intertidal may not be able to adapt rapidly enough to cope with ongoing global change, and instead many will shift to areas where stress is less severe or remain in the areas they currently occupy and suffer the consequences, which may ultimately lead to local extinction (Clarke, 1996). For example, increasing sea temperatures may be a chief driver of range shifts towards 
higher latitudes (Thompson et al., 2002). Conversely, "hot spots", areas where low tides routinely coincide with stressful daytime conditions, are predicted to cause local extinctions of intertidal organisms through aerial exposure and elevated desiccation risk as air temperatures continue to rise (Helmuth et al., 2002). Accompanying this warming is elevated UVR exposure reaching levels with which intertidal organism are behaviourally and physiologically ill-prepared to cope (Beardall et al., 1998), sea-level rise causing a reduction in the vertical extent of rocky shores (Thompson et al., 2002), and an increase in storm-associated wave action leading to reduced biodiversity (Ricciardi \& Bourget, 1999).

The intertidal zone is also prominently associated with the effects of oil spills, which although sporadic and relatively rare, range in impact from catastrophic acute damage to chronic alterations to intertidal ecosystems (Peterson, 2001). Other chemical pollution such as heavy metals and endocrine disrupters represent a far more common source of stress that are capable of inducing equally detrimental and highprofile effects such as imposex (Depledge \& Billinghurst, 1998). Yet more challenges to intertidal organisms posed by global change include eutrophication, largely through toxic algal blooms (Nixon, 1995), and greater sedimentation (Airoldi, 2003) by for example inhibiting filter feeding. Clearly, rocky intertidal habitats will be affected by ongoing global change in innumerable ways. However, much like the rocky intertidal was identified as a particularly vulnerable coastal habitat, so too can rock pools be labelled as an aspect of the intertidal zone that is especially prone to global change. This is because rock pools offer a refuge to intertidal organisms from aerial exposure and can thus harbour many species, while on the other hand exposing these organisms to extreme levels of certain stressors (Thompson $e t$ al., 2002).

\subsection{Stress in Rock Pools -}

\section{A Closer Examination of Temperature, UVR and Copper}

Rock pools are dynamic environments that experience dramatic fluctuations in a myriad of physicochemical parameters over diel, tidal and seasonal time scales (Ganning, 1971; Morros \& Taylor, 1983). This includes natural stressors such as high water temperature and UVR exposure, which are most limiting to rock pool inhabitants when low tides coincide with hot, clear weather during summer. These parameters may be natural, but such conditions are expected to become more common with ongoing anthropogenic climate change (Helmuth et al., 2002; Kemp, 2009), and for this reason elevated temperature and UVR exposure were selected as representative of climate change stressors in the experiments conducted for this thesis. 
However, man-made stressors such as pollution must also be considered as part of the fluctuating parameters of the rocky intertidal. For example, the accumulation of runoff polluted with copper $(\mathrm{Cu})$ in rock pools can be severe after rain (Stoffers et al., 1986). Because Cu pollution is directly related to human activity and because coastal populations continue to grow, it is likely that pollutants such as $\mathrm{Cu}$ will play an increasing role in future intertidal stress regimes. Therefore, $\mathrm{Cu}$ pollution was selected as representative of direct anthropogenic stress in the intertidal. Together, high temperature, UVR exposure and $\mathrm{Cu}$ pollution are herein intended to illustrate the stress brought about by global change, both by its climate change aspect (temperature and UVR) and by the influence of compounding factors $(\mathrm{Cu})$.

Of all stressors afflicting intertidal organisms in rock pools, high water temperature is probably the most ubiquitous. To understand why high temperatures can pose a problem, it is important to recognise that marine organisms generally occur near their upper thermal tolerance threshold. Exceeding this threshold can lead to protein damage and adversely affect vital physiological processes such as membrane fluidity and organ function (Somero, 2002). Moreover, this form of thermal stress is far from rare. In temperate waters for example, ambient summer sea temperatures may be around $18^{\circ} \mathrm{C}$, yet at low tide, rock pools may be heated to over $30^{\circ} \mathrm{C}$ by the sun (Kemp, 2009). Again, it must be emphasised that such wide temperature shifts are natural and that most intertidal organisms can tolerate rare or brief instances of this kind. Crucially however, global change is expected to increase the frequency of these occurrences (Harley et al., 2006). In response to more frequent, more severe or prolonged stress exposure, intertidal organisms have been demonstrated to suffer negative effects in terms of mortality, development, growth rate, fecundity and many other traits (review by Przeslawski et al., 2008).

The sun heats rock pools, and so, in this habitat high water temperatures occur almost invariably in concert with high UVR exposure. Solar UVR (wavelengths of 280-400nm), principally short wavelength UV-B (280-315nm), can negatively affect aquatic organisms through DNA damage, increased mutation rates, elevated disease risk and impaired or abnormal development (Sinha \& Hader, 2002; Przeslawski et al., 2005; reviews by Day \& Neale, 2002; Paul \& Gwynn-Jones, 2003). Surface UV-B levels correspond strongly with historical losses of stratospheric ozone (McKenzie et al., 2003). Yet, despite the success of the Montreal Protocol in curbing this ozone depletion, climate change indirectly facilitates the continued increase of UV-B exposure through a number of mechanisms, such as raising the average number of annual sunshine hours around the globe (Hofmann \& Pyle, 1999).

This ongoing increase in UVR exposure has been masked by large-scale seasonal and geographic variability (Solomon, 2004), causing a delay in its recognition as a legitimately worsening stressor (review by Hader et al., 2007). This is especially true for parts of the southern hemisphere (eg. New Zealand) where UVR exposure is accentuated relative to the northern hemisphere (McKenzie et al., 
1999). Furthermore, any increase in UVR exposure in temperate latitudes may have more profound ecological consequences than in equatorial regions because temperate organisms lack the mitigating repair mechanisms and behavioural strategies found in taxa that evolved under the normally high UVR levels of the tropics (Beardall et al., 1998).

Similar to high temperature and UVR, metals occur naturally in the intertidal, but their levels have been exaggerated by global change. Trace amounts of copper and other metals are natural components of the biosphere that are necessary for the growth and correct development of marine organisms, but which nonetheless become toxic at certain levels (Bryan, 1971). Copper is a common contaminant in coastal systems throughout the world, originating from urban or agricultural runoff, industrial discharge, and leaching from anti-fouling paints (Johnston et al., 2002). Intertidal communities may be particularly vulnerable to copper pollution because they exist close to its source, namely coastal human activity.

Copper exposure has an array of severe effects in diverse marine taxa. This includes physiological effects such as immune system suppression in mussels (Pipe et al., 1999), heart rate reduction in gastropods (Marchan et al., 1999) and impaired digestion in echinoderms (Chen et al., 2002), alterations to behaviour such as reduced clamping tenacity in limpets (Cartwright et al., 2006), as well as impaired reproduction, development and growth in organisms across a range of taxa from bacteria and algae to fish (Mayer-Pinto et al., 2010). Of course, apart from these sub-lethal effects, copper can also directly cause mortality, as it is generally considered to be one of the three most toxic metals along with mercury and silver (Bryan, 1971). Together, these lethal and sub-lethal effects of copper on individual organisms can alter ecological processes throughout their surrounding community, such as competition and predator-prey relationships, by changing the relative abundances of highly susceptible and more robust species and the ways in which different species interact (Ramos-Jiliberto et al., 2012). Despite the large scope this element possesses for influencing marine organisms, it has long been acknowledged that the toxicity of heavy metals like copper is highly variable and depends to a considerable extent on other environmental factors. This includes UVR exposure and the salinity, $\mathrm{pH}$ and temperature of water (McLusky et al., 1986). Therefore, a clear need exists to evaluate the interactions between these cooccurring stressors, and how they will be altered by ongoing global change. 


\subsection{Stressor Interactions}

Global change "stressors" are environmental and biotic factors that exceed their natural range of variation due to recent human activity (Sanderson et al., 2002; Halpern et al., 2007). Many stressors have been found to strongly affect organisms when examined individually, since this is how research in this field began. Although research focused on the cumulative and interactive effects of multiple stressors is increasing, it remains rare compared to the high number of studies on single stressors (review by Crain et al., 2008). This is despite the prevailing consensus that natural systems are almost always subjected to multiple human-derived stressors simultaneously (Halpern et al., 2008). It is not surprising therefore, that the need to better understand the effects of co-occurring stressors has been cited as one of the most pressing issues of modern ecology for more than a decade (Sala et al., 2000).

Theoretical and applied research commonly assumes the effects of multiple stressors to be additive, meaning that the impacts of single stressors simply combine (Ban \& Alder, 2008). However, multiple stressors may also exacerbate their respective negative impacts. A well-studied example is that of phototoxicity, where UVR greatly enhances the deleterious effects of toxins (review by Pelletier et al., 2006). This is known as a synergistic interaction between stressors. In contrast, the effect of multiple stressors may also be less than would be expected by their individual impacts, perhaps even to the point where the presence of one stressor mitigates the effects of another. Such stressor interactions are known as antagonistic (Folt et al., 1999). An example is the possible alleviation of UVR damage by nutrient enrichment (Wulff et al., 2000). Clearly, a great diversity of stressor combinations and interactions can occur throughout a broad range of ecological settings. Rather worryingly, meta-analyses suggest that synergistic interactions (the most severe) are by far the most common (review by Crain et al., 2008).

Interestingly, studies incorporating elevated UVR as a stressor, particularly when paired with elevated temperature and toxin exposure, produce almost exclusively synergistic interactions (Crain et al., 2008). However, it is important to understand that the majority of such studies are carried out under laboratory conditions, and that laboratory experiments tend to produce more strongly synergistic interactions than field studies (Crain et al., 2008). This may be because laboratories cannot replicate the conditions under which organisms would experience these stressors in nature with full realism. It is also true that laboratory-based experiments often specifically target those stressor combinations that are deemed likely to produce significant results. Thus, a degree of bias towards "high-profile" stressors such as UVR, reduced $\mathrm{pH}$ and elevated temperature does exist in the literature. Many other possible combinations remain virtually ignored. These reasons expose a need for caution when extrapolating the effects of laboratory-derived stressor interactions to "the real world" (Mayer-Pinto et al., 2010). 
Additionally, higher order interactions complicate the prediction of cumulative effects in general (Billick \& Case, 1994). For instance, the properties of stressors themselves may shift with interaction, such as toxin solubility varying according to temperature (Crain et al., 2008). This insight renders many inferences made from individual stressors difficult to interpret (Hoffman et al., 2003). Responses to stressors may also be context dependent, because the way an organism responds to one stressor may be changed by the presence of another, or by the presence of other organisms (Crain, 2008). Lastly, stressor responses may be highly species-specific, being determined by an organism's evolutionarily and ecologically derived tolerances. Therefore, data drawn from single-species experiments may not accurately reflect wider community responses (Vinebrooke et al., 2004).

However, it may be that such experiments can sensibly be used as a proxy for other species if they are closely related or share a similar ecological niche. Ultimately, research on the effects of global change will continue to heavily rely on predictions made from simplified laboratory settings, at least for the foreseeable future. Further, work on single species is also intrinsically valuable when species of exceptional ecological "importance" are considered. For example, many species of intertidal gastropods regulate and structure their ecosystems through activities such as grazing (Underwood, 1979). Perhaps responses to global change in single species of ecological significance, like certain gastropods, may therefore be used to infer repercussions at community or ecosystem levels.

\subsection{Carry-Over Effects between Life Stages}

Whatever the wider implications of stress on any one species may be, studies examining the effects of stress commonly concentrate on one life stage at a time (ie. either adults or larvae). This belies the fact that vulnerability to stress occurs throughout the life cycles of these animals, rather than being exclusive to one particular life stage. It is this oft-ignored procession through various life stages that is truly pivotal in understanding how organisms respond to stress, since stress exposure in one stage can profoundly influence stress responses in others (Marshall \& Morgan, 2011).

Gastropods such as snails, limpets and abalone are enthusiastically studied in laboratories around the world for two key reasons. Firstly, it is worth highlighting once more that adult gastropods often play important ecological roles in intertidal ecosystems (Underwood, 2000). Therefore, any manifestation of stress relating to global change in these animals is likely to affect their entire communities. Secondly, gastropods often possess complex life cycles. For example, a complex life cycle in an intertidal gastropod may commence with encapsulated embryos that are deposited as egg masses, followed by hatching larvae that pass through a series of planktonic forms before finally settling back in the intertidal as juveniles (Wilbur, 1980). Critically, this sequence of separate, morphologically and ecologically 
distinct life stages allows for the occurrence of "carry-over effects", whereby the conditions experienced by one stage can influence the characteristics or performance of the next (O'Connor et al., 2014).

This definition is relatively new and represents the most recent interpretation of a phenomenon that is extremely diverse and widespread. This can be appreciated when the historical evolution of the field of carry-over effects (abbreviated to COEs) is briefly examined. The idea of COEs was initiated through medical research on humans in the 1960s, when clinicians became aware that effects from one treatment can "carry over" into another (Wallenstein \& Fisher, 1977). The ecological study of COEs originated with migratory animals (see Norris, 2005), where they were defined as events or processes occurring in one "season", that alter how an organism transitions between seasons, and thus alter performance in subsequent seasons (Harrison et al., 2011). For the purposes of examining marine invertebrates, "life stage" has simply been supplemented in favour of “season" (O'Connor et al., 2014).

COEs have been studied intensively in terrestrial settings, but the literature is comparatively limited for the marine environment, where benthic invertebrates comprise the bulk of research subjects. While other taxa such as coral reef fish are beginning to emerge as prone to COEs (Reusch, 2014), many have been identified in invertebrates. In this group, exposure to salinity (Pechenik et al., 2001), temperature (Delorme \& Sewell, 2014) nutrition (Phillips, 2002; Phillips, 2004; Emlet \& Sadro, 2006) and pollution (Ng \& Keough, 2003) stress in larval stages is already known to produce legacies of poor juvenile survival and growth that in some cases stretch even into adulthood, where reduced fitness is incurred.

Larval forms are generally more vulnerable to stressors than adults or juveniles, and COEs can be induced when larvae are experimentally subjected to stress (Kurihara, 2008; Byrne et al., 2010; Talmage \& Gobler, 2011; Davis et al., 2013). Interestingly, gametes and fertilised zygotes in the form of eggs, are sometimes robust to environmental stressors (Byrne, 2011). However, results that directly contradict this have also been obtained, showing that eggs and early embryos in particular can be highly sensitive to stress (Przeslawski, 2004; Russell \& Phillips, 2009; Russell \& Phillips, 2009b), as well as evidence that fertilisation itself can be impaired under climate change scenarios in diverse taxa (Parker et al., 2009; Parker et al., 2010). While the relative vulnerability of life stages may therefore show some variation from species to species, ecologists generally regard the transitions between these stages as important in the propagation of stress effects through an animal's life. In other words, metamorphosis does not present "a new beginning" (Pechenik, 2006).

In stark contrast to this modern ecological perspective, metamorphosis has traditionally been considered as providing an "adaptive decoupling", leaving each life stage to evolve more or less independently from other stages and the selection pressures they experience (Wilbur, 1980; Moran, 1994; Parichy, 1998). While ecological evidence mounted for strong COEs that transcend the metamorphic boundary, 
a long debate ensued among evolutionary biologists regarding the existence and adaptive significance of COEs (see Schluter et al., 1991; De Block \& Stoks, 2005; Podolsky \& Moran, 2006). Only recently has a consensus accepting the reality of COEs been reached in the evolution-focused literature. Unfortunately, this amounted to little more than "patterns of performance across life-history stages are complex" (Crean et al., 2011). Furthermore, practically nothing is known about the genetic basis of COEs (Johnson et al., 2010). All this acts to underline the lack of understanding that persists in this area, particularly with regard to the true mechanisms of how complex life cycles function ecologically and how they initially evolved. This subject can justly be called nebulous, but yet more complicating factors are to follow. From the above incorporation of genetics and evolution into the mechanisms of COEs, it follows that these effects must necessarily be capable of influencing multiple generations.

\subsection{Carry-Over Effects between Generations}

"Trans-generational" carry-over effects, also known as parental effects (Agrawal et al., 1999), are defined as influences on offspring phenotype that cannot be attributed to offspring genotype or the offspring's environment (Lacey, 1998). This means that parental effects represent avenues for nongenetic inheritance (Bonduriansky, 2012; Bateson, 2014), by acting as conduits through which environmental factors occurring in the parental generation can manifest as manipulations of offspring phenotype (Badyaev \& Uller, 2009; Bonduriansky \& Day, 2009; Wolf \& Wade, 2009). COEs between generations have also been labelled as a form of "trans-generational phenotypic plasticity", where offspring phenotype is regulated by the parental phenotype and/or environment rather than that of the offspring itself (Mondor et al., 2004).

Importantly, trans-generational COEs do not represent "inheritance of acquired characteristics". In this long-defunct theory, characteristics acquired by somatic cell lineages during an organism's life were thought to somehow be capable of being represented in the germ-line and thus be genetically inherited (Bonduriansky, 2012). This is certainly not assumed by modern COE researchers. But clearly something is in fact being "passed on" from parents to offspring when COEs occur. If this "something" is not genetic, then what is it? Unfortunately, the underlying molecular mechanisms of trans-generational COEs are not yet understood. Nonetheless, evidence for the existence of novel mechanisms mediated by substances found in gametes at conception as well as by parental glandular and somatic donations to offspring is mounting (Bonduriansky \& Day, 2009). Trans-generational COEs are now a matter of discussion in the emerging field of epigenetics (Youngson \& Whitelaw, 2008), and have been acknowledged for some time as potentially major modifiers of evolutionary trajectories (Kirkpatrick \& Lande, 1989). 
In an ecological context, trans-generational COEs are characterised by a long history of research focusing on terrestrial taxa such as insects (Franzke \& Reinhold, 2012) and plants (Holeski et al., 2012), with intense interest in marine systems building only after the early 1990s (reviews by Roach \& Wulff, 1987; Mousseau \& Dingle, 1991; Mousseau \& Fox, 1998). In marine invertebrates, trans-generational COEs are thought to be predominantly mediated maternally rather than paternally. This is because most species are anisogamous, with females having to invest in larger gametes than males. As a result, the two sexes may influence offspring phenotype disproportionately and most of the literature utilises the term "maternal effects" to express the dominant role of mothers in this process (Marshall et al., 2008). Note however, that recent research has begun to indicate that paternal effects may be equally common (Crean et al., 2013; Ritchie \& Marshall, 2013).

Maternal effects can be further differentiated according to whether they benefit or disadvantage offspring. Maternal effects may increase offspring fitness and/or performance, in which case they are termed "anticipatory maternal effects" (AME) (Bernardo, 1996; Agrawal, 2001). This form of maternal effect may buffer offspring against the negative impacts of environmental heterogeneity if mothers are able to adjust the phenotype of their offspring to correspond with the environment that they are likely to experience (Fox et al., 1997). Existing examples of AMEs in marine invertebrates include increased tolerance to pollutants (Plautz et al., 2013) and enhanced predator avoidance (Krueger \& Dodson, 1981) in offspring. This can also result in consequences for population dynamics (Benton et al., 2001), and has been linked to enhanced population persistence in the face of climate change (Chevin \& Lande, 2010).

Conversely, maternal effects can also decrease offspring performance (Bayne et al., 1975; Rossiter, 1996) through "selfish maternal effects" (SME) (Marshall \& Uller, 2007). SMEs are known to be triggered by competition (McCormick, 2006), pollution (Cox \& Ward, 2002; Marshall, 2008), ocean acidification (Parker et al., 2012) and nutritional stress (George et al., 1991) on adult marine invertebrates of various groups. Because of the existence of both positive (AME) and negative (SME) impacts on offspring generations, there has been debate over the true adaptive significance of maternal effects (see Heath \& Blouw, 1998). Current opinion indicates that both types can be adaptive (Marshall et al., 2008; Burgess \& Marshall, 2011).

It is easy to recognise the adaptive significance of AMEs, where parents increase their own reproductive fitness by increasing that of their offspring. Similarly, in SMEs, parents increase their own fitness by temporarily producing inferior offspring in order to conserve energy which can later be utilised to produce higher quality offspring when conditions become more favourable (Marshall \& Keough, 2004). This shows how the respective interests of the parent and offspring generations can conflict, and may in fact only occasionally align to a common benefit (Trivers, 1974). One may justifiably be concerned 
that anthropogenic global change will prevent conditions from becoming favourable for extended periods of time, forcing mothers to be perpetually "selfish" and trade poor offspring survival chances for an increase in their own. This possibility has not so far been raised by other authors. Judging from the fact that more examples of SME's (negative effects) than AMEs (positive effects) currently exist in the literature, and the overall tendency for complex negative effects to increase in frequency under global change conditions (see section on synergistic stressor interactions in 1.3 above), this may indeed one day be the case.

Another form of trans-generational COEs is "maternal investment". This can best be described as a special case of "maternal effects". Maternal investment is essentially the parent-centric compliment to the more offspring-centric study of maternal effects. Specifically, maternal investment is the amount of energy that a female invests in her offspring, and much of the research focuses on the reasons for this investment and the scales over which it varies, including trade-offs between the size and number of offspring (Stearns, 1992). The energy that mothers put into reproduction has been found to dramatically affect virtually all stages of offspring life history both positively (as in AMEs) and negatively (as in SMEs) in diverse marine taxa (Chambers \& Leggett, 1996; Marshall \& Keough, 2008).

Because maternal investment is a foundational component of much COE research, it offers a wide range of examples of the kinds of effects that one generation can cause in another. For example, maternal investment leading to larger eggs, such as in response to food or salinity stress (Guisande et al., 1996; Gimenez \& Anger, 2001), may cause longer development times in subsequently hatching larvae (Marshall \& Bolton, 2007), greater larval longevity (Isomura \& Nishimura, 2001) and longer settlement site-selection periods (Marshall \& Keough, 2003). Larger eggs can lead to larger larvae, and this in turn can cause greater feeding ability, longer feeding period duration, and ultimately augmented postmetamorphic size (Hart, 1995; McEdward, 1996). Simultaneously, large size may render larvae the preferred targets of predation (Chambers \& Leggett, 1996; Heath \& Blouw, 1998; Allen et al., 2006), or offer a size refuge (Rivest, 1983; Segers \& Taborsky, 2012). Conversely, small eggs and larvae may be produced by old or small mothers (Jones et al., 1996; Ito, 1997; Sakai \& Harada, 2001), as well as by those in poor-quality environments (Baynes \& Howell, 1996; Moran \& Allen, 2007) where this may lead to greater dispersal ability (Krug, 1998). Irrespective of the initial reasons, larval size also corresponds with survival, growth and reproduction rates in later juvenile and adult life stages (Moran \& Emlet, 2001; Marshall et al., 2003).

Clearly, the existing literature documents a bewildering array of trans-generational COEs. Yet in the future, this heavy focus on effects between parents and offspring is likely to give way to studies examining the possibility of COEs spanning multiple generations (eg. from grandparent to grandoffspring). Extensive evidence for this has been collected in the biomedical and epidemiological 
literature (Susser et al., 2012), but has so far been elusive in ecology (Burton \& Metcalfe, 2014). Undoubtedly, the literature surrounding COEs has suffered from widespread confusion, not only because of the amount and inconsistent use of terminology, but also due to having been suffused with contradictory evidence, debate, and a lack of communication between budding sub-fields as indicated throughout the above.

In conclusion, trans-generational COEs are intrinsically tied to those occurring between life stages. There is no reason why the fate of a given individual should be determined either solely by the experiences and environments of parents or by earlier stages. In the real world both will play a role, although this is seldom replicated by experimenters. The occurrence of both types of COEs is closely allied. Further, COEs in general are intricately tied to the ways in which stressors interact, the particular effects of prominent stressors (in this case high temperature, UVR and copper), and the ways in which global change will affect coastal habitats. It is these factors that dictate the nature of any observed carryover effects. Unfortunately, it is rare for all these elements to be considered simultaneously, and this was key in formulating the aims of this thesis.

\subsection{Aim}

Carry-over effects (COEs) are natural and occur in response to normal environmental variability. However, the severity of certain stressors is augmented by ongoing anthropogenic global change. Elevated water temperature, high UVR exposure and copper pollution are likely to increasingly impact intertidal invertebrates in the future, particularly their vulnerable early life stages, by initiating new or exacerbating existing carry-over effects. Yet this global change aspect is lacking in most studies of COEs, which also tend to focus only on COEs between life stages or between generations, seldom both. Finally, most incorporate only one stressor and fail to take into account the complex stress interactions that manifest in nature.

These common limitations mean that realistic patterns of stress exposure, varying throughout an organism's life cycle, are rarely replicated in experimental settings. Consequently, our understanding of how carry-over effects will influence marine organisms in the face of ongoing global change remains rudimentary. In light of this, I aimed to elucidate the role of carry-over effects by addressing these common limitations and examining how the effects of multiple stressors relating to global change (temperature, UVR and copper) carry over from a parental generation through the life stages of their offspring. 


\title{
CHAPTER 2 \\ Trans-Generational Carry-Over Effects Caused by Stress Exposure in Adults and Egg Masses of Siphonaria australis
}

\begin{abstract}
2.1 Abstract
Ongoing anthropogenic global change is threatening rocky intertidal systems by subjecting invertebrates to elevated levels of stress. Early life stages, such as embryos contained within benthic egg masses, are particularly vulnerable, yet their responses can be highly dependent on stress experienced by the parental generation through trans-generational carry-over effects. This phenomenon is rarely studied using multiple stressors simultaneously. Here, adult Siphonaria australis were subjected to one of four treatments: a no-stress control, a pollution treatment with added copper $(5.0 \mu \mathrm{g} / \mathrm{L})$, a climate change treatment with elevated temperature $\left(25^{\circ} \mathrm{C}\right)$ and $\mathrm{UVR}\left(1.7 \mathrm{~W} / \mathrm{m}^{2}\right)$, and a full global change treatment incorporating all three of these stressors. Stress levels were selected to represent maximum readings for rock pools during low tide in Wellington, New Zealand. Adults were stressed 4h/day for four weeks, and at the end of this period, the egg masses they laid were collected and subjected to further experimentation. Egg masses were taken from each of the four adult treatments and redistributed among the same four treatments again, so as to produce 16 unique treatment histories of adult-to-egg mass stress. Adults were largely unaffected by stress in terms of the number of survivors, but survivor size, the size of egg masses laid and the size of individual eggs varied in complex ways over time and across treatments. Egg masses were unaffected in terms of hatching time but displayed strong responses in hatching success and the percentage of viable eggs per egg mass. In particular, copper limited hatching success, prevented hatching when augmented with other stressors, and reduced viability to a greater extent than high temperature and UVR exposure. Parental treatment also strongly influenced egg masses; copper-treated egg masses failed to hatch if adults were exposed to all three stressors, and viability declined according to the severity of the parental treatment. Egg mass viability was lowest when laid by parents subjected to all stressors, followed by those that were copper-stressed, then temperature and UVR-stressed and finally unstressed parents. This is clear evidence that transgenerational carry-over effects can mediate offspring responses to global change-type stress.
\end{abstract}




\subsection{Introduction}

Global change threatens coastal marine environments by subjecting resident organisms to elevated levels of stress that exceed their tolerance thresholds (Harley et al., 2006). The rocky intertidal zone is particularly vulnerable as it already experiences a relatively high degree of natural stress, which when augmented by climate change and other anthropogenic interference renders its inhabitants potentially unable to cope, possibly leading to local extinctions (Clarke, 1996). Here, elevated water temperature, UVR exposure and concentrations of heavy metals are becoming more common with ongoing global change (Depledge \& Billinghurst, 1998; Helmuth et al., 2002; Hader et al., 2007). Critically, the early life stages of intertidal invertebrates, like developing embryos, can be highly sensitive and are likely to suffer more severe consequences of direct stress exposure than adults (Thorson, 1950), but the ways in which adult stress affect that of developing offspring through trans-generational carry-over-effects is increasingly recognised as fundamental to evaluating the persistence of marine invertebrates to ongoing global change (Chevin \& Lande, 2010). Nevertheless, studies examining this in marine systems remain rare.

Many marine organisms are free-spawning with embryos developing in the plankton, but mixed developmental strategies are also common, especially among gastropods. In these species, embryonic development takes place in gelatinous or capsular egg masses that are deposited on the benthos, and from which hatch veliger larvae that then enter the plankton to feed and grow before settling in their adult habitat (Przeslawski, 2004). Such egg masses are able to buffer developing embryos from abiotic and biotic stress to some extent (Pechenik, 1979), such as the effects of salinity fluctuations, heat, desiccation (Pechenik et al., 2003), UVR (Przeslawski et al. 2005), predation and disease (Rawlings, 1990). However, egg masses cannot escape prevailing conditions, and this makes them vulnerable to extreme levels of stress in harsh environments such as the rocky intertidal.

Within tolerable levels, increasing water temperature usually corresponds with a decrease in the development time of encapsulated embryos of gastropods (Spight, 1975), as well as other marine invertebrates (Caveriviere et al., 1999). Despite this, developing embryos are particularly vulnerable to mortality caused by high temperatures, as it has long been known that their thermal tolerance thresholds are generally lower than those of adults (Thompson, 1958). UVR co-occurs with high water temperature in the intertidal, and causes stunted development, deformities and direct mortality in gastropod egg masses, particularly at early stages (Biermann et al., 1992), while the shells possessed by adult gastropods impart a certain degree of immunity to its adverse effects (Vermeij, 1971). Although some species deposit their egg masses in sheltered locations, which may mitigate UVR damage, many others do not and instead often deposit their egg masses in full exposure to sunlight (Benkendorff \& Davis, 2002), including this study’s focal species Siphonaria australis (Russell \& Phillips, 2009). 
S. australis (Quoy \& Gaimard, 1833) is a small pulmonate limpet found throughout the intertidal zones of rocky shores in New Zealand (Fig. 2.1 A; B). It is abundant around Wellington, New Zealand and deposits benthic, gelatinous egg masses in the rocky intertidal zone throughout the year $($ Fig. $2.1 \mathbf{A} ; \mathbf{C})$, particularly between September and March (Russell \& Phillips, 2009). These hatch after between 1 and 2 weeks into feeding veliger larvae that live as plankton for several weeks before settling back in the intertidal and metamorphosing into juveniles (Creese, 1980). It has previously been shown by Russell \& Phillips (2009) that tide-pool conditions, including high UVR and water temperature, can cause severe embryo mortality in the egg masses of $S$. australis. Fisher \& Phillips (2014) reaffirmed this by documenting embryo hatching success rates as low as $24 \%$ in experimentally stressed egg masses. Clearly, reproduction in S. australis can be affected by global change conditions. Fisher \& Phillips (2014) then proceeded to also stress hatching larvae, and found that those coming from previously stressed egg masses showed more stunted growth and lower survival. This clearly demonstrates a carryover effect (COE) from the embryo to larval life stage by showing that previous experience can influence stress vulnerability.

The current study is based on Russell \& Phillips (2009) and Fisher \& Phillips (2014), but extends this body of work by examining the link between early life stage vulnerability to stress and parental experience through "trans-generational" COEs, whereby the environment experienced by a parental generation influences the characteristics or performance of offspring (Bonduriansky \& Day, 2009). This has not yet been explored in S. australis. Further, this study expands on Russell \&Phillips (2009) and Fisher \& Phillips (2014) by adding copper $(\mathrm{Cu})$ as a stressor, to represent the compounding effects of pollution on the climate change-associated stressors of UVR and high temperature to represent a fuller picture of global change conditions.

$\mathrm{Cu}$ affects gametogenesis in adult marine invertebrates and early development of their offspring, particularly in bivalves, sea urchins, sponges and ascidians, causing deformity, reduced settling ability and direct mortality (review by Mayer-Pinto et al., 2010). However, the existing literature deals almost universally with planktonic embryos and larvae, and the effects of copper on benthic egg masses are rarely considered. Adult responses to metal contaminates are varied. For example, some barnacles (Morillo et al., 2005) and polychaetes (Olla et al., 1988) simply accumulate metals in their tissues without showing any ecological responses, while other organisms are emerging as highly vulnerable to copper as adults, even more so than indicator species used to assess maximum "safe" levels of such contaminates (Brown et al., 2004).

The ways in which this adult stress affects offspring also appears to be species specific, as gastropod that juveniles produced by $\mathrm{Cu}$-exposed parents can be more tolerant to this metal than juveniles whose parents did not experience Cu pollution (Untersee \& Pechenik, 2007). However, this is a rare example 
of a positive trans-generational COE. The majority of COEs that have been documented in marine invertebrates, arising from parental exposure to abiotic stressors, are detrimental to offspring. For example, $\mathrm{Cu}$ stress can induce lowered maternal investment in egg production, leading to poorer quality offspring (Marshall, 2008). Similarly, temperature stress in parents has been linked to smaller offspring size (Burgess \& Marshall, 2011). Crucially however, it is rare for more than one such stressor to be examined simultaneously in COE research. This, combined with the fact that stressors tend to act synergistically and thus exacerbate one another's effects (Crain et al., 2008), suggests that deleterious effects in coastal marine systems resulting from trans-generational COEs may be underestimated by the existing literature.

This study is novel because it combines an examination of COEs between life stages (the subject of Chapter 3) with trans-generational COEs, and does so with the implementation of multiple stressors that cover both the climate change aspect (UVR and high temperature) of anthropogenic global change as well as the influence of compounding factors $(\mathrm{Cu})$. This chapter aims to examine trans-generational COEs from adult $S$. australis to their offspring in the egg mass stage, manifesting through the interaction of temperature, UVR and $\mathrm{Cu}$ stress exposure in both generations. It was hypothesised that adult $S$. australis would be minimally affected by stress exposure but that egg mass responses to stress would reflect parental experience.

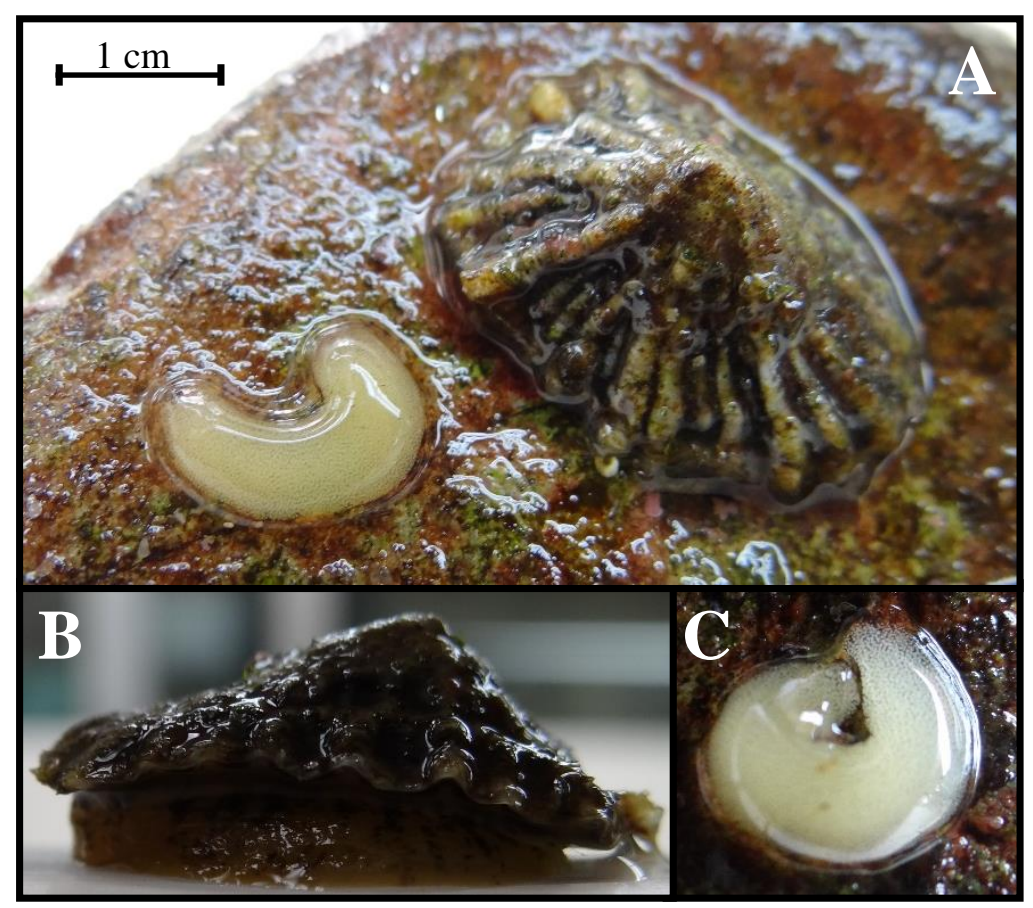

Figure 2.1 Siphonaria australis: A) Adult with freshly deposited egg mass at Victoria University Coastal Ecology Laboratory (VUCEL); B) side view of adult at VUCEL; C) Egg mass exposed during low tide on Wellington south coast. Scale bar applies to all three images. 


\subsection{Methods}

\subsubsection{Specimen Collection}

Adult $S$. australis $(\mathrm{n}=120)$ were collected during low tide from rock pools on the Wellington south coast adjacent to Houghton Bay $\left(41^{\circ} 20^{\prime} 51.9^{\prime \prime} S 174^{\circ} 47^{\prime} 29.0^{\prime \prime E}\right)$ on January $21^{\text {st }}, 2015$. These adults ranged in shell length from $0.5 \mathrm{~cm}$ to $3 \mathrm{~cm}$. Additionally, $\sim 60 \mathrm{~kg}$ of rocks were collected from tide pools at this site to serve as substrate for the limpets during captivity. Rocks were selected to offer a range of sizes, shapes and algal growth for limpets to cling to and feed on. Limpets were carefully removed from the benthos using a scalpel and transported to the Victoria University of Wellington Coastal Ecology Laboratory (VUCEL) in seawater.

\subsubsection{Experimental Stress Exposure in Adult $S$. australis}

Adult $S$. australis were held at VUCEL for the duration of the experiment. Limpets were maintained in twelve 10L buckets, each containing 10 specimens that were evenly distributed among buckets so as to ensure that each bucket contained a similar range of sizes. Mean shell length per bucket ranged from 15 to $15.3 \mathrm{~mm}$. Each bucket was furnished with $\sim 5 \mathrm{~kg}$ of the collected rocks and connected to a continuous supply of filtered seawater $(15 \mu \mathrm{m}$ mesh size $)$. All buckets were placed under two fluorescent T8 30W PowerGlo@ daylight bulbs designed for aquarium use, to allow algal growth to occur and thus offer a food supply to the limpets. Prior to experimental treatment, the adult limpets were acclimated in this set-up for four weeks. During this time adequate feeding was confirmed by the presence of faecal material in buckets. The condition of all buckets was examined, and removal of excess algal growth and detritus was carried out daily.

Adults were subjected to four experimental treatments for another four weeks immediately following acclimation. Each of the four treatments consisted of three replicate buckets. Treatments included a "no stress" control with ambient levels (in laboratory) of all stressors, a "climate change" treatment with elevated levels of temperature and UVR, a pollution treatment featuring added $\mathrm{Cu}$ only, and an "extreme stress" treatment with elevated levels of all stressors (Table 2.1). Limpets were exposed to these treatments for four hours each day during the four-week experiment. This was done to approximate the duration of low tide, at which time limpets would be most vulnerable to these stressors in rock pools. During these four hours of treatment exposure, buckets were disconnected from their seawater supply. Additionally, depending on the treatment, aquarium heaters were placed in buckets to raise water temperature, UV bulbs were installed, and $\mathrm{Cu}$ was added daily to commence the daily stress period. After the four hours had elapsed, buckets were reconnected to the seawater supply and returned to ambient conditions. Food-grade Teflon ${ }^{\circledR}$ buckets were used to ensure that no $\mathrm{Cu}$ was absorbed and that limpets would not be exposed to $\mathrm{Cu}$ residue outside of stressing times, as this material is commonly 
used in laboratory studies on the vulnerability of marine invertebrates to metal pollutants (eg. Bellas et al., 2004).

Ambient water temperature varied from $14^{\circ} \mathrm{C}$ to $18^{\circ} \mathrm{C}$ with an average over the four-week experimental period of $16^{\circ} \mathrm{C}$. Elevated temperature treatments were heated to $25^{\circ} \mathrm{C}$ at the beginning of daily stressing. Treatments were designed to always pair elevated temperature with elevated UVR, and conversely, ambient temperature with ambient UVR (Table 2.1). This was done for two reasons. Firstly, in rock pools elevated temperature is unlikely to occur in the absence of elevated UVR and vice versa, since both stressors are derived from sun exposure. Secondly, identifying the effects of each of these stressors individually was not a goal of this research. In effect, temperature and UVR herein represent a collective single stressor, namely, climate change.

Buckets treated with ambient UVR remained under daylight bulbs during daily four-hour stressing. For buckets treated with elevated UVR, one daylight bulb was replaced with a Philips TL40W/03RS UV bulb. Lighting was suspended $30 \mathrm{~cm}$ above the buckets' water surface. UV bulbs were wrapped in clear PVC foil to eliminate extremely short wavelength UV-C. This ensured that the amount of UVR reaching the water surface in buckets was $1.7 \mathrm{~W} / \mathrm{m}^{2} \mathrm{UVB}$ radiation. This value was chosen as it represents the average daily maximum value for Wellington rock pools at low tide during clear weather in summer, as measured on several cloudless days in January 2015 using a Skye SpectroSense2+ UV-B sensor radiometer (Kessel, unpublished data). By comparison, buckets treated with ambient UVR received only $0.08 \mathrm{~W} / \mathrm{m}^{2}$, the constant level of daytime UVR found inside VUCEL without augmentation by UV bulbs. Finally, buckets treated with elevated $\mathrm{Cu}$ were dosed with $50 \mu \mathrm{l}$ of a copper stock solution (copper sulphate: $\mathrm{CuSO}_{4} .5 \mathrm{H}_{2} \mathrm{O}$ ) to achieve a concentration of $5.0 \mu \mathrm{g} / \mathrm{L}$. Again, this represents a maximum common reading for Wellington sea water (Stoffers et al., 1986). Buckets dosed with Cu were stirred to ensure the pollutant was distributed evenly throughout the water available to the limpets.

Table 2.1. Details of the four experimental treatments, including a description of each treatment's purpose, and a list of stressors and their levels for each treatment. Experimentally elevated stressors appear in bold. Note that Temp and UVR are always both ambient or both elevated. Both adults and egg masses of $S$. australis were subjected to these treatments.

\begin{tabular}{|c|c|c|}
\hline Treatment & Stressors & Stressor Values \\
\hline No Stress (Ambient Control) & None & $\begin{array}{c}\sim 16^{\circ} \mathrm{C} ; 0.087 \mathrm{~W} / \mathrm{m}^{2} ; 0 \mu \mathrm{g} / \mathrm{L} \\
\text { (ambient) }\end{array}$ \\
\hline Climate Change Stress & Temp/UV & $\mathbf{2 5}^{\circ} \mathbf{C} ; \mathbf{1 . 7 W} / \mathbf{m}^{2} ; 0 \mu \mathrm{g} / \mathrm{L}$ \\
\hline Pollution Stress & $\mathrm{Cu}$ & $\sim 16^{\circ} \mathrm{C} ; 0.087 \mathrm{~W} / \mathrm{m}^{2} ; \mathbf{5 . 0} \mu \mathrm{g} / \mathrm{L}$ \\
\hline Extreme Stress (Full Global Change Scenario) & Temp/UV/Cu & $25^{\circ} \mathrm{C} ; 1.7 \mathrm{~W} / \mathrm{m}^{2} ; 5.0 \mu \mathrm{g} / \mathrm{L}$ \\
\hline
\end{tabular}




\subsubsection{Stress Exposure in Egg Masses}

All egg masses laid by the adult limpets during the four-week experiment were collected daily and preserved with $5 \%$ buffered formalin for later analysis. However, those egg masses laid on the last day of, and up to two days after, the adult stress experiment were transferred to dishes (one egg mass per dish containing $100 \mathrm{ml}$ of filtered seawater) for further experimentation. These egg masses were subjected to the same four treatments as adults (Table 2.1) for around two weeks until hatching occurred, again for four hours per day. Egg masses were dosed with $0.5 \mu l$ of copper stock solution to achieve the same concentration as above, and because aquarium heaters could not be placed in dishes, dishes were instead placed on water-filled trays in which the heaters were immersed (although temperature was checked in dishes). The aim was to obtain all possible combinations of treatments under which eggs were laid (ie. adult treatments) and under which they would develop and hatch (ie. egg mass treatments). Because four treatments were devised for both adults and the eggs, this equates to a maximum of 16 possible adult-to-egg treatment histories (4 adult treatments $\mathrm{x} 4$ egg treatments). Each of these 16 treatment histories consisted of three replicate dishes, for a total of 48 dishes.

\subsubsection{Data Collection}

At the end of the four weeks of adult exposure to stress treatments, surviving adults were counted and their shell lengths measured. Egg masses collected during this time were examined using microscopy, and the sizes of individual eggs were measured. Subsequently, egg masses that failed to hatch by the end of the two-week egg mass stress period, as well as pieces of $\sim 5 \mathrm{~mm}$ removed from successful egg masses upon hatching, were preserved (Figure 2.2; 2.3). Additionally, the number of days taken until hatching was recorded for successful egg masses. Preserved egg masses that failed to hatch (not those collected during the four weeks of adult stress exposure) were then observed and the percentage of abnormal or deformed embryos was estimated for each (by examining 50 random embryos per egg mass). The illustrations of Siphonaria developmental stages by Ocana \& Emson (1999) were used as a guide, and because abnormalities were severe, abnormal embryos were deemed inviable (Figure 2.2). 


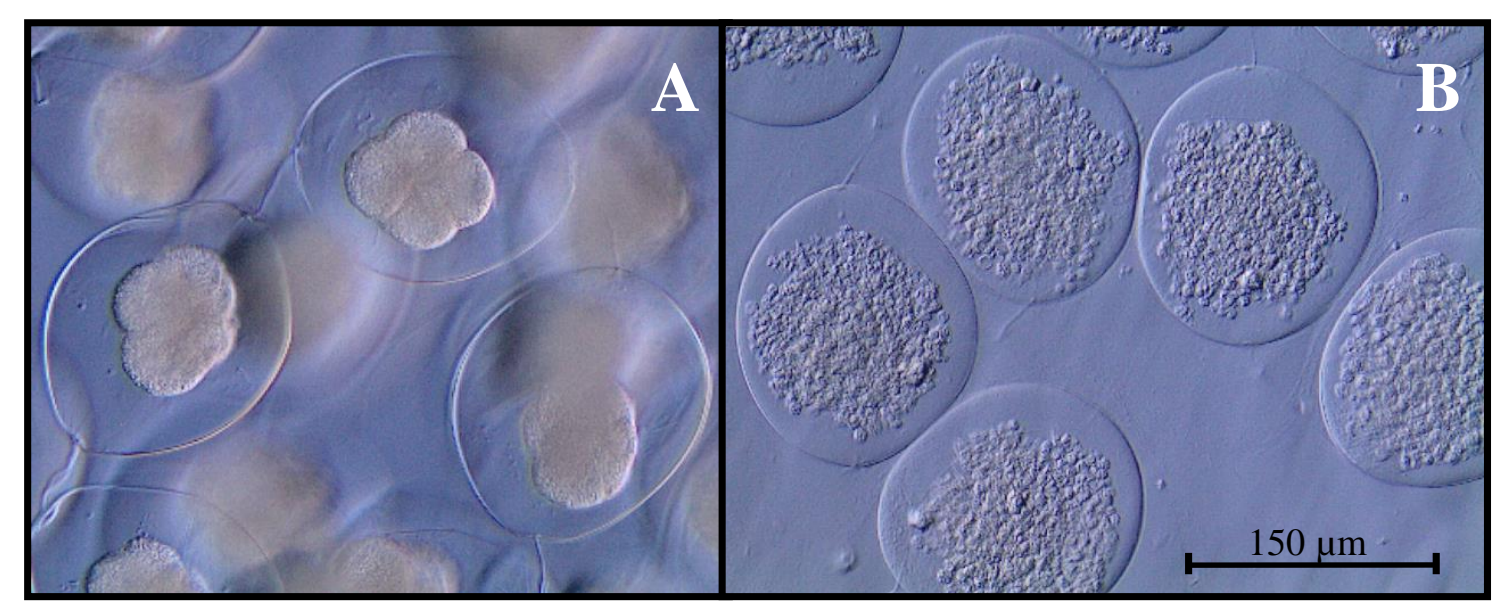

Figure 2.2 A) S. australis eggs containing viable blastulae; B) Failed eggs containing inviable blastulae.

This appearance was typical of egg masses that failed to hatch. Scale bar applies to both images.

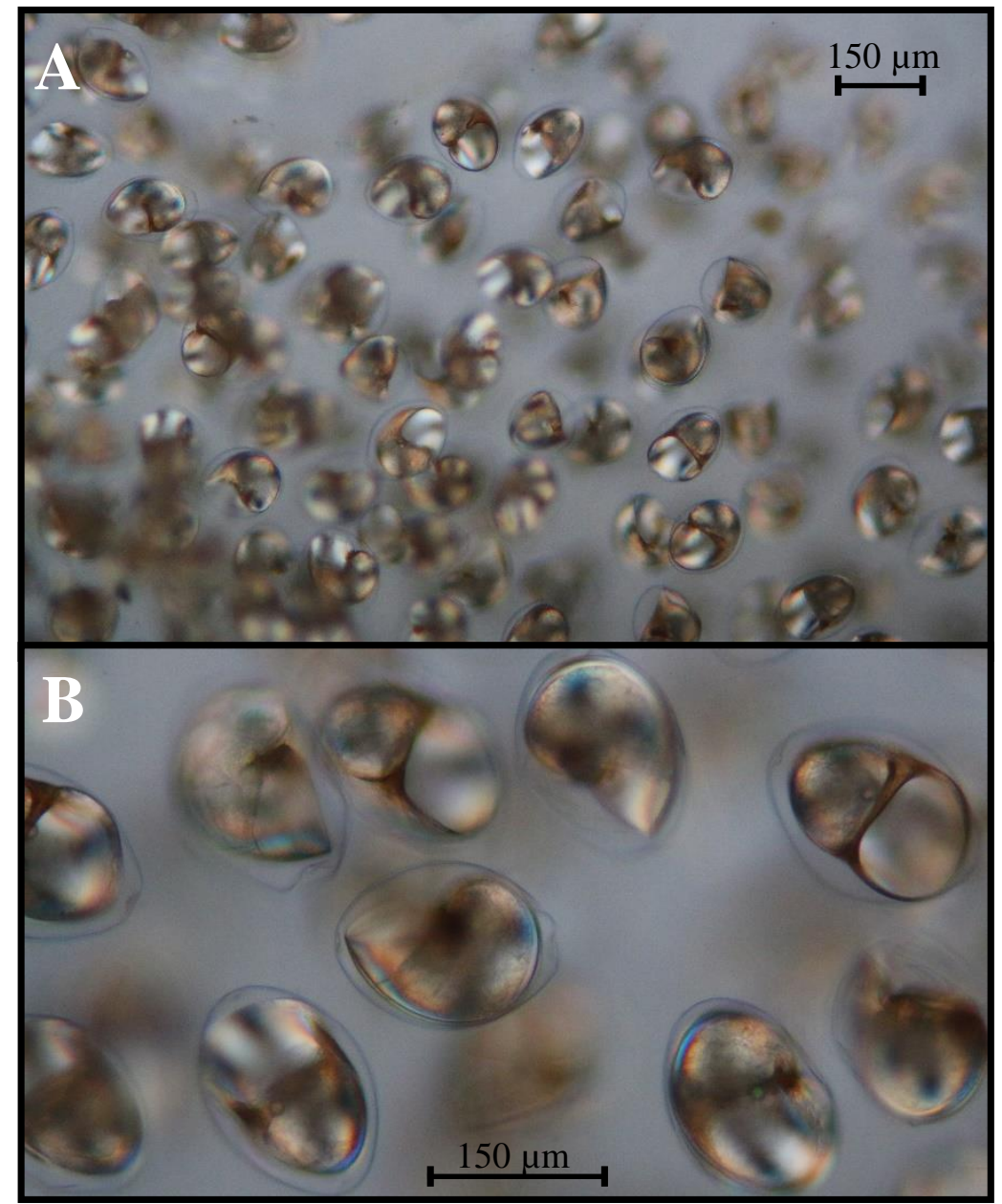

Figure 2.3 S. australis eggs containing veliger larvae ready to hatch under A) low magnification and B) high magnification. 


\subsubsection{Data Analysis}

All data analysis was carried out using IBM SPSS 22. All data were explored and the assumptions for each statistical procedure were tested prior to analysis. This included the use of Kolmogorov-Smirnov and Shapiro-Wilk tests for normality, Levene's test for homogeneity of variance, and diagnostic graphs. Non-parametric tests were used where data failed the assumptions of parametric tests.

\subsubsection{Size and Number of Surviving Adult $S$. australis}

Data on pre-treatment adult size, as well as survivor size (shell length in $\mathrm{mm}$ ) ( $\mathrm{n}=90$ limpets measured) and the number of survivors ( $\mathrm{n}=12$ buckets containing survivors) at the end of the four-week adult stress period departed from normality and homogeneity of variance. Therefore, Kruskal-Wallis tests were used (non-parametric equivalent of one-way ANOVA; Dytham, 2011) with adult treatment as a factor (4 levels). A post-hoc Mann-Whitney U test was also performed on survivor size data for pairwise comparisons between adult treatments.

\subsubsection{Number of Egg Masses Laid}

To examine the effects of adult treatment on the number of egg masses laid over time, a Sheirer-RayHare test was performed (the non-parametric equivalent of 2-way ANOVA; Dytham, 2011) because normality and homogeneity of variance were not met by data ( $\mathrm{n}=48$ observations of the number of egg masses laid since last count in a given bucket). Here adult treatment (4 levels) and week of adult treatment (4 levels) were used as factors. The number of egg masses laid is the mean laid since the previous week's observation (eg. no. at week 2 = mean no. laid since week 1).

\subsubsection{Sizes of Egg Masses and Eggs}

Egg mass size data (length $\mathrm{x}$ width in $\mathrm{mm}$ ) were $\log 10$ transformed, but nonetheless departed from homogeneity of variance. Because the test is considered relatively robust to this departure (Dytham, 2011), a 2-way ANOVA was nevertheless performed with week (4 levels) and adult treatment (4 levels) as factors ( $n=76$ measured egg masses). The size of eggs within egg masses was then also analysed using a two-way ANOVA, although these data also departed from normality, using the same factors. Because egg masses rather than individual eggs are in this case considered as replicates, mean egg size was calculated for each egg mass (using 50 randomly selected eggs per egg mass) ( $\mathrm{n}=76$ egg masses).

\subsubsection{Hatching Success}

Because data failed normality and homogeneity of variance assumptions, and due to small sample size, Binary Logistic Regression was used to analyse the association between treatments and hatching success, using yes/no as categories ( $\mathrm{n}=48$ egg masses observed). Those egg masses deemed unsuccessful (ie. in the "no" category) did not hatch within 2 weeks of transfer to dishes. The test was 
carried out three times, once taking into account total treatment history (16 levels), once only adult treatment (4 levels), and once only egg mass treatment (4 levels)

\subsubsection{Hatching Times}

Only successfully hatching egg masses were considered in hatching time analyses. Hatching time here equates to the number of days taken from egg masses being laid to their first hatching. Again, because of departures from normality and homogeneity of variance, a Kruskal-Wallis test was used ( $n=30$ egg masses measured for hatching time), with total treatment history as factor (11 levels; not 16 because some treatment histories failed to hatch). Spearman's rank-order correlation was then used to assess the relationship between hatching time and egg mass size.

\subsubsection{Egg Viability}

These data also departed from normality and homogeneity of variance, and a Kruskal-Wallis test was used again. This was done excluding failed egg masses ( $n=30$ successful egg masses), with total treatment history as factor (11 levels). Post-hoc Mann-Whitney $U$ tests were also performed for pairwise comparisons between treatment histories. These pairwise comparisons were then used to ascertain whether trans-generational COEs occurred. This was done by comparing viability in egg masses of the same egg mass treatment, but different parental treatments. When these differed, a trans-generational COE was indicated. All treatment histories that showed at least one significant difference indicative of a COE were then simply counted to determine how many of the possible trans-generational COEs that could have occurred did indeed manifest in terms of egg viability.

\subsection{Results}

\subsubsection{Size and Number of Surviving Adult $S$. australis}

No significant difference was found between treatment containers in mean shell lengths of adult limpets prior to actual experimentation (Kruskal-Wallis Chi-square= 2.534; $\mathrm{df}=3 ; \mathrm{p}=0.469$ ). However, mean shell length of surviving limpets, at the end of the four-week adult stress phase, did differ significantly between the four treatments (Kruskal-Wallis Chi-square=7.896; $\mathrm{df}=3 ; \mathbf{p}=\mathbf{0 . 0 4 8}$ ), with surviving limpets that had been exposed to $\mathrm{Cu}$ significantly smaller than those under no or Temperature/UV stress (Figure 2.4; Table 2.2;). The number of adult survivors (Figure 2.5) did not differ significantly between treatments (Kruskal-Wallis Chi-square $=2.543 ; \mathrm{df}=3 ; \mathrm{p}=0.468$ ).

\subsubsection{Number of Egg Masses Laid}

No significant difference in the number of egg masses laid was found between adult treatments $(\mathrm{F}=1.183 ; \mathrm{df}=3 ; \mathrm{p}=0.0237)$ or week $(\mathrm{F}=0.330 ; \mathrm{df}=3 ; \mathrm{p}=0.757)$, and there was no significant interaction $(\mathrm{F}=0.315 ; \mathrm{df}=9 ; \mathrm{p}=0.947$; Figure 2.6). 


\subsubsection{Sizes of Egg Masses and Eggs}

A significant difference in the size of egg masses laid by adults was found among weeks of the adult stress period $(\mathrm{F}=12.029 ; \mathrm{df}=3 ; \mathbf{p}<\mathbf{0 . 0 0 1})$, but not among treatments $(\mathrm{F}=2.408 ; \mathrm{df}=3 ; \mathrm{p}=0.076)$, and a significant interaction among week and treatment was found $(\mathrm{F}=3.437 ; \mathrm{df}=9 ; \mathbf{p}=\mathbf{0 . 0 0 2})$. Egg masses tended to be larger in week 4 than at any other time, particularly for adults under Temp/UV and no stress, while adults under extreme stress laid the largest of all egg masses in week 2 (Figure 2.7). In terms of the size of individual eggs within egg masses, a significant difference was found among weeks $(\mathrm{F}=9.439 ; \mathrm{df}=3 ; \mathbf{p}<\mathbf{0 . 0 0 1})$ and treatments $(\mathrm{F}=10.614 ; \mathrm{df}=3 ; \mathbf{p}<\mathbf{0 . 0 0 1})$, as well as a significant interaction between these factors $(\mathrm{F}=16.740 ; \mathrm{df}=9 ; \mathbf{p}<\mathbf{0 . 0 0 1})$. The sizes of eggs were highly specific depending on the treatment-week combination, with all treatments showing considerable variation over the four-week experiment (Figure 2.8).

\subsubsection{Hatching Success}

A significant relationship was found between hatching success and egg mass treatment (S.E. $=0.293$; $\mathrm{df}=1 ; \mathbf{p}=\mathbf{0 . 0 3 9}$ ), but not between hatching success and adult treatment (S.E. $=0.270 ; \mathrm{df}=1 ; \mathrm{p}=0.806$ ) or hatching success and total treatment history (S.E. $=0.069 ; \mathrm{df}=1 ; \mathrm{p}=0.088)$. None of the egg masses subjected to extreme stress hatched, none exposed to $\mathrm{Cu}$ from extremely stressed parents hatched, and one each of the remaining treatment histories where eggs were exposed to $\mathrm{Cu}$ also failed to hatch (Figure 2.9). In total, 18 of 48 egg masses failed. All failed egg masses were composed entirely of inviable early blastulae (see Figure 2.2 B), with no other developmental stages present.

\subsubsection{Hatching Times}

No significant difference in hatching time was found among total treatment histories (Kruskal-Wallis Chi-square $=11.969 ; \mathrm{df}=10 ; \mathrm{p}=0.287$ ), and no significant correlation was found between egg mass size and hatching time $\left(r_{s}=0.240 ; \mathrm{df}=28 ; \mathrm{p}=0.21\right)$. Egg masses tended to hatch between 6 and 9 days after being laid, regardless of treatment history (Figure 2.10).

\subsubsection{Egg Viability}

A significant difference between the percentage of viable eggs per egg mass was found among total treatment histories (Kruskal-Wallis Chi-square $=28.298 ; \mathrm{df}=10 ; \mathbf{p}<\mathbf{0 . 0 0 1}$ ). Viability tended to decrease according to egg mass treatment in the order No Stress $>\mathrm{Temp} / \mathrm{UV}>\mathrm{Cu}$, and according to adult treatment in the order No Stress $>\mathrm{Cu}>\mathrm{Temp} / \mathrm{UV}>\mathrm{Temp} / \mathrm{UV} / \mathrm{Cu}$ (Figure 2.11; Table 2.3). Failed egg masses all contained $0 \%$ viable eggs, and those subjected to extreme stress with extremely stressed parents constituted the only treatment history whose egg masses contained $\sim 5 \%$ egg capsules completely devoid of embryos. Lastly, trans-generational COEs were displayed by every treatment history (ie. 11 of 11 possible times) (Table 2.3 ). 


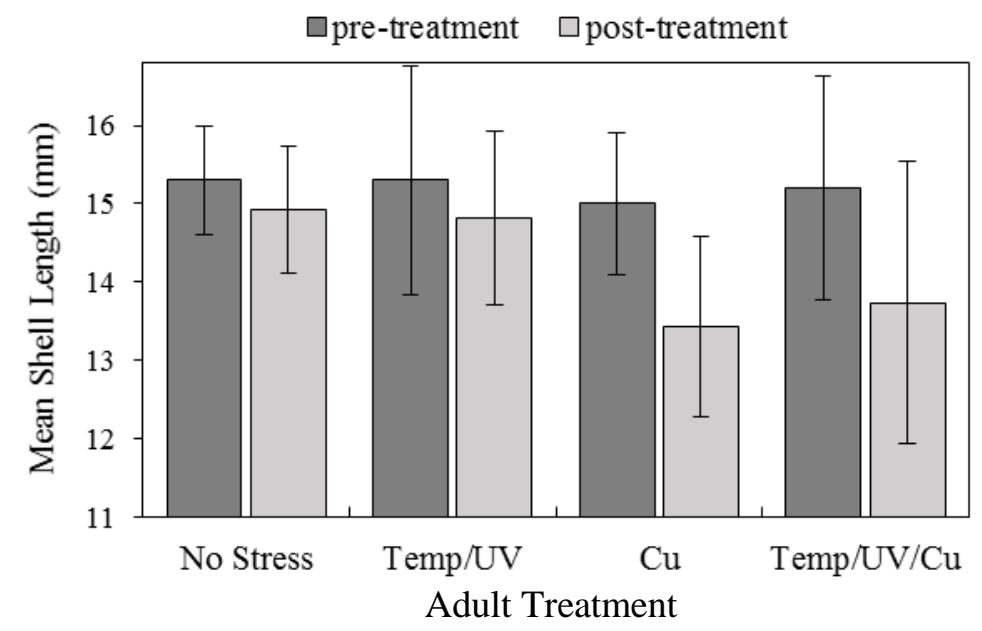

Figure 2.4 Mean shell length (mm; +/- 95\% C.I.) of adult S. australis before (n=120 limpets) and after $(n=90) 4$ weeks of experimental stress exposure.

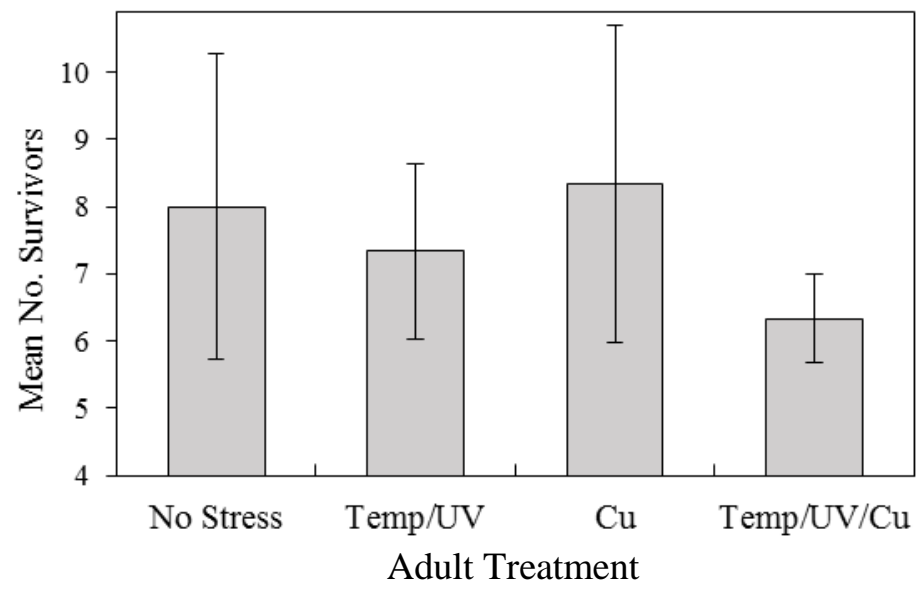

Figure 2.5 Mean number of surviving adult S. australis out of 10 (+/- 95\% C.I.) after 4 weeks of experimental stress exposure ( $\mathrm{n}=12$ buckets).

Table 2.2 Survivor size pairwise comparisons. Results of post-hoc Mann-Whitney U tests showing pairwise comparisons of adult treatment, performed after Kruskal-Wallis test examining the effect of adult treatment ( 4 levels) on the size of surviving limpets ( $n=90)$. Differences significant at the $\alpha=0.05$ level appear in bold.

\begin{tabular}{|c|cccc|}
\hline Pairwise Comparison & No Stress & Temp/UV & $\mathrm{Cu}$ & Temp/UV/Cu \\
\hline No Stress & - & 0.893 & $\mathbf{0 . 0 0 6}$ & 0.115 \\
Temp/UV & - & - & $\mathbf{0 . 0 4 7}$ & 0.154 \\
$\mathrm{Cu}$ & - & - & - & 0.933 \\
Temp/UV/Cu & - & - & - & - \\
\hline
\end{tabular}




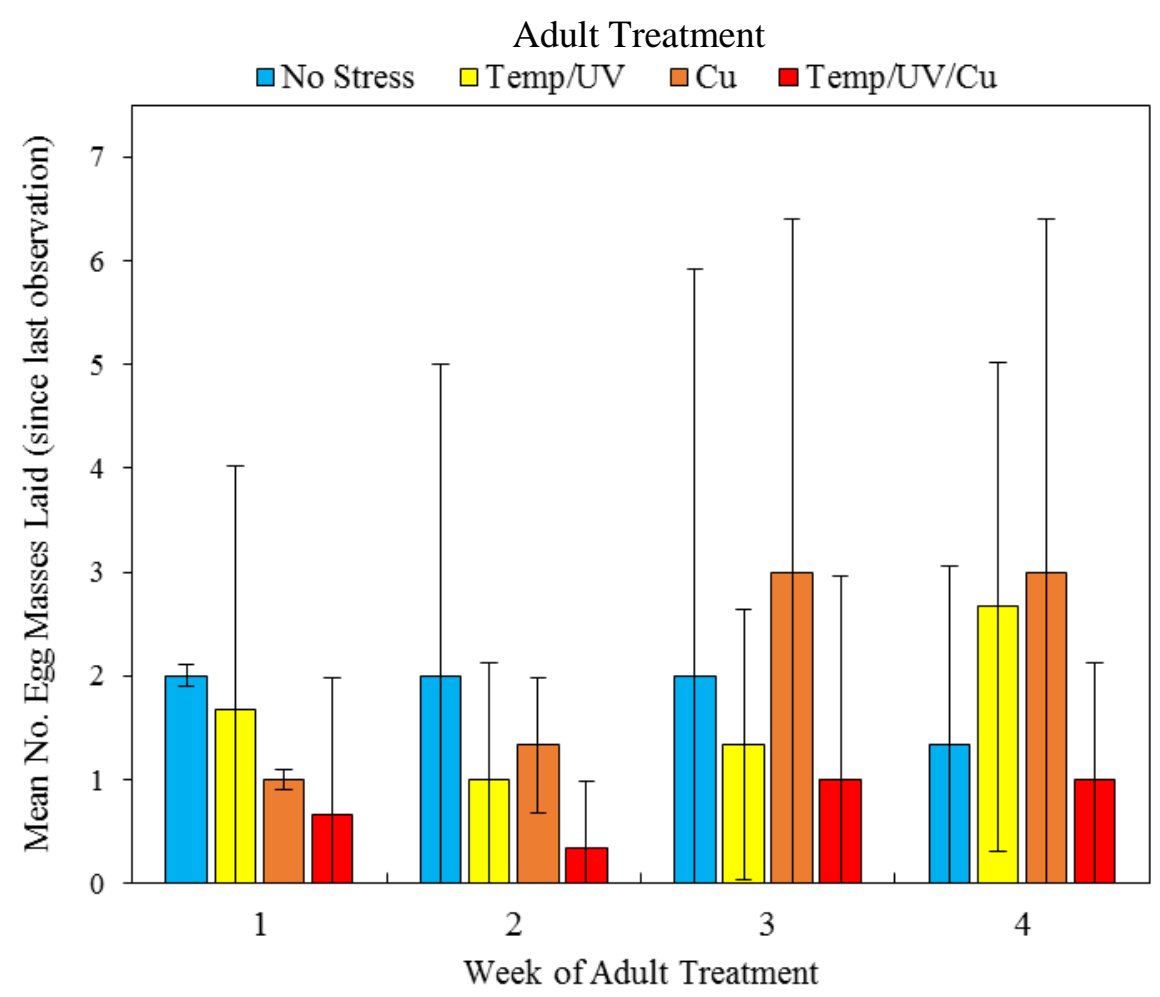

Figure 2.6 Mean number of egg masses laid by adult $S$. australis (+/- $95 \%$ C.I.) during each of the 4 weeks of adult stress across treatments ( $\mathrm{n}=48$ observations).

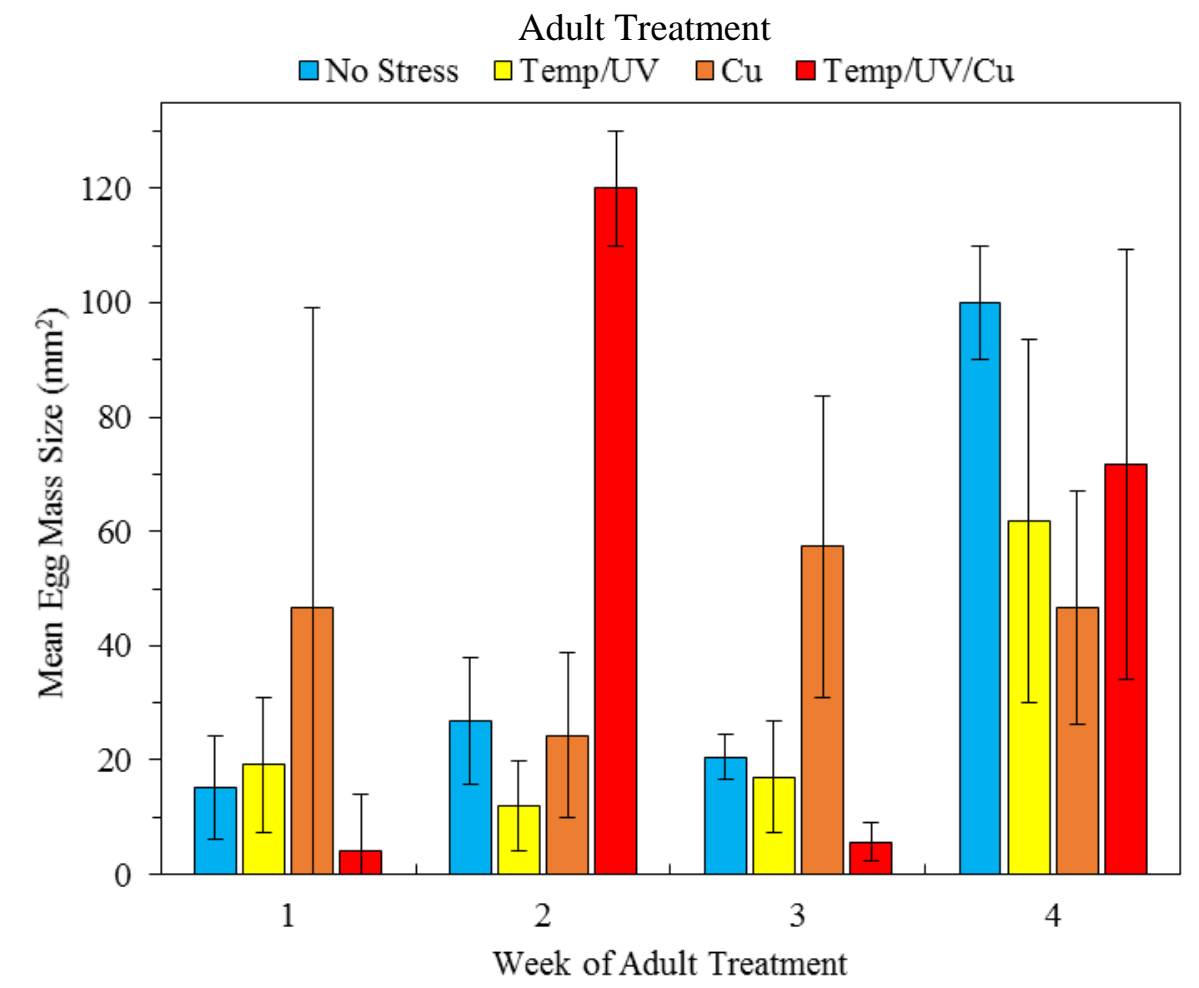

Figure 2.7 Mean sizes of egg masses laid by adult S. australis (+/- 95\% C.I.) during each of the 4 weeks of adult stress across treatments ( $\mathrm{n}=76$ egg masses). 


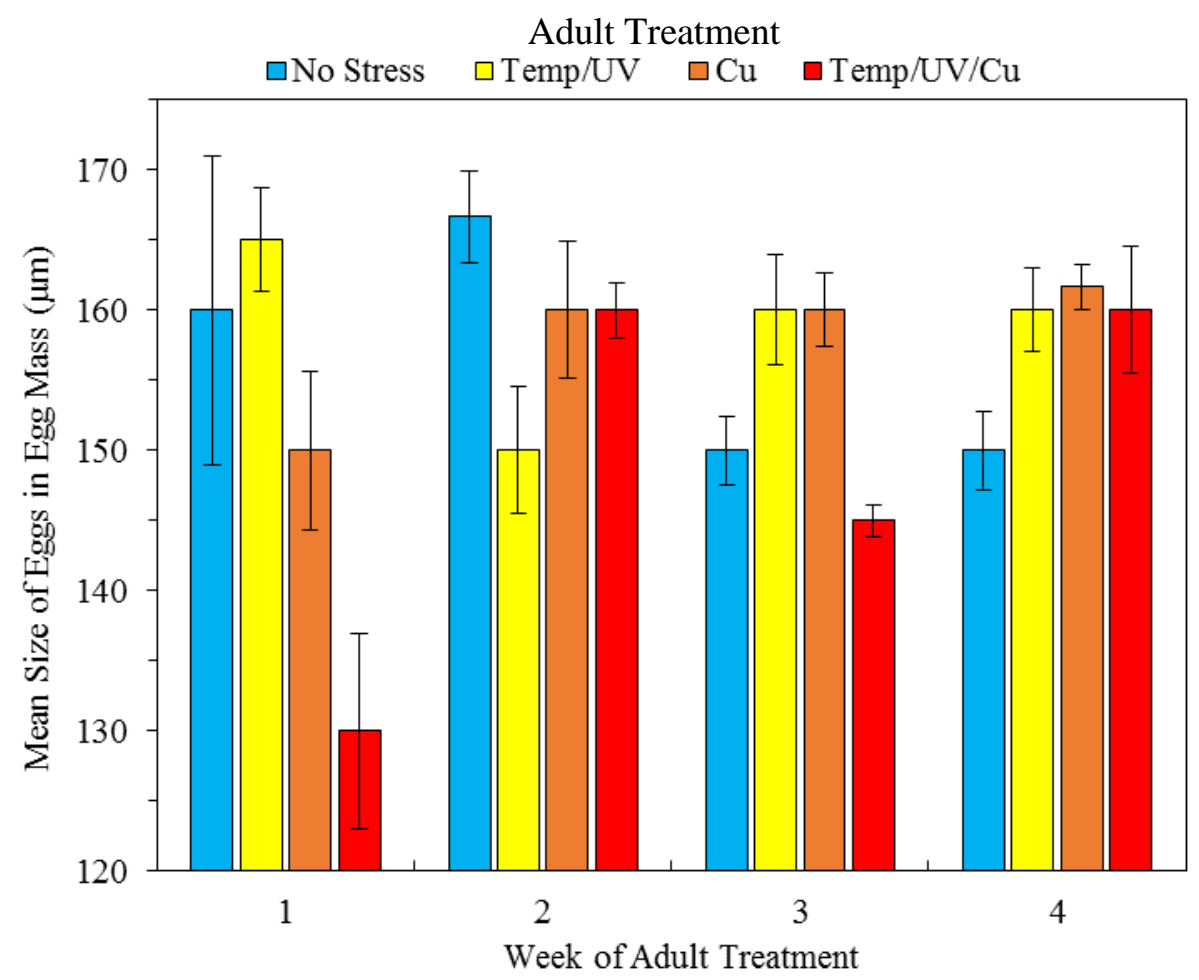

Figure 2.8 Mean sizes of individual eggs in egg masses laid by adult S. australis (+/- 95\% C.I.) during each of the 4 weeks of adult stress across treatments ( $n=76$ egg masses).

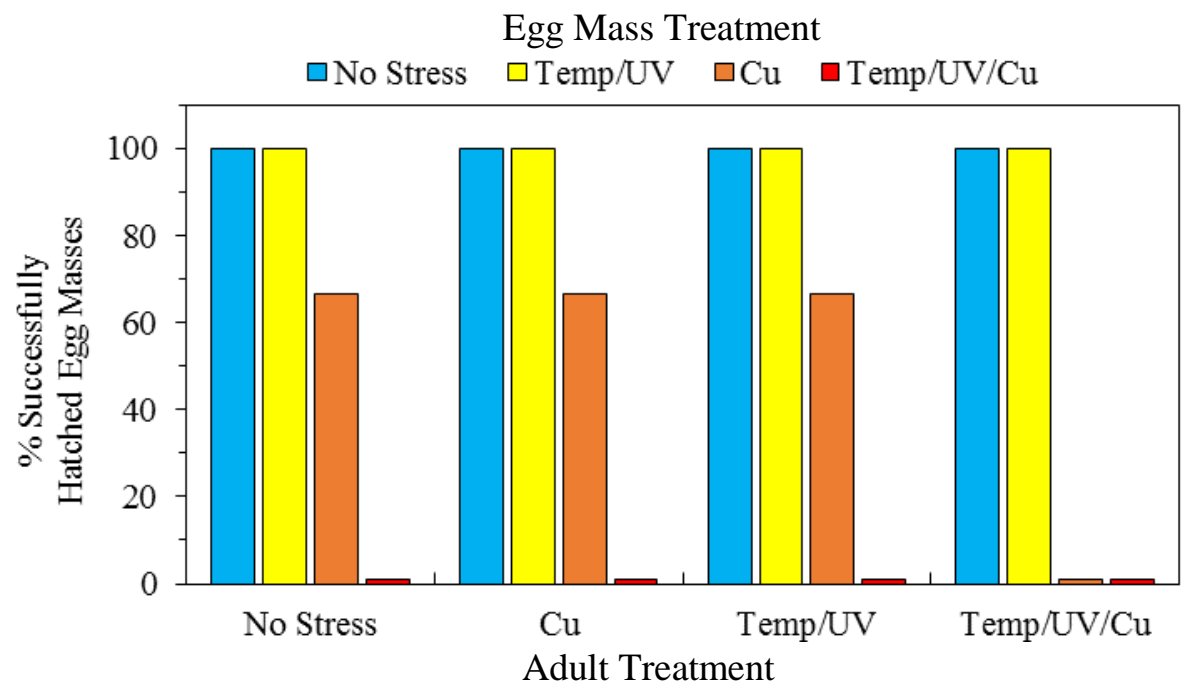

Figure 2.9 The $\%$ of successfully hatching egg masses. Each bar represents one of the 16 treatment histories, composed of an adult treatment (x axis) and an egg mass treatment (colours), and shows \% out of 3 replicate egg masses $(n=48)$. Effects of egg mass treatments can be seen by comparing the heights of the differently coloured bars (eg. blue vs. orange). Adult treatment effects, and therefore trans-generational COEs, can be seen by comparing the clusters of bars in each adult treatment. Note that no error bars are displayed because graphed data does not represent mean $\%$, but the absolute $\%$ of egg masses that hatched out of the 3 replicate egg masses. 
Egg Mass Treatment

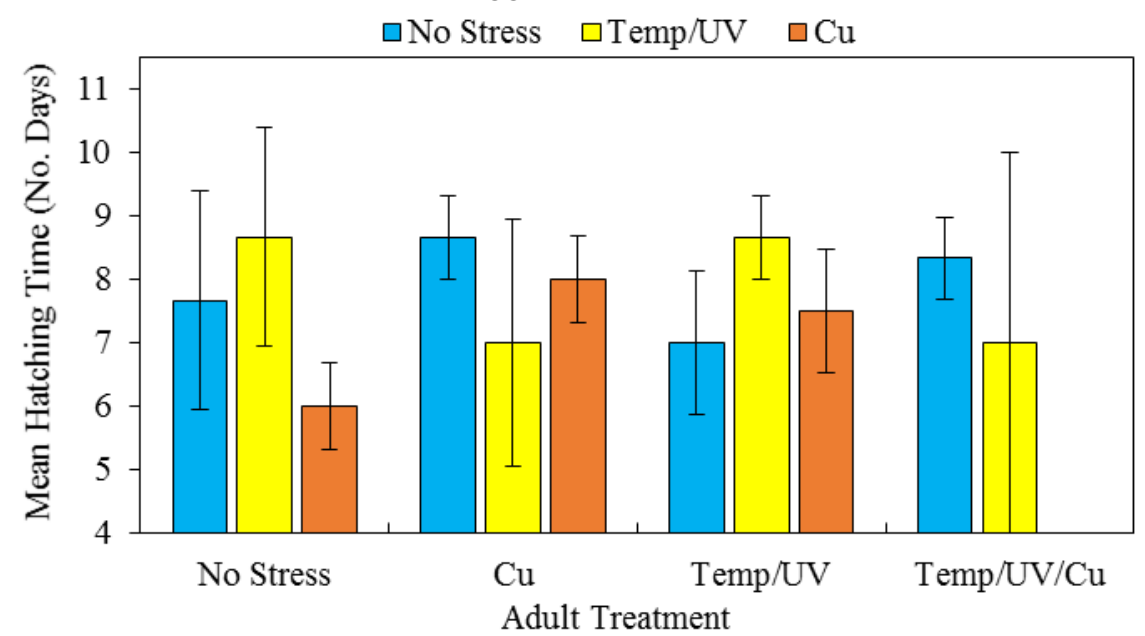

Figure 2.10 Mean hatching time of egg masses (+/- 95\% C.I.) as the number of days from egg masses being laid to first hatching ( $\mathrm{n}=30$ hatched egg masses). Each bar represents one of the treatment histories from which larvae successfully hatched, composed of an adult treatment ( $\mathrm{x}$ axis) and an egg mass treatment (colours).

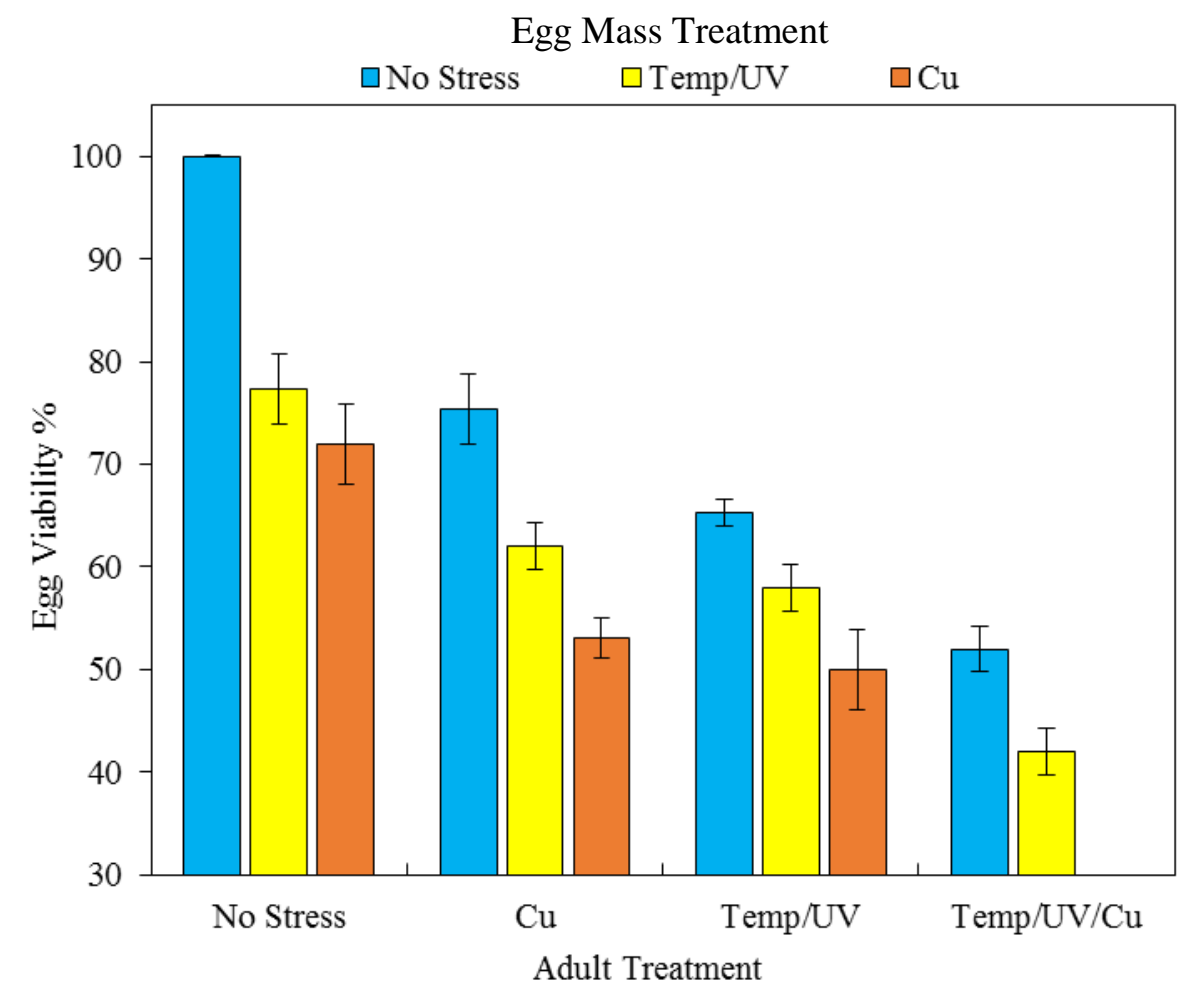

Figure 2.11 Mean \% of viable eggs per egg mass (+/- 95\% C.I.). Each bar represents one of the successfully hatching treatment histories, composed of an adult treatment (x axis) and an egg mass treatment (colours) $(n=30)$. 
Table 2.3 Egg viability pairwise comparisons. Results of post-hoc Mann-Whitney U tests performed after Kruskal-Wallis test examining the effect of treatment history (11 levels) on the \% of viable eggs per egg mass $(n=30)$. Each treatment history incorporates an adult (parent) treatment, named first, followed by an egg mass treatment. Differences significant at the $\alpha=0.05$ level appear in bold ( $p$ values). Pairwise comparisons are also labelled according to whether a trans-generational COE would be indicated by a significant difference ("GEN").

\begin{tabular}{|c|c|c|c|c|c|c|c|c|c|c|c|}
\hline $\begin{array}{c}\text { Pairwise Comparisons } \\
\text { between Treatment } \\
\text { Histories } \\
\text { (parent treatment - egg mass } \\
\text { treatment) }\end{array}$ & 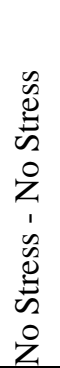 & 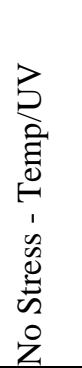 & 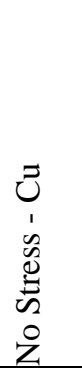 & 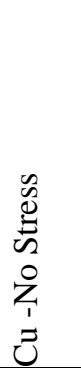 & 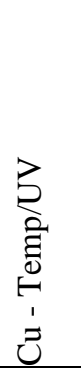 & $\begin{array}{l}\vec{U} \\
\dot{J} \\
\end{array}$ & 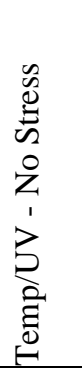 & 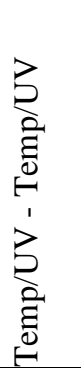 & 己̇ & 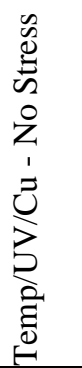 & 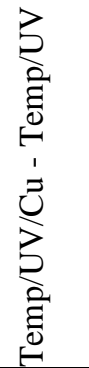 \\
\hline No Stress - No Stress & & 0.037 & 0.043 & $\begin{array}{l}0.037 \\
\text { GEN }\end{array}$ & 0.037 & 0.043 & $\begin{array}{l}0.034 \\
\text { GEN }\end{array}$ & $\overline{0.037}$ & $\overline{0.043}$ & $\begin{array}{l}0.037 \\
\text { GEN }\end{array}$ & $\overline{0.037}$ \\
\hline No Stress - Temp/UV & - & - & 0.139 & 0.376 & $\begin{array}{l}0.040 \\
\text { GEN }\end{array}$ & 0.033 & 0.046 & $\begin{array}{l}0.040 \\
\text { GEN }\end{array}$ & 0.033 & 0.040 & $\begin{array}{l}0.040 \\
\text { GEN }\end{array}$ \\
\hline No Stress - Cu & - & - & - & 0.248 & 0.050 & $\begin{array}{l}0.021 \\
\text { GEN }\end{array}$ & 0.050 & 0.043 & $\begin{array}{l}0.021 \\
\text { GEN }\end{array}$ & 0.040 & 0.040 \\
\hline $\mathrm{Cu}$ - No Stress & - & - & - & - & 0.040 & 0.043 & 0.046 & 0.040 & 0.043 & $\begin{array}{l}0.040 \\
\text { GEN }\end{array}$ & 0.040 \\
\hline $\mathrm{Cu}-\mathrm{Temp} / \mathrm{UV}$ & - & - & - & - & - & 0.043 & 0.072 & $\begin{array}{l}0.077 \\
\text { GEN }\end{array}$ & 0.043 & 0.040 & $\begin{array}{l}0.040 \\
\text { GEN }\end{array}$ \\
\hline $\mathrm{Cu}-\mathrm{Cu}$ & - & - & - & - & - & - & 0.046 & 0.083 & $\begin{array}{l}0.221 \\
\text { GEN }\end{array}$ & 0.543 & 0.043 \\
\hline Temp/UV - No Stress & - & - & - & - & - & - & - & 0.046 & 0.046 & $\begin{array}{l}0.046 \\
\text { GEN }\end{array}$ & 0.046 \\
\hline Temp/UV - Temp/UV & - & - & - & - & - & - & - & - & 0.050 & 0.050 & $\begin{array}{l}0.040 \\
\text { GEN } \\
\end{array}$ \\
\hline Temp/UV - Cu & - & - & - & - & - & - & - & - & - & 0.374 & 0.043 \\
\hline Temp/UV/Cu - No Stress & - & - & - & - & - & - & - & - & - & - & 0.050 \\
\hline Temp/UV/Cu - Temp/UV & - & - & - & - & - & - & - & - & - & - & - \\
\hline
\end{tabular}




\subsection{Discussion}

These results demonstrate trans-generational COEs by showing that parental environment, or parental experiences, can influence the development of benthic egg masses in S. australis when both are exposed to intertidal stressors. Additionally, the conditions experienced by egg masses themselves play a crucial role, interacting with parental history to produce a high diversity of responses to stress during embryonic development. This is despite the fact that adult $S$. australis appeared to be virtually unaffected by experimental stress exposure in terms of survival.

\subsubsection{Effects of Stress on Adult Limpets}

The limpets that survived four weeks of adult stress exposure were generally similar in size and number regardless of treatment, although there was a marginally significant effect on survivor size where those exposed to $\mathrm{Cu}$ were around $12 \%$ smaller than those of No Stress and Temp/UV treatments. Because there was no difference in the initial sizes of limpets and mean size was greater at the start of the experiment, this small effect must be due to selective mortality of larger individuals in those treatments. Combined with the non-significant trend for limpets under extreme stress (Temp/UV/Cu) to experience slightly lower survival than others, this suggests that treatments were on the cusp of negatively affecting the performance of adult limpets and that increased exposure duration or experiment time may have resulted in stronger direct effects. For example, De Pirro \& Marshall (2005) found similar $\mathrm{Cu}$ concentrations caused mortality in adult patellid limpets after at least 48 hours of continuous exposure.

Generally however, copper concentrations of $5.0 \mu \mathrm{g} / \mathrm{L}$ and exposure times as brief as four hours per day, are rarely sufficient to cause mortality among adults of any taxonomic group. Even sensitive freshwater animals such as daphnids, amphipods snails and salmonid fishes, as well as aquatic plants, commonly require at least 96 hours of continuous exposure to similar concentrations as used in this study before suffering significant mortality (review by Hodson et al., 1979). Marine taxa appear more robust, with some of the most $\mathrm{Cu}$-sensitive marine organisms yet documented, including copepods, clams and flounders, showing significant mortality only after exposure for 96 hours to concentrations as high as 28 to $39 \mu \mathrm{g} / \mathrm{L}$ (review by Eisler, 1997). However, in mussels for example, synergistic interactions of $\mathrm{Cu}$ and other stressors, particularly high water temperature, are known to reduce the exposure time necessary for mortality to occur (Weber et al., 1992). Such synergistic effects are a likely cause for the apparent trend of reduced survival among extreme stress adults in this study. 
In contrast to direct mortality, $\mathrm{Cu}$ routinely triggers a myriad of sub-lethal effects across a broad spectrum of aquatic animals at low concentrations and short exposure times. For example, sub-lethal effects on the growth, reproductive effort, feeding efficiency and behaviour of molluscs and arthropods frequently manifest at concentrations as low as $1 \mu \mathrm{g} / \mathrm{L}$ (review by Bryan \& Langston, 1992). While limpets here were not assessed for these sorts of responses, it is possible that some sub-lethal effects did occur, particularly a reduction in heart rate, which has been documented in limpets under prolonged $\mathrm{Cu}$ stress (Marchan et al., 1999). However, gastropods in general are relatively robust to high temperatures (Thompson, 1958; Helmuth et al., 2006) and sunlight (including UV) exposure (Vermeij, 1971), and adult Siphonaria limpets specifically are particularly resistant to Cu (De Pirro \& Marshall, 2005). This offers a good explanation for the lack of difference in mortality between the control and Temp/UV or Cu-only treatments.

The reasons for the observed size-selective mortality favouring the survival of smaller individuals in response to $\mathrm{Cu}$, are however more difficult to corroborate with the existing literature. Phytoplankton cultures are well known to respond to high $\mathrm{Cu}$ concentrations $(>20 \mu \mathrm{g} / \mathrm{L})$ with a shift towards smaller size (Perez et al., 2006), and invertebrates, such as daphnids, also do so in response to various other pollutants, but not copper (Agatz et al., 2012). Fish on the other hand commonly respond to pollutants in the opposite way, with elevated mortality of small individuals (Yeom et al., 2007). Ultimately, the occurrence and nature of size-selective mortality is highly pollutant and species specific (Mayer-Pinto et al., 2010). The physiological mechanisms that rendered larger individuals more vulnerable herein remain unclear, especially when one considers that small individuals of bivalves can contain relatively higher concentrations of $\mathrm{Cu}$ in their tissues than those of greater body size (Cossa et al., 1980).

Similarly, no clear patterns emerged in terms of the reproductive characteristics of adult limpets. In intertidal gastropods the number of egg masses laid and the size of egg masses generally decreases with parental stress, including pollutants, high temperature, food stress and other perturbations, while the size of individual eggs tends to increase (review by Przeslawski, 2004). This is not reflected by results herein. Egg mass number did not respond to stress at all, and the interaction of treatment and week for egg mass size is driven almost exclusively by the anomalously large size of those laid by extremely stressed adults in week 2 . The size of individual eggs is equally dependent on specific week-treatment combinations, and no clear link can be observed between a reduction in size and stress of any kind. This is despite the fact that both $\mathrm{Cu}$ and high temperature are known to cause smaller egg size in diverse taxa, from ascidians (Burgess \& Marshall, 2011) to fish (Chambers \& Leggett, 1996). 
Crucially however, egg size can also vary substantially between individual mothers without any environmental stress, as has been shown in mussels (Phillips, 2007), and this has been linked to traits such as maternal size and age (review by Marshall et al., 2008) with smaller mothers tending to produce smaller eggs among intertidal gastropods (Ito, 1997). It is thus clear that the size of eggs can be as dependent on maternal as on environmental characteristics, and it is here more likely that the intricate patterns of egg mass and egg size reflect this individual variability among mothers rather than responses to stressful conditions. Ultimately, these findings largely support the hypothesis that adults would be minimally affected by stress exposure.

\subsubsection{Effects of Stress on Egg Masses}

Egg masses were much more vulnerable to stress than adults, with hatching success largely determined by egg mass treatment. $\mathrm{Cu}$ exposure in egg masses was the main factor that either limited hatching success when it was the only stressor, or prevented hatching entirely when paired with elevated temperature and UVR under the extreme stress treatment. This is consistent with the general literature, which documents taxonomically wide-spread vulnerability to metal pollution at early life stages (Mayer-Pinto et al., 2010), particularly when paired with other stressors (Crain et al., 2008). This also reaffirms the notion that egg masses do not possess protective adaptations against such pollutants (Conrad, 1988), in contrast to thermal and UVR stress, as discussed below. Since all failed egg masses contained only inviable blastulae, $\mathrm{Cu}$ is likely to have interfered with cell division and entirely halted proper embryonic development (Bryan, 1971).

The lack of response to high temperatures also mirrors the wider literature, since the encapsulated embryos of intertidal gastropods are generally robust to this common stressor provided it occurs at nonlethal levels (Dehnel \& Kong, 1979). This may be achieved through the presence of thermally protective proteins (Podolsky \& Hoffmann, 1998), although their presence has not yet been substantiated for Siphonaria limpets. However, UVR is highly deleterious to embryos contained within gelatinous egg masses of marine gastropods in general, being capable of causing deformity and mortality at similar levels to those incorporated here (Biermann et al., 1992). The fact that all Temp/UV-treated egg masses hatched successfully is nonetheless unsurprising, since Siphonaria limpets routinely deposit their egg masses in full sunlight (Benkendorff \& Davis, 2002) and may consequently have evolved protective or repair mechanisms that mitigate effects of UVR. However, although UV-B absorbing compounds have been identified in some other gastropods (Rawlings, 1996; Shick \& Dunlap, 2002), they appear to play no role in the Siphonaria species so far examined (Wraith et al., 2006), and S. australis egg masses can indeed suffer high UVR-induced embryonic mortality (Russell \& Phillips, 2009). Ultimately, it must be acknowledged that "yes/no" hatching success is a coarse response variable, and that egg masses can still be defined as successful even if many individual larvae fail to hatch. 
Crucially, despite no significant difference in hatching success among adult treatments, all Cu-treated egg masses failed to hatch if, and only if, their parents were exposed to extreme stress. Under all other adult treatments, Cu-treated egg masses hatched $2 / 3$ of the time. This is a clear difference in offspring hatching success that can only be attributed to the different treatments their parents experienced. This is therefore good evidence for a trans-generational $\mathrm{COE}$, in which extreme stress in adults prevents hatching if offspring encounter $\mathrm{Cu}$, highlighting a complex interaction between parental and offspring experiences. Importantly, the other $\mathrm{Cu}$-treated egg masses hatched at the same rate regardless of whether their parents experienced $\mathrm{Cu}$ stress or not, showing that the apparent tolerance to $\mathrm{Cu}$ of adults discussed above did not convey any evident resistance to offspring. This contrasts most previous studies of COEs in which parents exposed to various toxicants have been demonstrated to produce offspring that are themselves at least initially resistant in diverse taxa (Lin et al. 2000; Vidal \& Horne 2003), including to $\mathrm{Cu}$ in gastropods (Untersee \& Pechenik, 2007), but supports others that found reduced offspring quality (Marshall, 2008).

Furthermore, it is interesting to note that empty egg capsules were found only in those egg masses that were treated with extreme stress themselves as well as being laid by adults under extreme stress. Empty egg capsules may be attributable to failed fertilisation due to stress in adults affecting gamete quality (Ritchie \& Marshall, 2013). Here however, this was observed only in this one specific treatment history, meaning that egg mass stress exposure must also have somehow played a role in the development of empty egg capsules. The mechanism for this is unknown, but the presence of empty egg capsules in the $\mathrm{Temp} / \mathrm{UV} / \mathrm{Cu}-\mathrm{Temp} / \mathrm{UV} / \mathrm{Cu}$ treatment history represents a clear interaction between adult and offspring environment in determining egg mass characteristics, and therefore a trans-generational COE.

It is somewhat surprising that there was no correspondence between treatment history and hatching time, as the duration of embryonic development among marine gastropods is well known to vary greatly in response to prevailing environmental stressors (review by Przeslawski, 2004). Generally, among invertebrates the presence of heavy metals, such as $\mathrm{Cu}$, slows development (Bryan, 1971), while increasing temperature accelerates it (Caveriviere et al., 1999), particularly in gastropods (Spight, 1975), including siphonarid limpets (review by Hodgson, 1999).

In contrast, UVR is usually associated only with causing mortality and deformity (Biermann et al., 1992), and not with altered rates of development. However, the deleterious effects of UVR are dampened by higher temperatures in algae and amphibians (Hoffman et al., 2003; Searle et al., 2010). This mitigating effect between these two stressors may be mirrored by results herein, as temperature and UVR were elevated together, making it possible that the accelerating effects of high temperature may have been counteracted by the decelerating effects of UVR, thus causing no differences in hatching time to be detected. This would illustrate an antagonistic stressor interaction (Folt et al., 1999) that 
contrasts the broader literature, which documents an overwhelming majority of synergistic effects of increased severity between high temperature and UVR (Crain et al., 2008). Additionally, transgenerational COEs failed to manifest in hatching times. This is in keeping with the general literature, where hatching time does not vary with parental $\mathrm{Cu}$, temperature or UVR stress. When hatching time has been affected by a parental generation, this has been mainly through maternal investment strategies leading to either large or small eggs or egg masses, which then alters the duration of development (Marshall \& Keough, 2008), also not evident here.

Trans-generational COEs are however highly conspicuous through the percentage of viable eggs in successfully hatching egg masses. Unstressed adults tended to lay egg masses with higher viability than $\mathrm{Cu}$-stressed adults, which were in turn higher than those laid by Temp/UV-stressed adults, with adults under extreme stress producing the least viable egg masses. This clearly shows that offspring viability suffered according to parental treatment. The very low viability of eggs laid by extremely stressed adults also indicates a synergistic effect between climate change (Temp/UV) and pollution $(\mathrm{Cu})$ stress in parents on their offspring. Synergistic trans-generational effects such as this have previously been documented only in plants (Lau et al., 2008; Pias et al., 2011).

Furthermore, phototoxicity describes the tendency for UVR to enhance the deleterious effects of pollutants (review Pelletier et al., 2006), and the observed synergistic effect of parental $\mathrm{Cu}$ and UVR exposure on offspring, offers perhaps the first evidence for this phenomenon occurring transgenerationally. This is despite the lack of a strong response to $\mathrm{Cu}$ observed in adults. Nonetheless, this pollutant must have had some effect in the parental generation to account for the above patterns, particularly the lower viability of egg masses laid by $\mathrm{Cu}$-exposed parents than unstressed parents. Perhaps this can be explained by the $\mathrm{Cu}$ to which adults were exposed affecting fertilisation or the formation of gametes, as this took place in the adult enclosures. Such impairments to reproduction have been observed in response to numerous metals, including $\mathrm{Cu}$ (Mayer-Pinto et al., 2010). Similarly, high temperature showed no response in adults but produced trans-generational effects, with eggs laid by Temp/UV-treated parents displaying similar to slightly lower viability than those coming from $\mathrm{Cu}$ stressed parents. This was somewhat expected, since parental temperature may influence offspring response to temperature in polychaetes (Massamba-N'Siala et al., 2014), copepods (Vehmaa et al., 2012) and fish (Salinas \& Munch, 2012), and because gastropods breed even at temperatures lethal to developing embryos (Thompson, 1958).

Finally, egg mass treatment also played a role in determining embryonic viability through complex interactions with adult treatments. This is evident in Table 2.3, which shows that nearly all treatment histories produced unique viability values. Generally, unstressed egg masses tended to produce more viable embryos than Temp/UV stressed egg masses, which produced greater embryonic viability than 
$\mathrm{Cu}$-stressed egg masses. Firstly, this reaffirms the results of Russell \& Phillips (2009) and Fisher \& Phillips (2014), who also documented reduced embryonic viability in S. australis egg masses with temperature and UVR stress. Secondly, this shows that developing embryos are particularly vulnerable to metal pollution, supporting the general literature, which considers exposure to heavy metals to be particularly disastrous during early development (review by Eisler, 1997). The 0\% viability of failed egg masses exposed to all stressors also indicates dramatic developmental synergism between climate change stress (high temperature and UVR) and pollution that is similar to previously documented responses in other taxa (Crain et al., 2008) but has not yet been observed in benthic egg masses in this way.

More importantly, this pattern of decreasing viability according to egg mass treatment holds true regardless of parental experience, but at progressively lower values according to adult treatment, resulting in the step-like pattern in Figure 2.11. Therefore, at least for the egg masses of S. australis, parental effects are not the single most dominant determinant of offspring performance, contrary to the notion that this is often the case (Wade, 1998). However, while not necessarily stronger than offspring experience, the fact that parental environment can be an exceedingly common influence on offspring under global change-type scenarios is underlined by the fact that trans-generational COEs were found in all 11 treatment histories from which larvae successfully hatched. This supports the initial hypothesis that offspring stress vulnerability reflects parental experience, and implies that trans-generational COEs may become more prominent with ongoing global change in the future, a prospect of undoubtedly profound ecological consequence, but one which has not yet been raised by other authors. 


\title{
CHAPTER 3 \\ Parental and Embryonic Stress Causes Carry-Over Effects in Larvae of Siphonaria australis
}

\begin{abstract}
3.1 Abstract
The performance or characteristics of marine invertebrates with complex life histories can be influenced by carry-over effects (COEs) between life stages and between generations. COEs may be an important factor determining the persistence of certain organisms with ongoing global change, particularly for those depositing benthic egg masses in the intertidal. However, there is currently a lack of studies that examine COEs over more than one generation and life stage simultaneously. Consequently, the ways in which COEs from parent to offspring might impact the propagation of stress through offspring life stages remains unclear, especially in the context of global change. Here, Siphonaria australis larvae were produced from 11 successfully hatching treatment histories that combined parental and egg mass exposure to stress (ambient, elevated Temperature + UVR, Copper, and elevated Temperature + UVR + Copper). These larvae were subsequently reared under ambient conditions (ie. no added stressors) for 27 days. This was done to allow COEs from stress that occurred during the egg mass stage and from the parental generation, as well as any interaction between these, to be clearly observable in larvae. Treatment histories differed significantly in larval hatching size, size reached by 27 days, growth rate, and size at death. All these response variables showed evidence of COEs between generations and life stages, as well as interaction between both types of COE, causing larval characteristics to be extremely varied and highly context-dependent. Generally, copper exposure during the egg mass stage appeared to be most deleterious to larvae. The number of survivors was the only variable that was not significantly affected by treatment histories. Overall, trans-generational COEs were slightly more common than those between life stages, a result that has not been demonstrated before. It is suggested that the existing ecological literature, especially that focusing on effects of global change and anthropogenic stress, has so far underestimated the diversity of factors that can contribute to shape the performance or characteristics of a given organism at a given time, as these can be heavily dependent on conditions that prevailed during earlier life stages or even during previous generations.
\end{abstract}




\subsection{Introduction}

Traditionally, the separate life stages of marine invertebrates with complex life histories were considered to be adaptively decoupled by metamorphosis, and the performance of each stage was seen as independent from the experiences of the last (Wilbur, 1980). However, it is now becoming increasingly recognised that conditions during one life stage can significantly influence the performance or characteristics of subsequent stages (Schluter et al., 1991; Podolsky \& Moran, 2006). These effects comprise carry-over effects (COEs) between the life stages of one generation (O'Connor et al., 2014). COEs occurring between early stages can take the form of a variety of lethal and sub-lethal effects and can influence recruitment, reproductive rates and other population dynamics, as has recently been shown in beetles (Van Allen \& Rudolf, 2013). Because in marine invertebrates these processes are often heavily dependent on stress-prone larval stages (Roughgarden et al., 1988), COEs may play an important role in population persistence with ongoing global change.

The manifestation of COEs between life stages is taxonomically wide spread, common under many circumstances, and capable of affecting a broad range of characteristics (review by Pechenik, 2006). Nutritional stress in larvae, for example, has depressive effects on juvenile growth in gastropods (Pechenik et al., 1996), echinoderms (Miller \& Emlet, 1999), bivalves (Phillips, 2002; 2004) and polychaetes (Qian \& Pechenik, 1998). Similarly, embryonic osmotic stress causes increased larval mortality in barnacles (Qiu \& Qian, 1999), and reduced juvenile growth and survival in polychaetes (Pechenik et al., 2001). In response to low egg mass oxygen availability gastropod larvae hatch at smaller sizes with slower swimming speeds (Chan et al. 2008), and declines in survival and growth occur in bryozoan colonies if larvae are exposed to copper $(\mathrm{Cu})(\mathrm{Ng} \& \mathrm{Keough}, 2003)$. The pulmonate limpet Siphonaria australis has already been shown by Fisher \& Phillips (2014) to suffer COEs in the form of increased larval mortality, reduced growth, and smaller feeding structures due to UVR and high temperature stress during embryonic development in benthic egg masses. Beyond marine invertebrates, photoperiod constraints during development reduce adult mating success in insects (De Block \& Stoks, 2005), salmon display reduced survival and growth in response to embryonic crude oil exposure (Heintz et al., 2000), and amphibian larvae show an increased frequency of developmental abnormalities when embryos are exposed to UVR (Pahkala et al., 2001). Similarly, in plants growth was compromised by drought conditions experienced by seedlings (Lof \& Welander, 2000).

Clearly, experiences from separate life stages can interact to form highly context dependent vulnerability (review by Marshall \& Morgan, 2011). However, conspicuous knowledge gaps remain. Most marine species with complex life cycles possess exclusively planktonic development (Stearns, 1992), and consequently the majority of studies examining COEs between life stages in marine taxa do so by focusing on transitions from larvae to post-metamorphic juveniles or from juveniles to adults. By 
contrast, in organisms with mixed development, such as many gastropods, embryos may be deposited in benthic egg masses or brooded, and these species thus effectively pass through an additional stage that will experience drastically different environments than subsequent planktonic stages (Przeslawski, 2004). COEs from embryos still contained within benthic egg masses to later stages, as examined in Fisher \& Phillips (2014), are rarely demonstrated. This is despite the generally accepted notion that conditions experienced during early development are critical to the fitness of later stages (Crean et al., 2011).

Furthermore, in the field, anthropogenic global change will invariably affect organisms through multiple stressors, which can interact to dramatically alter their respective effects (Crain et al., 2008). The presence of high temperature, for example, often ameliorates the influence of other stressors through antagonistic interactions by increasing larval survivorship, whereas most stressor interactions exacerbate one another's impacts and occur synergistically through deleterious sub-lethal effects (review by Przeslawski et al., 2015). Notwithstanding, only around a third of marine studies relating to climate change conducted between 2000 and 2010 were multifactorial in design (Wernberg et al., 2012). Crucially, it is rare for studies examining COEs across life stages to incorporate multiple stressors. This study takes the approach of inducing COEs through both climate change stress combining high UVR and temperature (as in Fisher \& Phillips, 2014), and the compounding factor of pollution in the form of copper $(\mathrm{Cu})$ exposure, to implement a more holistic global change-type scenario than has so far been offered by the existing literature.

Moreover, marine invertebrates with complex life histories are not only subjected to trans-generational influences and direct effects on developing embryos, as established in Chapter 2. For those individuals that survive the embryonic phase, the conditions experienced during development can continue to play a significant role throughout the larval stage by causing legacies of poor performance that may persist even into adulthood (Marshall \& Morgan, 2011). COE studies tend to examine only effects between life stages or between generations, seldom both (but see Marshall, 2008). Consequently, the effects of trans-generational COEs on the ways in which COEs propagate through life stages remains unknown under global change scenarios. This paucity of studies examining both types of COEs simultaneously is surprising, since virtually all stages of offspring life history can be affected by parental stress (review by Marshall et al., 2008).

Here, it was aimed to extend the knowledge gained by Fisher \& Phillips (2014), who examined COEs from $S$. australis egg masses to larvae, by adding a stressed parental generation and thus a transgenerational influence. In this chapter, larvae of S. australis are examined for COEs triggered by climate change-type (elevated temperature and UVR) and pollution $(\mathrm{Cu})$ conditions experienced during embryonic development within egg masses (ie. COEs between life stages), and by the parental 
generation (trans-generational COEs), as covered in Chapter 2. It was hypothesised that effects manifesting in larvae would be the result of interactions between parental and embryonic conditions, and thus highly context-dependent.

\subsection{Methods}

\subsubsection{Rearing of Larvae}

Larvae were obtained from the combinations of parental and egg mass stress treatments described in Chapter 2. Upon hatching from these treatments, 500 larvae were individually transferred from each egg mass dish (described in Chapter 2) into one $800 \mathrm{ml}$ plastic container (FSW, mesh size $=15 \mu \mathrm{m}$ ), giving a stocking density of one larva per $1.6 \mathrm{ml}$. Because not all egg masses hatched, only 11 of the 16 treatment histories are included in this chapter. Since 18 egg masses failed, 30 rather than 48 larval containers were used. Note that some of the treatment histories were only able to be represented by two rather than three replicates as a result of hatching failure.

All larval containers were sealed with a lid, placed in trays filled with water and reared in the absence of stress under ambient conditions identical to those described in Chapter 2 (water temperature at $\sim 16^{\circ} \mathrm{C}$, UVR exposure at $0.087 \mathrm{~W} / \mathrm{m} 2$, and $0 \mu \mathrm{g} / \mathrm{L}$ of $\mathrm{Cu}$ ) so that any carry-over effects manifesting in the characteristics and performance of larvae could be clearly identified. Additionally, cetyl alcohol granules were sprinkled liberally across the water surface of these containers, where they floated and acted to break up the surface tension, which may otherwise entrap larvae and cause mortality (Strathmann, 1987). Water changes $(80 \%)$ were carried out every three days, after which alcohol granules were renewed. Larvae were fed after each water change with a 50:50 mixture of two algal species, Isochrysis galbana and Pavlova lutheri (cultured at VUCEL), at a concentration of 20,000 cells per ml. All containers were stirred daily to resuspend algal cells and hinder the formation of flocculent detritus. Larvae were reared for 27 days.

\subsubsection{Data Collection}

Upon hatching and every three days subsequently, to coincide with water changes, a sample of larvae was taken from each container and observed under a microscope. The shell length of 30 larvae was measured. Of these larvae, 15 were preserved with $5 \%$ buffered formalin, while all others were returned to their containers alive. At 27 days, the surviving larvae in each container were counted and all dead shells were collected and preserved. The shell lengths of up to 30 survivors were also measured, while preserved dead shells (100 per container) were measured later. 


\subsubsection{Data Analysis}

All data analyses were carried out using IBM SPSS 22, and the assumptions for each statistical procedure were tested prior to analysis through Kolmogorov-Smirnov and Shapiro-Wilk tests for normality, Levene's test for homogeneity of variance, and diagnostic graphs. Data that departed from the assumptions of parametric tests were analysed using non-parametric methods where stated. Note that because some of the combinations of parental and egg mass stress did not hatch, the design is no longer fully crossed, and each combination is therefore treated as a level within the single factor "treatment history".

\subsubsection{Hatching Size}

Hatching size was averaged for each treatment using mean size per container. Because data departed from normality and homogeneity of variance, a Kruskal-Wallis test (the non-parametric equivalent of a one-way ANOVA; Dytham, 2011) was carried out to test for differences between treatment histories (11 levels) in larval hatching size ( $\mathrm{n}=30$ larval containers). Additionally, the coefficient of variation $(\mathrm{CV}=$ standard deviation $\div$ mean) was calculated for the hatching size of each container and also analysed using a Kruskal-Wallis test. This was done to regain information on size variability otherwise lost through the implementation of non-parametric techniques, namely the inability to use a nested design and incorporate 30 larvae per container in the analysis rather than merely a mean for each container.

Post-hoc Mann-Whitney U tests were used for pairwise comparisons of treatment histories after both analyses. These pairwise comparisons were used to identify whether trans-generational or between-lifestage (ie. embryo to larva) COEs occurred. Treatment histories were counted as displaying a transgenerational COE if they showed at least one significant difference indicative of such a COE, namely, between another treatment history of the same egg mass treatment but a differing parental treatment. Treatment histories displayed a COE between life stages if they showed at least one significant difference between another treatment history that included the same parental treatment but a different egg mass treatment. Note that each treatment history can be counted as having been influenced by both types of COE, since one does not preclude the other.

Note that the Bonferroni Correction was not used for any post-hoc pairwise comparisons because of its oft-criticised disadvantage of reducing statistical power when a high number of comparisons are made by increasing the probability of false negatives (Rothman, 1990; Savitz \& Olzhan, 1995; Garcia, 2004). Using the technique would, with the 55 pairwise comparisons employed herein, cause the critical pvalue to drop from 0.05 to an exceedingly stringent 0.0009 , causing some treatment histories that clearly differ when graphed to be labelled insignificant. It is therefore reasonable to reject the use of this multiple comparison adjustment on the basis that the number of comparisons being made is too high 
for any detection of false positives to outweigh the effect of false negatives created through the use of the Bonferroni Correction.

\subsubsection{Growth Rate}

Data departed from normality and homogeneity of variance, not allowing for the use of repeated measures ANOVA. Larval growth rate (as $\mu \mathrm{m}$ per day) was calculated for 3 time periods, from hatching to day 9 , from day 9 to day 18 , and from day 18 to the end of the larval rearing period at day 27 . A Kruskal-Wallis test was used for each of these with treatment history at 11 levels, and with post-hoc Mann-Whitney U tests used to identify COEs as above. This was done to observe any changes in growth rate between early, middle and late phases of the 27-rearing period. Growth was calculated for each period by subtracting the mean shell length at the first day from that of the final day in each period and dividing this by 10 (the number of days in each of the three periods). This was done for each larval container separately $(n=30)$.

\subsubsection{Size After 27 Days}

Again, data departed from normality and homogeneity, and a Kruskal-Wallis test was used with treatment history as factor (11 levels; $\mathrm{n}=30$ containers) for both mean size and CV per container, followed by post-hoc Mann-Whitney $U$ tests for pairwise comparisons of treatment histories. This was again used to identify the occurrence of COEs as described above.

\subsubsection{Size at Death}

Data departed only from normality, and since it is considered robust to violations of this assumption (Dytham, 2011), a one-way ANOVA was used in this case to examine the difference between treatment histories (11 levels) in mean size at death of larvae ( $\mathrm{n}=30$ containers). This was followed by a Tukey test employed in the same way as post-hoc tests described above.

\subsubsection{Survivorship}

Because data departed from normality and homogeneity of variance, a Kruskal-Wallis test was used to test for a difference between treatment histories (11 levels) in the number of surviving larvae at 27 days out of the initially stocked 500 per container ( $\mathrm{n}=30$ containers). 


\subsection{Results}

\subsubsection{Hatching Size}

A significant difference in hatching size was found across treatment histories (Kruskal-Wallis Chisquare $=353.534 ; \mathrm{df}=10 ; \mathbf{p}<\mathbf{0 . 0 0 1})$. Mean hatching size ranged from $\sim 120 \mu \mathrm{m}$ in larvae coming from unstressed parents and $\mathrm{Cu}$-stressed egg masses, to $\sim 150 \mu \mathrm{m}$ in larvae from Temp/UV-stressed parents and unstressed egg masses. Larvae from most treatments hatched at $140-145 \mu \mathrm{m}$ on average (Figure 3.1). Overall, there was a high degree of variation in hatching size (Table 3.1), with trans-generational COEs occurring in all 11 treatment histories. COEs between life stages (ie. from embryo to larva) occurred in 9 treatment histories and were absent from Temp/UV/Cu-No Stress and Temp/UV/CuTemp/UV, as these did not differ significantly. Of 55 pairwise comparisons, 37 showed a significant difference.

A significant difference in the coefficient of variation $(\mathrm{CV})$ was also found across treatment histories (Kruskal-Wallis Chi-square $=20.592 ; \mathrm{df}=10 ; \mathbf{p}=\mathbf{0 . 0 2 4}$ ). Most treatments showed a CV of $\sim 0.03-0.05$, with No Stress-Cu displaying by far the highest at $\sim 0.11$ (Figure 3.2). COEs between generations were evident in 6 treatment histories (absent from No Stress-No Stress, Cu-No Stress, $\mathrm{Cu}-\mathrm{Cu}$, Temp/UV-No Stress, and Temp/UV/Cu-No Stress), and those between life stages in 5 treatment histories (absent from No Stress-Temp/UV, Cu-No Stress, Cu-Temp/UV, Cu-Cu, Temp/UV/Cu-No Stress, and Temp/UV/CuTemp/UV) (Table 3.2). Significant differences were found in 25 of 55 pairwise comparisons.

\subsubsection{Growth Rate}

A significant difference in larval growth rate was found between treatment histories in all examined periods of larval rearing, from hatching to day 9 (Kruskal-Wallis Chi-square $=25.616 ; \mathrm{df}=10 ; \mathbf{p}=\mathbf{0 . 0 0 4}$ ), from day 9 to day 18 (Kruskal-Wallis Chi-square=26.000; $\mathrm{df}=10 ; \mathbf{p = 0 . 0 0 4}$ ), and from day 18 to day 27 Kruskal-Wallis Chi-square $=25.868 ; \mathrm{df}=10 ; \mathbf{p}=\mathbf{0 . 0 0 4})$. For the growth period between hatching and day 9 (Figure 3.3), 9 treatment histories showed evidence of COEs between generations (absent from $\mathrm{Cu}$ Temp/UV and Temp/UC/Cu-Temp/UV, and 6 between life stages (absent from all treatment histories featuring no stressors or all simultaneously), with 33 of 55 pairwise comparisons being significant (Table 3.3). For the period between days 9 and 18 (Figure 3.4), all 11 treatment histories showed transgenerational COEs and 9 showed COEs between life stages (absent from Temp/UC/Cu-No Stress and Temp/UC/Cu-Temp/UV), with 38 significantly different pairwise comparisons out of 55 (Table 3.4). For the last period between days 18 and 27 (Figure 3.5), trans-generational COEs manifested in 10 treatment histories (only absent from $\mathrm{Cu}-\mathrm{Cu}$ ), and COEs between life stages in 7 (absent from $\mathrm{Cu}-\mathrm{Cu}$, Temp/UV-Cu, Temp/UC/Cu-No Stress, and Temp/UC/Cu-Temp/UV), with 26 of 55 pairwise comparisons yielding a significant difference (Table 3.5). 


\subsubsection{Size After 27 Days}

A significant difference was found across treatment histories in the size that larvae reached after 27 days of rearing (Kruskal-Wallis Chi-square $=142.430 ; \mathrm{df}=10 ; \mathbf{p}<\mathbf{0 . 0 0 1}$ ). The mean size that larvae reached by day 27 ranged from the smallest at $\sim 180 \mu \mathrm{m}$ in larvae coming from $\mathrm{Cu}$-stressed parents and egg masses to $\sim 220 \mu \mathrm{m}$ in those from Temp/UV-stressed parents and unstressed egg masses. Most other treatment histories produced larvae of $190-210 \mu \mathrm{m}$ (Figure 3.6). A high degree of variation in larval size was revealed by pairwise comparisons (Table 3.6), as trans-generational COEs occurred in 10 of 11 treatment histories. COEs between life stages were evident in 6 treatment histories, and absent from all that included parental No Stress and Temp/UV/Cu treatments. Of 55 pairwise comparisons, 24 showed a significant difference.

A significant difference in the coefficient of variation (CV) for size at 27 days was also found (KruskalWallis Chi-square $=24.441 ; \mathrm{df}=10 ; \mathbf{p}=\mathbf{0 . 0 0 7}$ ). Overall size variability was greater than at hatching, with most treatment histories showing a CV of $\sim 0.9-1.1$ (Figure 3.7). Trans-generational COEs were found in 7 treatment histories (absent from No Stress-Cu, Cu-Cu, Temp/UV-Cu, and Temp/UV/Cu-No Stress), and COEs between life stages in 8 (absent from Temp/UV-Cu, Temp/UV/Cu-No Stress, and Temp/UV/Cu-Temp/UV (Table 3.7). Of 55 pairwise comparisons, only 17 showed a significant difference.

\subsubsection{Size at Death}

A significant difference in mean larval size at death was found between treatment histories $(\mathrm{F}=145.72$; $\mathrm{df}=10 ; \mathbf{p}<\mathbf{0 . 0 0 1})$. Larvae died at average shell lengths between $\sim 145$ and $\sim 205 \mu \mathrm{m}$. Overall larvae tended to die according to adult treatment at progressively smaller sizes in the order No Stress $>\mathrm{Cu}>\mathrm{Temp} / \mathrm{UV}$ $>\mathrm{Temp} / \mathrm{UV} / \mathrm{Cu}$, and at progressively smaller sizes according to egg mass treatment in the order No Stress $>\mathrm{Temp} / \mathrm{UV}>\mathrm{Cu}$ (Figure 3.8). A clear exception to this is the treatment history $\mathrm{Cu}-\mathrm{Temp} / \mathrm{UV}$, which shows the largest of all mean sizes at death. Trans-generational COEs occurred in all 11 treatment histories (Table 3.8), and COEs between life stages in 9 (absent from Temp/UV/Cu-No Stress and Temp/UV/Cu-Temp/UV). Of 55 pairwise comparisons, 44 showed a significant difference.

\subsubsection{Survivorship}

No significant difference was found among treatment histories in terms of the number of surviving larvae at 27 days (Kruskal-Wallis Chi-square $=14.662 ; \mathrm{df}=10 ; \mathrm{p}=0.145$ ). Survivor numbers were highly variable and varied from $<10$ (beyond the 30 that were sampled), with treatment histories incorporating $\mathrm{Cu}$-stressed egg masses tending to be the lowest, to $\sim 80$ as by far the highest number in $\mathrm{Cu}-\mathrm{Temp} / \mathrm{UV}$, while most were $\sim 20-45$ (Figure 3.9). 


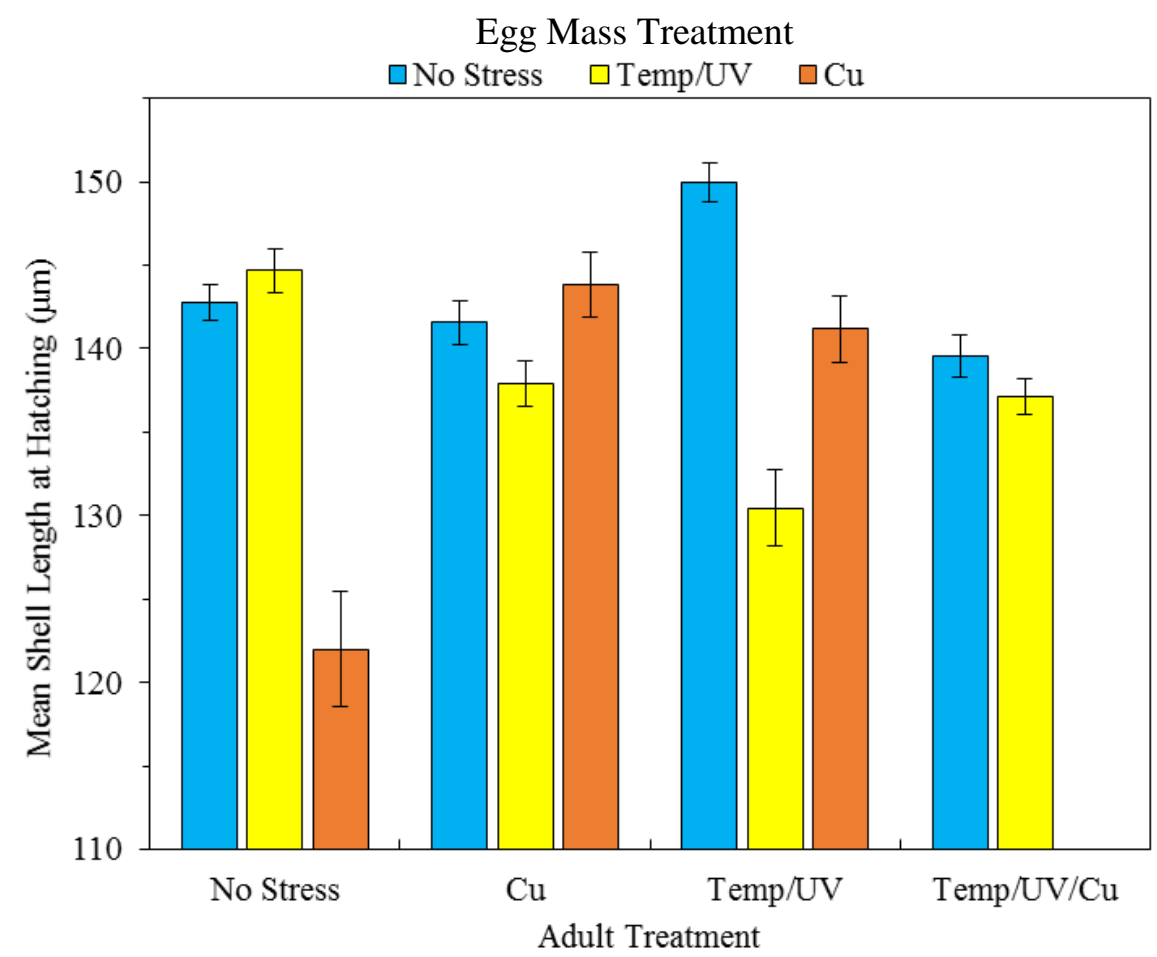

Figure 3.1 Mean shell length $(\mu \mathrm{m})$ at hatching (+/-95\% C.I.) of S. australis larvae across treatments $(n=30)$. Each bar represents one of the 11 successfully hatching treatment histories, composed of an adult treatment (x axis) and an egg mass treatment (colours).

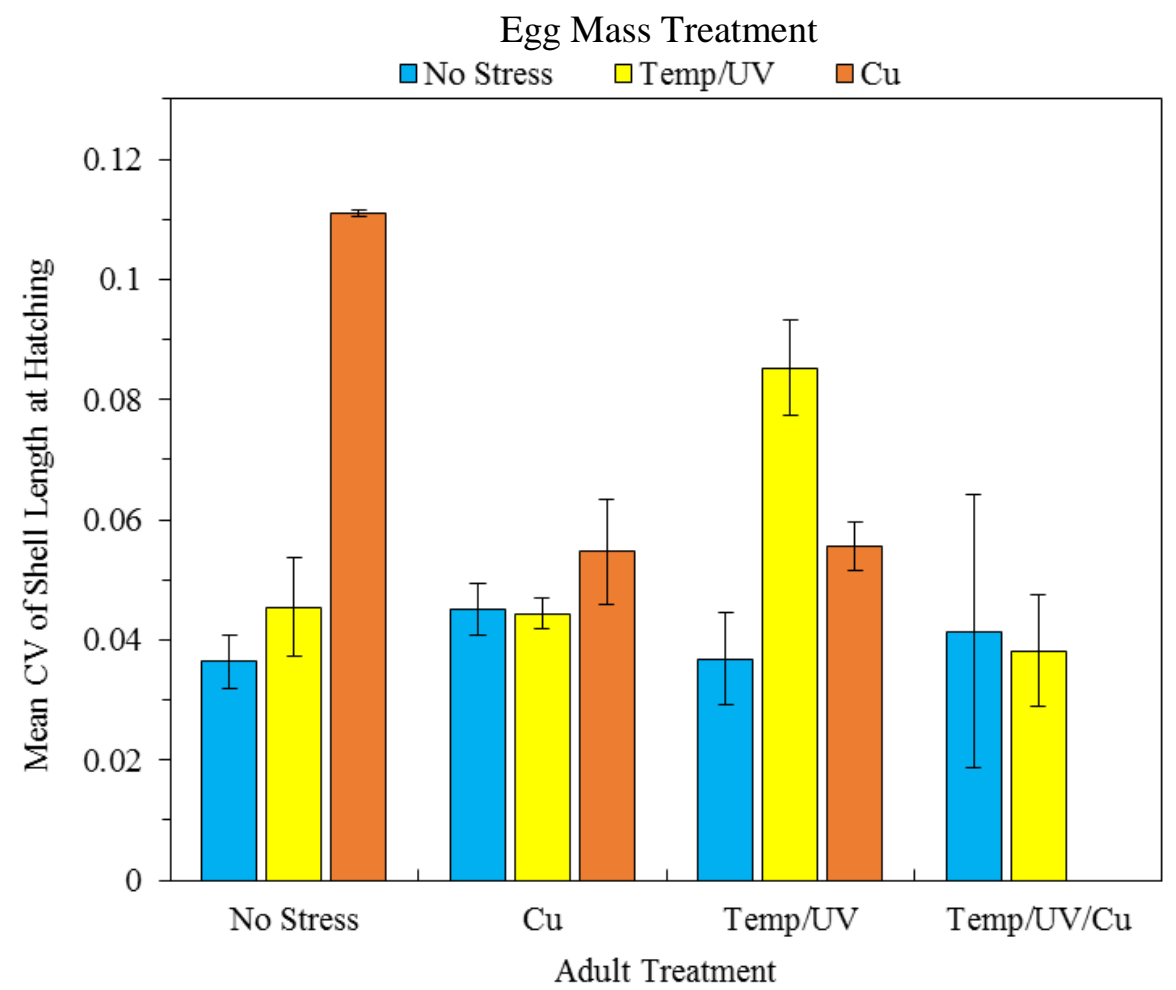

Figure 3.2 Mean coefficient of variation (CV) for shell length at hatching of S. australis larvae (+/95\% C.I.) across treatments $(n=30)$. Each bar represents one of the 11 successfully hatching treatment histories, composed of an adult treatment (x axis) and an egg mass treatment (colours). 
Egg Mass Treatment

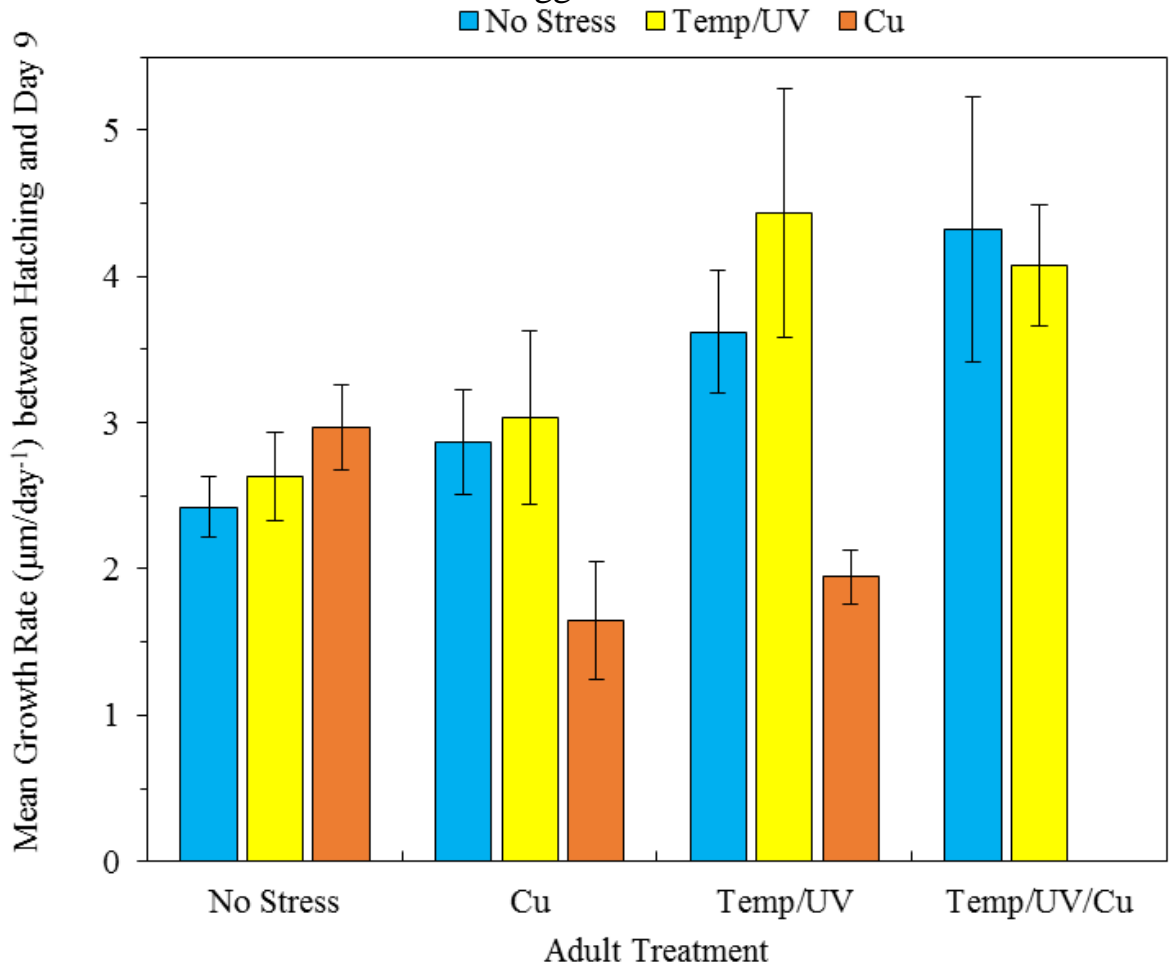

Figure 3.3 Mean growth rate ( $\mu \mathrm{m}$ per day) of $S$. australis larvae from hatching to day 9 of rearing period (+/-95\% C.I.) across treatments $(n=30)$. Each bar represents one of the 11 successfully hatching treatment histories, composed of an adult treatment (x axis) and an egg mass treatment (colours).

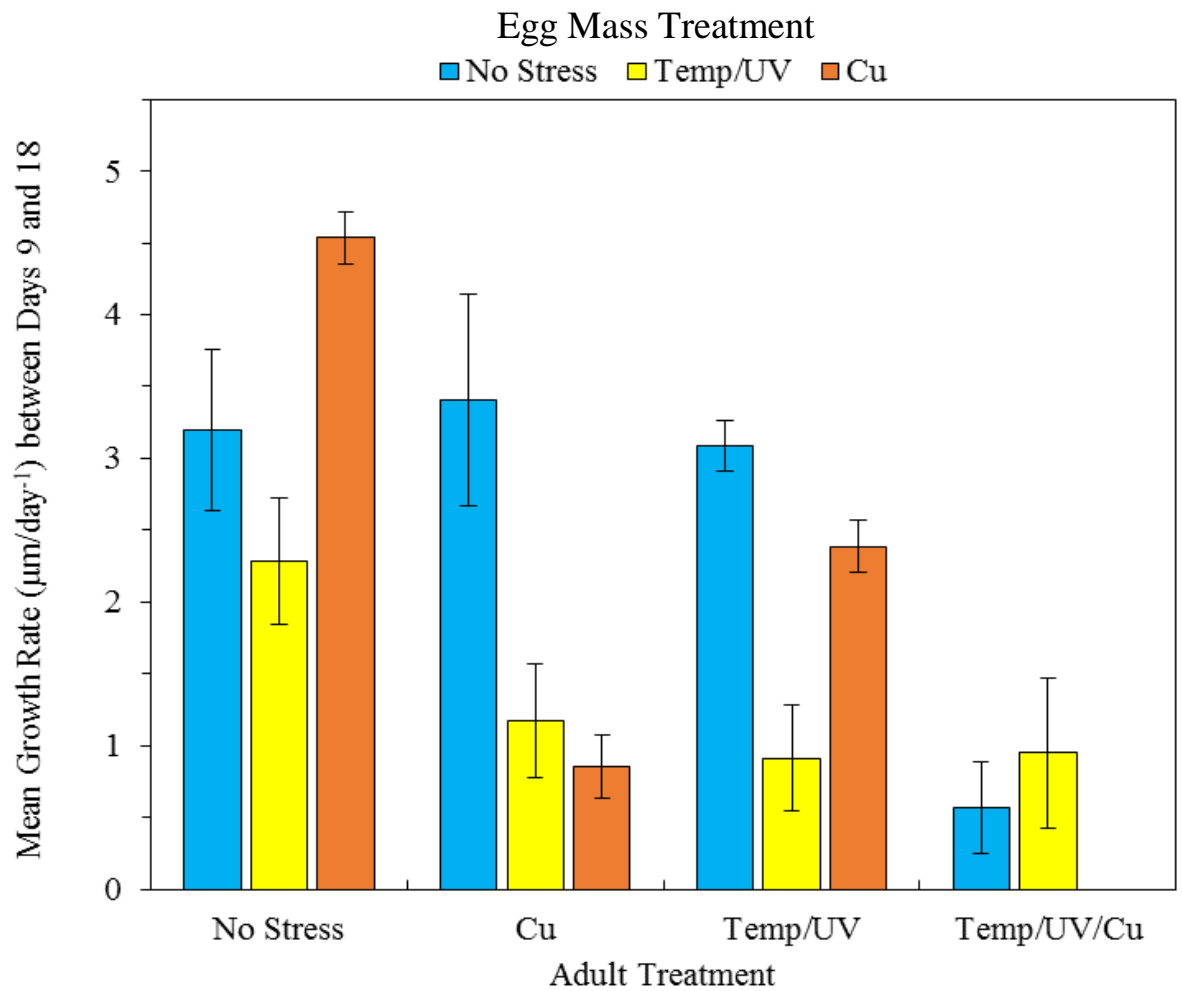

Figure 3.4 Mean growth rate ( $\mu \mathrm{m}$ per day) of $S$. australis larvae from day 9 to day 18 (+/-95\% C.I.) across treatments $(n=30)$. Each bar represents one of the 11 successfully hatching treatment histories, composed of an adult treatment (x axis) and an egg mass treatment (colours). 
Egg Mass Treatment

$\square$ No Stress $\square \mathrm{Temp} / \mathrm{UV} \quad \square \mathrm{Cu}$

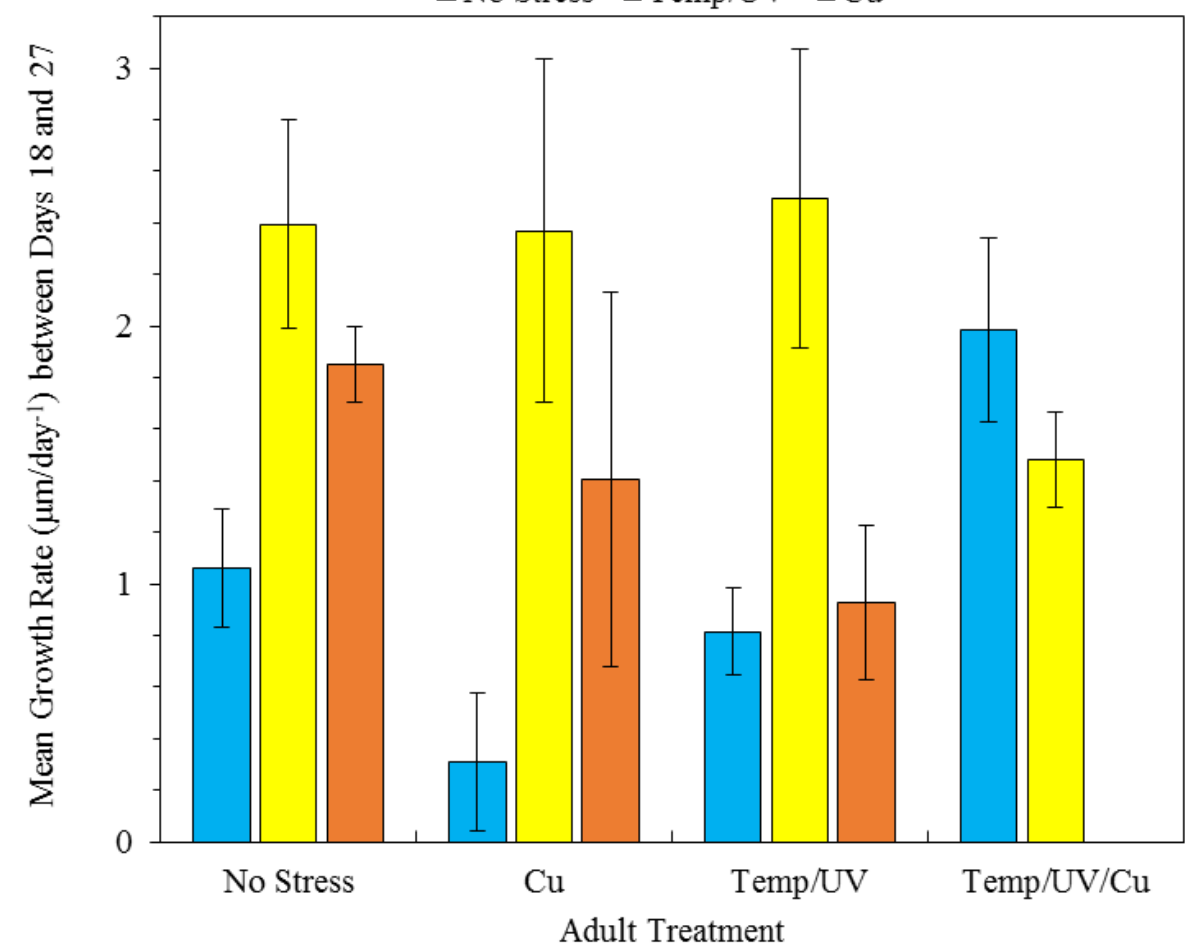

Figure 3.5 Mean growth rate ( $\mu \mathrm{m}$ per day) of S. australis larvae from day 18 to day 27 (+/-95\% C.I.) across treatments $(n=30)$. Each bar represents one of the 11 successfully hatching treatment histories, composed of an adult treatment (x axis) and an egg mass treatment (colours).

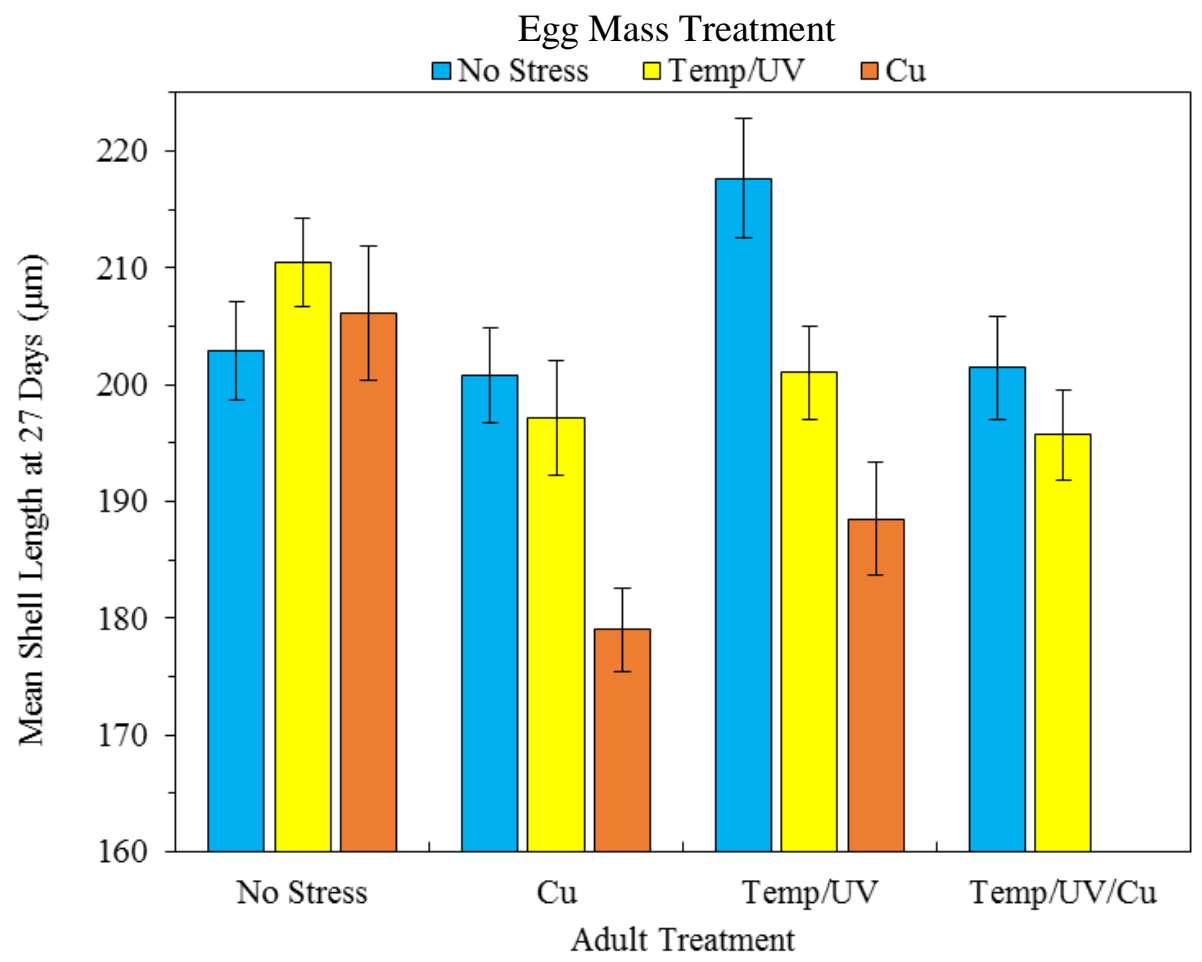

Figure 3.6 Mean shell length $(\mu \mathrm{m})$ at 27 days (+/-95\% C.I.) of $S$. australis larvae across treatments $(n=30)$. Each bar represents one of the 11 successfully hatching treatment histories, composed of an adult treatment (x axis) and an egg mass treatment (colours). 


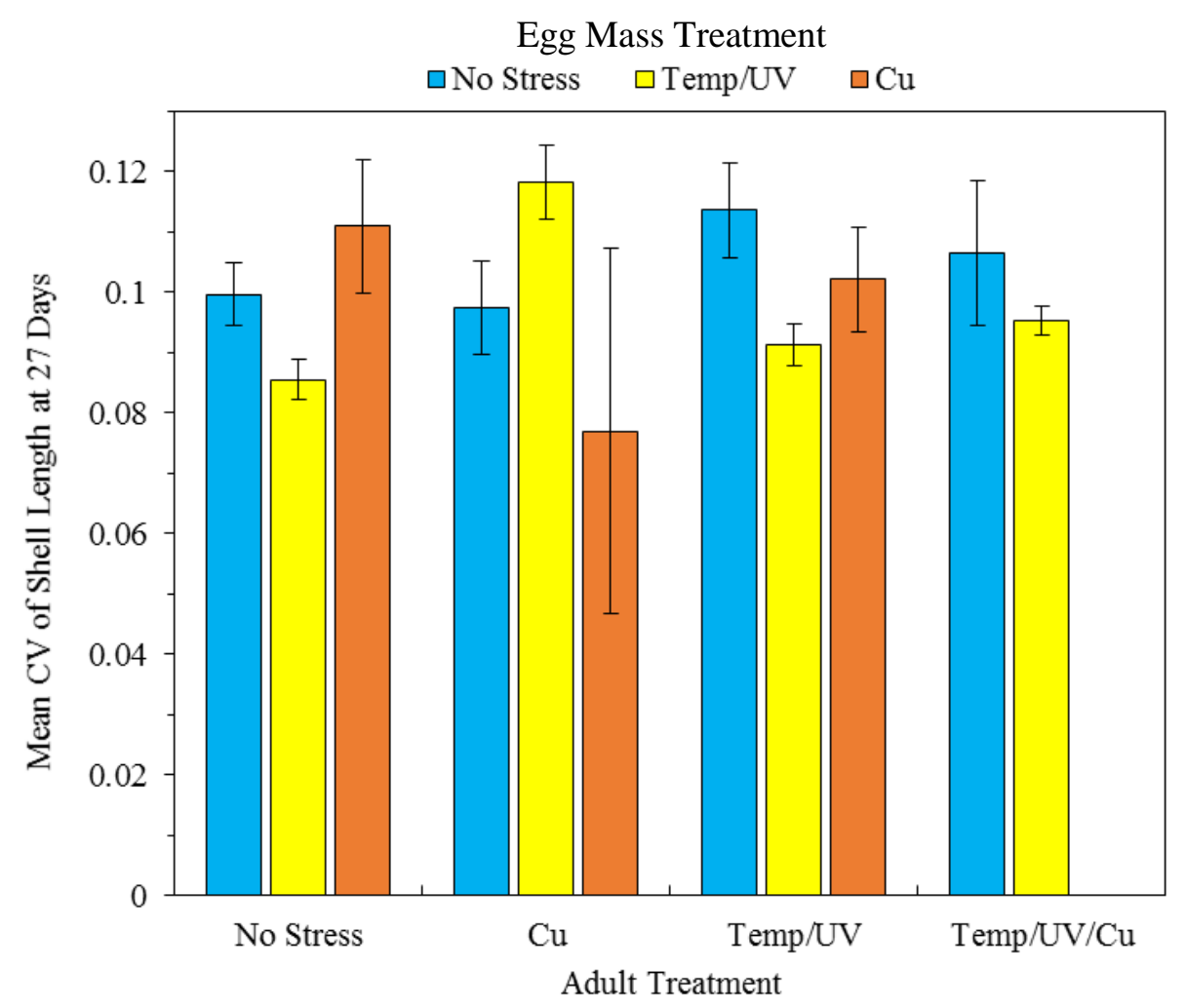

Figure 3.7 Mean coefficient of variation (CV) for shell length of S. australis larvae at 27 days (+/-95\% C.I.) across treatments $(n=30)$. Each bar represents one of the 11 successfully hatching treatment histories, composed of an adult treatment (x axis) and an egg mass treatment (colours).

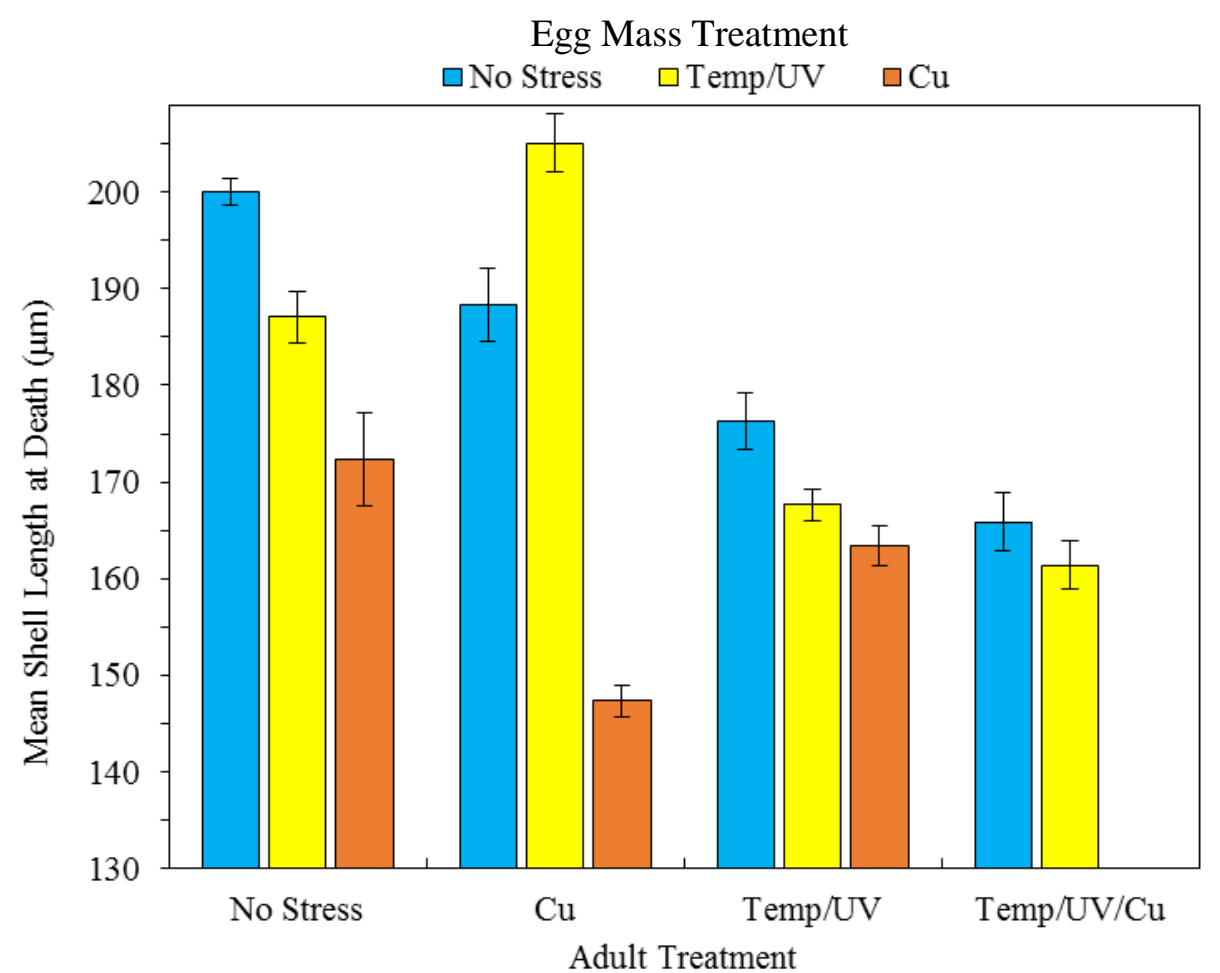

Figure 3.8 Mean shell length $(\mu \mathrm{m})$ at death of $S$. australis larvae (+/-95\% C.I.) across treatments $(\mathrm{n}=30)$.

Each bar represents one of the 11 successfully hatching treatment histories, composed of an adult treatment (x axis) and an egg mass treatment (colours). 


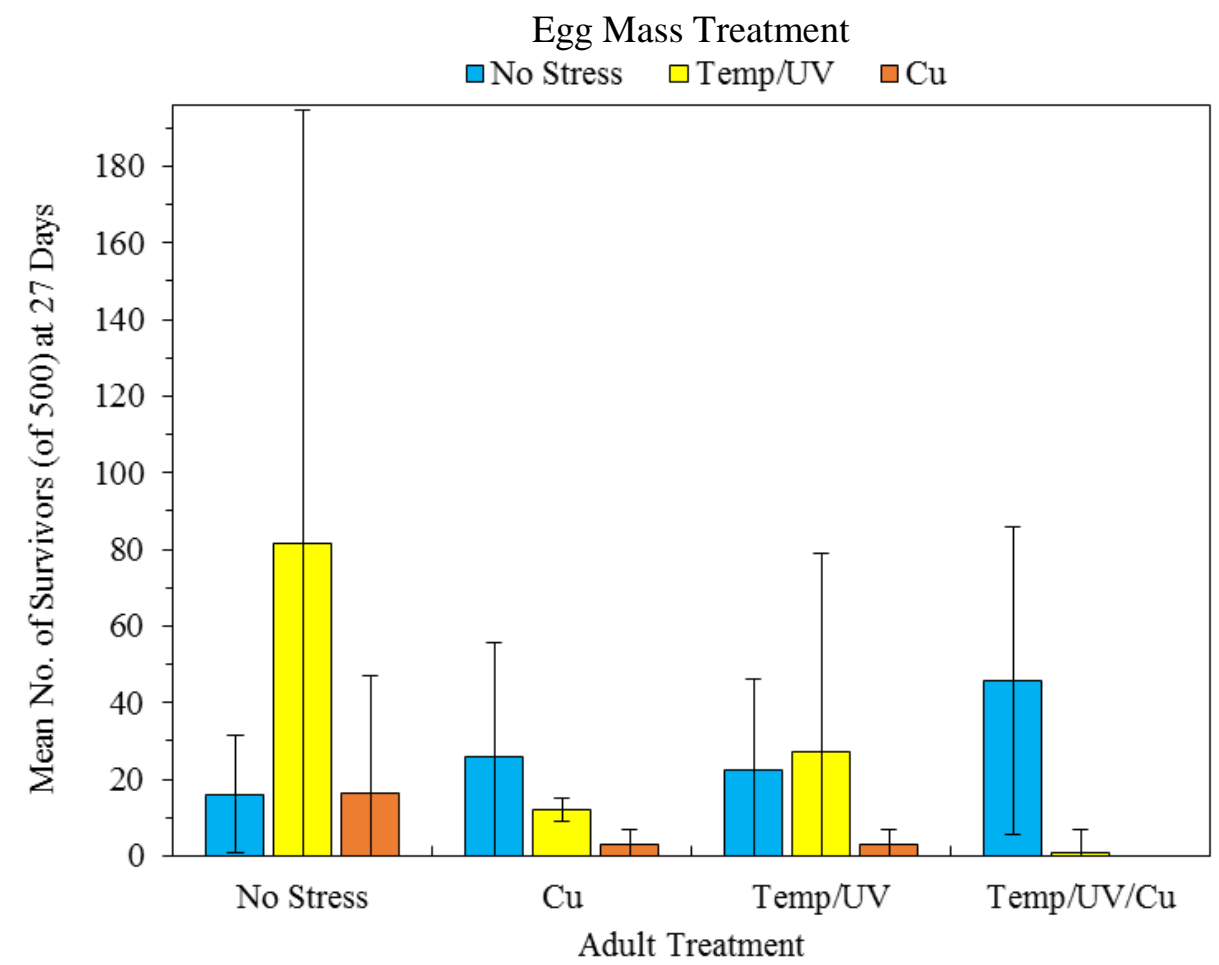

Figure 3.9 Mean number of surviving S. australis larvae (out of 500) at 27 days (+/-95\% C.I.) across treatments $(n=30)$. Each bar represents one of the 11 successfully hatching treatment histories, composed of an adult treatment (x axis) and an egg mass treatment (colours). 
Table 3.1 Hatching size pairwise comparisons. Results of post-hoc Mann-Whitney U tests performed after Kruskal-Wallis test examining the effect of treatment history (11 levels) on hatching size of larvae $(n=30)$. Each treatment history incorporates an adult (parent) treatment, named first, followed by an egg mass treatment. Differences significant at the $\alpha=0.05$ level appear in bold ( $p$-values). Pairwise comparisons are also labelled according to the type of COE that would be indicated by a significant difference ("GEN" = trans-generational COE; "STGE" = COE between egg mass and larval life stages). No label is present where this distinction cannot be made.

\begin{tabular}{|c|c|c|c|c|c|c|c|c|c|c|c|}
\hline $\begin{array}{c}\text { Pairwise Comparisons } \\
\text { between Treatment } \\
\text { Histories } \\
\text { (parent treatment - egg } \\
\text { mass treatment) }\end{array}$ & 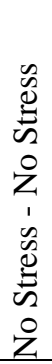 & 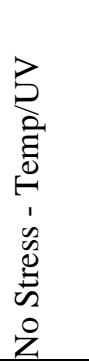 & 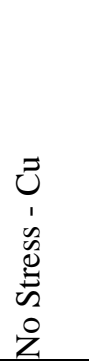 & 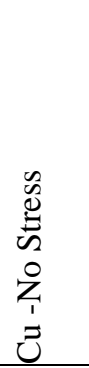 & 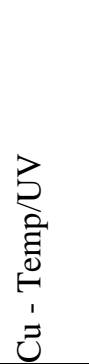 & $\begin{array}{l}\vec{U} \\
\bar{J} \\
\vec{J}\end{array}$ & 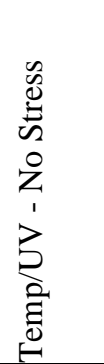 & 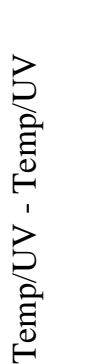 & 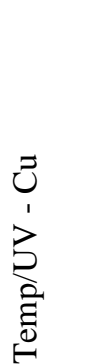 & 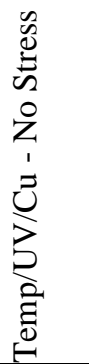 & 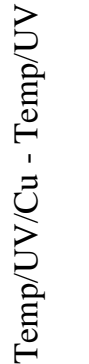 \\
\hline No Stress - No Stress & 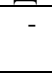 & $\begin{array}{l}0.0852 \\
\text { STGE } \\
\end{array}$ & $\begin{array}{l}<0.001 \\
\text { STGE } \\
\end{array}$ & $\begin{array}{l}0.992 \\
\text { GEN }\end{array}$ & $<0.001$ & 0.999 & $\begin{array}{l}\angle \mathbf{6 0 0 1} \\
\text { GEN }\end{array}$ & $<0.001$ & 0.973 & $\begin{array}{l}0.143 \\
\text { GEN } \\
\end{array}$ & $<0.001$ \\
\hline No Stress - Temp/UV & - & - & $\begin{array}{l}<0.001 \\
\text { STGE } \\
\end{array}$ & 0.181 & $\begin{array}{l}<0.001 \\
\text { GEN }\end{array}$ & 0.900 & $<0.001$ & $\begin{array}{l}<0.001 \\
\text { GEN }\end{array}$ & 0.174 & $<0.001$ & $\begin{array}{l}<0.001 \\
\text { GEN }\end{array}$ \\
\hline No Stress - $\mathrm{Cu}$ & - & - & - & $<0.001$ & $<0.001$ & $\begin{array}{l}<0.001 \\
\text { GEN }\end{array}$ & $<0.001$ & $<0.001$ & $\begin{array}{l}<0.001 \\
\text { GEN }\end{array}$ & $<0.001$ & $<0.001$ \\
\hline $\mathrm{Cu}$ - No Stress & - & - & - & - & $\begin{array}{c}\text { 0.049 } \\
\text { STGE } \\
\end{array}$ & $\begin{array}{l}0.781 \\
\text { STGE }\end{array}$ & $\begin{array}{l}<\mathbf{0 . 0 0 1} \\
\text { GEN }\end{array}$ & $<0.001$ & 0.900 & $\begin{array}{l}0.800 \\
\text { GEN }\end{array}$ & 0.004 \\
\hline $\mathrm{Cu}-\mathrm{Temp} / \mathrm{UV}$ & - & - & - & - & - & $\begin{array}{l}<0.001 \\
\text { STGE } \\
\end{array}$ & $<0.001$ & $\begin{array}{l}<0.001 \\
\text { GEN } \\
\end{array}$ & 0.256 & 0.929 & $\begin{array}{l}0.900 \\
\text { GEN } \\
\end{array}$ \\
\hline $\mathrm{Cu}-\mathrm{Cu}$ & - & - & - & - & - & & $<0.001$ & $<0.001$ & $\begin{array}{l}0.703 \\
\text { GEN } \\
\end{array}$ & 0.031 & $<0.001$ \\
\hline Temp/UV - No Stress & - & - & - & - & - & - & - & $\begin{array}{l}<0.001 \\
\text { STGE }\end{array}$ & $\begin{array}{l}<0.001 \\
\text { STGE }\end{array}$ & $\begin{array}{l}<0.001 \\
\text { GEN }\end{array}$ & $<0.001$ \\
\hline Temp/UV - Temp/UV & - & - & - & - & - & - & - & & $\begin{array}{l}<0.001 \\
\text { STGE }\end{array}$ & $<0.001$ & $\begin{array}{l}<0.001 \\
\text { GEN } \\
\end{array}$ \\
\hline Temp/UV - Cu & - & - & - & - & - & - & - & - & - & 0.973 & 0.054 \\
\hline Temp/UV/Cu - No Stress & - & - & - & - & - & - & - & - & - & - & $\begin{array}{l}0.536 \\
\text { STGE } \\
\end{array}$ \\
\hline Temp/UV/Cu - Temp/UV & - & - & - & - & - & - & - & - & - & - & - \\
\hline
\end{tabular}


Table 3.2 Hatching size CV pairwise comparisons. Results of post-hoc Mann-Whitney U tests performed after Kruskal-Wallis test examining the effect of treatment history (11 levels) on the coefficient of variation (CV) for hatching size of larvae $(n=30)$. Each treatment history incorporates an adult (parent) treatment, named first, followed by an egg mass treatment. Differences significant at the $\alpha=0.05$ level appear in bold ( $p$-values). Pairwise comparisons are also labelled according to the type of COE that would be indicated by a significant difference ("GEN" = trans-generational COE; "STGE" = COE between egg mass and larval life stages). No label is present where this distinction cannot be made.

\begin{tabular}{|c|c|c|c|c|c|c|c|c|c|c|c|}
\hline $\begin{array}{l}\text { Pairwise Comparisons } \\
\text { between Treatment } \\
\text { Histories } \\
\text { (parent treatment - egg } \\
\text { mass treatment) }\end{array}$ & 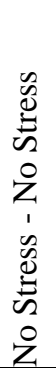 & 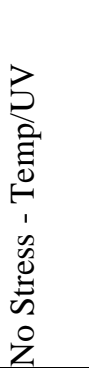 & 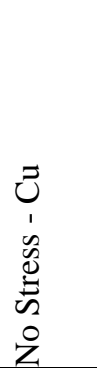 & $\begin{array}{l}0 \\
0 \\
\vdots \\
0 \\
0 \\
0 \\
z_{1} \\
3 \\
\tilde{J}\end{array}$ & 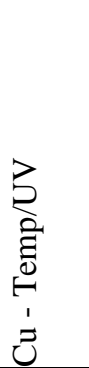 & $\begin{array}{l}\vec{U} \\
\dot{3}\end{array}$ & 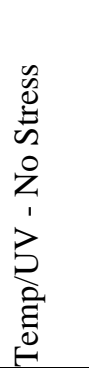 & 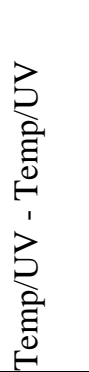 & 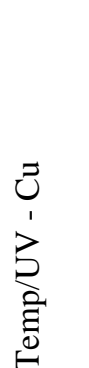 & 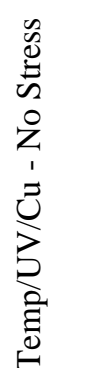 & 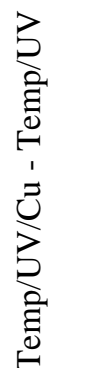 \\
\hline No Stress - No Stress & - & $\begin{array}{l}0.127 \\
\text { STGE }\end{array}$ & $\begin{array}{l}<0.001 \\
\text { STGE }\end{array}$ & $\begin{array}{l}0.077 \\
\text { GEN }\end{array}$ & 0.083 & 0.050 & $\begin{array}{l}0.827 \\
\text { GEN } \\
\end{array}$ & $<0.001$ & 0.050 & $\begin{array}{l}0.513 \\
\text { GEN }\end{array}$ & 0.513 \\
\hline No Stress - Temp/UV & - & - & $\begin{array}{l}<\mathbf{< . 0 0 1} \\
\text { STGE }\end{array}$ & 0.827 & $\begin{array}{l}0.827 \\
\text { GEN } \\
\end{array}$ & 0.248 & 0.275 & $\begin{array}{l}0.050 \\
\text { GEN } \\
\end{array}$ & 0.083 & 0.083 & $\begin{array}{l}0.827 \\
\text { GEN } \\
\end{array}$ \\
\hline No Stress - $\mathrm{Cu}$ & - & - & - & $<0.001$ & $<0.001$ & $<0.001$ & $<0.001$ & $<0.001$ & $\begin{array}{l}<0.001 \\
\text { GEN }\end{array}$ & $<0.001$ & $<0.001$ \\
\hline $\mathrm{Cu}$ - No Stress & - & - & - & - & $\begin{array}{c}0.827 \\
\text { STGE } \\
\end{array}$ & $\begin{array}{l}0.083 \\
\text { STGE } \\
\end{array}$ & $\begin{array}{l}0.127 \\
\text { GEN } \\
\end{array}$ & 0.015 & 0.050 & $\begin{array}{l}0.083 \\
\text { GEN } \\
\end{array}$ & 0.513 \\
\hline $\mathrm{Cu}-\mathrm{Temp} / \mathrm{UV}$ & - & - & - & - & 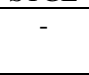 & $\begin{array}{l}0.083 \\
\text { STGE }\end{array}$ & 0.275 & $\begin{array}{l}0.015 \\
\text { GEN }\end{array}$ & 0.050 & 0.513 & $\begin{array}{l}0.513 \\
\text { GEN }\end{array}$ \\
\hline $\mathrm{Cu}-\mathrm{Cu}$ & - & - & - & - & - & - & 0.083 & 0.043 & $\begin{array}{l}0.900 \\
\text { GEN }\end{array}$ & 0.564 & 0.083 \\
\hline Temp/UV - No Stress & - & - & - & - & - & - & - & $\begin{array}{l}<0.001 \\
\text { STGE }\end{array}$ & $\begin{array}{r}\text { 0.043 } \\
\text { STGE } \\
\end{array}$ & $\begin{array}{l}0.513 \\
\text { GEN } \\
\end{array}$ & 0.827 \\
\hline Temp/UV - Temp/UV & - & - & - & - & - & - & - & - & $\begin{array}{c}\text { 0.015 } \\
\text { STGE } \\
\end{array}$ & 0.050 & $\begin{array}{l}0.050 \\
\text { GEN }\end{array}$ \\
\hline Temp/UV - Cu & - & - & - & - & - & - & - & - & - & 0.248 & 0.043 \\
\hline Temp/UV/Cu - No Stress & - & - & - & - & - & - & - & - & - & - & $\begin{array}{l}0.513 \\
\text { STGE } \\
\end{array}$ \\
\hline Temp/UV/Cu - Temp/UV & - & - & - & - & - & - & - & - & - & - & - \\
\hline
\end{tabular}


Table 3.3 Hatching to day 9 growth rate pairwise comparisons. Results of post-hoc Mann-Whitney U tests performed after Kruskal-Wallis test examining the effect of treatment history (11 levels) on larval growth rate $(\mathrm{n}=30)$. Each treatment history incorporates an adult (parent) treatment, named first, followed by an egg mass treatment. Differences significant at the $\alpha=0.05$ level appear in bold ( $p$-values). Pairwise comparisons are also labelled according to the type of COE that would be indicated by a significant difference ("GEN" = trans-generational COE; "STGE" = COE between egg mass and larval life stages). No label is present where this distinction cannot be made.

\begin{tabular}{|c|c|c|c|c|c|c|c|c|c|c|c|}
\hline $\begin{array}{c}\text { Pairwise Comparisons } \\
\text { between Treatment } \\
\text { Histories } \\
\text { (parent treatment - egg } \\
\text { mass treatment) }\end{array}$ & 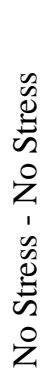 & 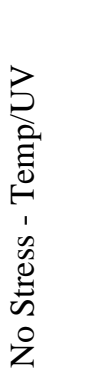 & 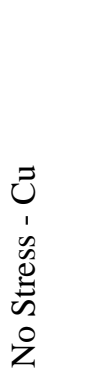 & 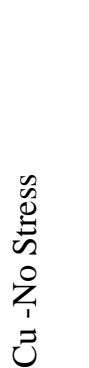 & 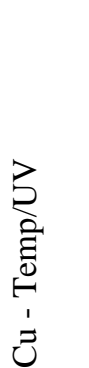 & $\begin{array}{l}\vec{U} \\
\dot{J} \\
\vec{J}\end{array}$ & 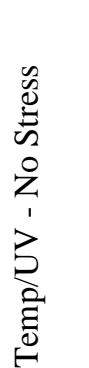 & 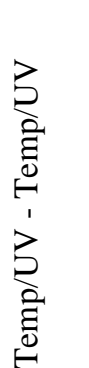 & 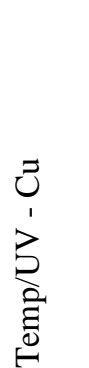 & 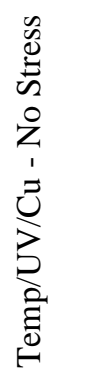 & 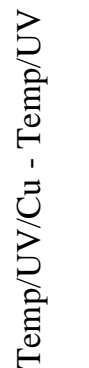 \\
\hline No Stress - No Stress & - & $\begin{array}{l}0.184 \\
\text { STGE }\end{array}$ & $\begin{array}{l}0.083 \\
\text { STGE }\end{array}$ & $\begin{array}{l}0.077 \\
\text { GEN }\end{array}$ & 0.127 & $<0.001$ & $\begin{array}{l}<0.001 \\
\text { GEN }\end{array}$ & $<0.001$ & $<0.001$ & $\begin{array}{l}<0.001 \\
\text { GEN }\end{array}$ & $<0.001$ \\
\hline No Stress - Temp/UV & - & - & $\begin{array}{l}0.083 \\
\text { STGE } \\
\end{array}$ & 0.184 & $\begin{array}{l}0.513 \\
\text { GEN } \\
\end{array}$ & $<0.001$ & $<0.001$ & $\begin{array}{l}<0.001 \\
\text { GEN }\end{array}$ & $<0.001$ & $<0.001$ & $\begin{array}{l}<\mathbf{0 . 0 0 1} \\
\text { GEN }\end{array}$ \\
\hline No Stress - $\mathrm{Cu}$ & - & - & & 0.564 & 0.900 & $\begin{array}{l}<0.001 \\
\text { GEN }\end{array}$ & 0.083 & 0.043 & $\begin{array}{l}0.012 \\
\text { GEN }\end{array}$ & 0.043 & 0.043 \\
\hline $\mathrm{Cu}$ - No Stress & - & - & - & & $\begin{array}{l}0.827 \\
\text { STGE }\end{array}$ & $\begin{array}{l}<0.001 \\
\text { STGE }\end{array}$ & $\begin{array}{l}.050 \\
\text { GEN }\end{array}$ & 0.050 & $<0.001$ & $\begin{array}{l}0.050 \\
\text { GEN }\end{array}$ & 0.050 \\
\hline $\mathrm{Cu}-\mathrm{Temp} / \mathrm{UV}$ & - & - & - & - & 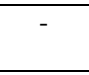 & $\begin{array}{c}\text { 0.043 } \\
\text { STGE } \\
\end{array}$ & 0.184 & $\begin{array}{l}0.083 \\
\text { GEN } \\
\end{array}$ & $<0.001$ & 0.127 & $\begin{array}{l}0.083 \\
\text { GEN } \\
\end{array}$ \\
\hline $\mathrm{Cu}-\mathrm{Cu}$ & - & - & - & - & - & - & $<0.001$ & $<0.001$ & $\begin{array}{l}0.221 \\
\text { GEN }\end{array}$ & $<0.001$ & $<0.001$ \\
\hline Temp/UV - No Stress & - & - & - & - & - & - & - & $\begin{array}{l}0.127 \\
\text { STGE }\end{array}$ & $\begin{array}{l}<0.001 \\
\text { STGE }\end{array}$ & $\begin{array}{l}0.275 \\
\text { GEN }\end{array}$ & 0.127 \\
\hline Temp/UV - Temp/UV & - & - & - & - & - & - & - & - & $\begin{array}{l}<<.001 \\
\text { STGE }\end{array}$ & 0.827 & $\begin{array}{l}0.827 \\
\text { GEN }\end{array}$ \\
\hline Temp/UV - Cu & - & - & - & - & - & - & - & - & - & $<0.001$ & $<0.001$ \\
\hline Temp/UV/Cu - No Stress & - & - & - & - & - & - & - & - & - & - & $\begin{array}{r}0.513 \\
\text { STGE } \\
\end{array}$ \\
\hline Temp/UV/Cu - Temp/UV & - & - & - & - & - & - & - & - & - & - & - \\
\hline
\end{tabular}


Table 3.4 Day 9 to 18 growth rate pairwise comparisons. Results of post-hoc Mann-Whitney U tests performed after Kruskal-Wallis test examining the effect of treatment history (11 levels) on larval growth rate $(\mathrm{n}=30)$. Each treatment history incorporates an adult (parent) treatment, named first, followed by an egg mass treatment. Differences significant at the $\alpha=0.05$ level appear in bold (p-values). Pairwise comparisons are also labelled according to the type of COE that would be indicated by a significant difference ("GEN" = trans-generational COE; "STGE" = COE between egg mass and larval life stages). No label is present where this distinction cannot be made.

\begin{tabular}{|c|c|c|c|c|c|c|c|c|c|c|c|}
\hline $\begin{array}{c}\text { Pairwise Comparisons } \\
\text { between Treatment } \\
\text { Histories } \\
\text { (parent treatment - egg } \\
\text { mass treatment) }\end{array}$ & 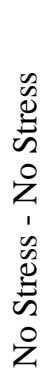 & 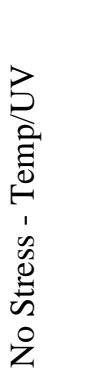 & 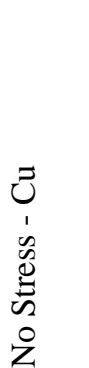 & 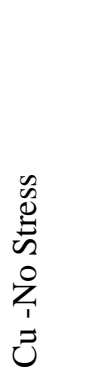 & 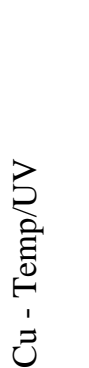 & $\begin{array}{l}\vec{U} \\
\dot{J} \\
\vec{J}\end{array}$ & 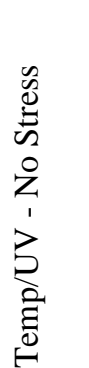 & 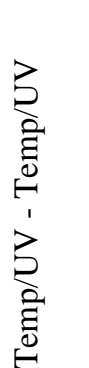 & 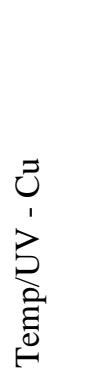 & 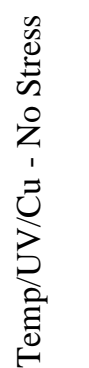 & 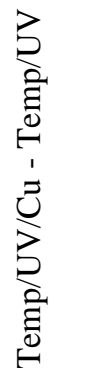 \\
\hline No Stress - No Stress & - & $\begin{array}{l}0.083 \\
\text { STGE }\end{array}$ & $\begin{array}{l}0.050 \\
\text { STGE }\end{array}$ & $\begin{array}{l}0.827 \\
\text { GEN }\end{array}$ & $<0.001$ & $<0.001$ & $\begin{array}{l}0.827 \\
\text { GEN }\end{array}$ & $<0.001$ & 0.046 & $\begin{array}{l}<0.001 \\
\text { GEN }\end{array}$ & $<0.001$ \\
\hline No Stress - Temp/UV & - & - & $\begin{array}{l}<0.001 \\
\text { STGE }\end{array}$ & 0.077 & $\begin{array}{l}0.043 \\
\text { GEN } \\
\end{array}$ & 0.043 & 0.050 & $\begin{array}{l}<0.001 \\
\text { GEN }\end{array}$ & 0.767 & $<0.001$ & $\begin{array}{l}<0.001 \\
\text { GEN }\end{array}$ \\
\hline No Stress - $\mathrm{Cu}$ & - & - & & 0.083 & $<0.001$ & $\begin{array}{l}<0.001 \\
\text { GEN }\end{array}$ & 0.043 & $<0.001$ & $\begin{array}{l}0.012 \\
\text { GEN }\end{array}$ & $<0.001$ & $<0.001$ \\
\hline $\mathrm{Cu}$ - No Stress & - & - & - & 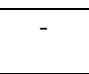 & $\begin{array}{l}<0.001 \\
\text { STGE }\end{array}$ & $\begin{array}{l}<0.001 \\
\text { STGE }\end{array}$ & $\begin{array}{l}0.513 \\
\text { GEN }\end{array}$ & $<0.001$ & 0.043 & $\begin{array}{l}<0.001 \\
\text { GEN }\end{array}$ & $<0.001$ \\
\hline $\mathrm{Cu}-\mathrm{Temp} / \mathrm{UV}$ & - & - & - & - & & $\begin{array}{l}0.248 \\
\text { STGE } \\
\end{array}$ & $<0.001$ & $\begin{array}{l}0.275 \\
\text { GEN } \\
\end{array}$ & $<0.001$ & 0.121 & $\begin{array}{l}0.513 \\
\text { GEN } \\
\end{array}$ \\
\hline $\mathrm{Cu}-\mathrm{Cu}$ & - & - & - & - & - & - & $<0.001$ & 0.564 & $\begin{array}{l}.012 \\
\text { GEN }\end{array}$ & 0.236 & 0.767 \\
\hline Temp/UV - No Stress & - & - & - & - & - & - & - & $\begin{array}{l}<\mathbf{0 . 0 0 1} \\
\text { STGE }\end{array}$ & $\begin{array}{r}0.043 \\
\text { STGE }\end{array}$ & $\begin{array}{l}<0.001 \\
\text { GEN }\end{array}$ & $<0.001$ \\
\hline Temp/UV - Temp/UV & - & - & - & - & - & - & - & - & $\begin{array}{c}.012 \\
\text { STGE }\end{array}$ & 0.121 & $\begin{array}{l}0.827 \\
\text { GEN }\end{array}$ \\
\hline Temp/UV - Cu & - & - & - & - & - & - & - & - & 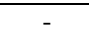 & $<0.001$ & $<0.001$ \\
\hline Temp/UV/Cu - No Stress & - & - & - & - & - & - & - & - & - & - & $\begin{array}{r}0.268 \\
\text { STGE }\end{array}$ \\
\hline Temp/UV/Cu - Temp/UV & - & - & - & - & - & - & - & - & - & - & - \\
\hline
\end{tabular}


Table 3.5 Day 18 to 27 growth rate pairwise comparisons. Results of post-hoc Mann-Whitney U tests performed after Kruskal-Wallis test examining the effect of treatment history (11 levels) on larval growth rate $(\mathrm{n}=30)$. Each treatment history incorporates an adult (parent) treatment, named first, followed by an egg mass treatment. Differences significant at the $\alpha=0.05$ level appear in bold (p-values). Pairwise comparisons are also labelled according to the type of COE that would be indicated by a significant difference ("GEN" = trans-generational COE; "STGE" = COE between egg mass and larval life stages). No label is present where this distinction cannot be made.

\begin{tabular}{|c|c|c|c|c|c|c|c|c|c|c|c|}
\hline $\begin{array}{c}\text { Pairwise Comparisons } \\
\text { between Treatment } \\
\text { Histories } \\
\text { (parent treatment - egg } \\
\text { mass treatment) }\end{array}$ & 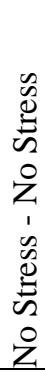 & 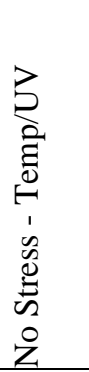 & 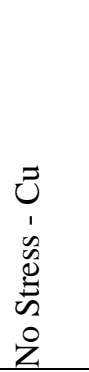 & 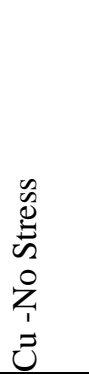 & 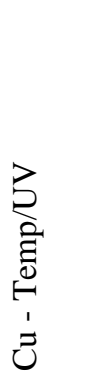 & $\begin{array}{l}\vec{U} \\
\dot{J} \\
\vec{J}\end{array}$ & 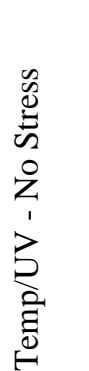 & 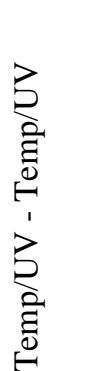 & 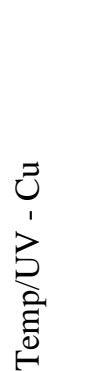 & 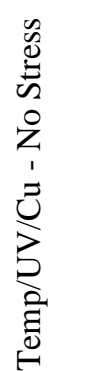 & 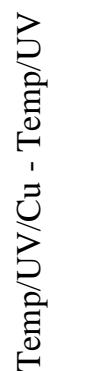 \\
\hline No Stress - No Stress & - & $\begin{array}{l}<0.001 \\
\text { STGE } \\
\end{array}$ & $\begin{array}{c}.005 \\
\text { STGE } \\
\end{array}$ & $\begin{array}{l}.005 \\
\text { GEN }\end{array}$ & 0.005 & 0.248 & $\begin{array}{l}0.184 \\
\text { GEN }\end{array}$ & $<0.001$ & 0.197 & $\begin{array}{l}.050 \\
\text { GEN }\end{array}$ & 0.197 \\
\hline No Stress - Temp/UV & - & - & $\begin{array}{l}0.083 \\
\text { STGE } \\
\end{array}$ & $<0.001$ & $\begin{array}{l}0.827 \\
\text { GEN } \\
\end{array}$ & 0.083 & $<0.001$ & $\begin{array}{l}0.827 \\
\text { GEN } \\
\end{array}$ & 0.005 & 0.127 & $\begin{array}{l}\text { 0.050 } \\
\text { GEN } \\
\end{array}$ \\
\hline No Stress - $\mathrm{Cu}$ & - & - & & $<0.001$ & 0.564 & $\begin{array}{l}0.221 \\
\text { GEN }\end{array}$ & $<0.001$ & 0.139 & $\begin{array}{l}<0.001 \\
\text { GEN }\end{array}$ & 0.564 & 0.083 \\
\hline $\mathrm{Cu}$ - No Stress & - & - & - & & $\begin{array}{l}<0.001 \\
\text { STGE }\end{array}$ & $\begin{array}{l}0.083 \\
\text { STGE }\end{array}$ & $\begin{array}{l}.050 \\
\text { GEN }\end{array}$ & $<0.001$ & 0.076 & $\begin{array}{l}<0.001 \\
\text { GEN }\end{array}$ & $<0.001$ \\
\hline $\mathrm{Cu}-\mathrm{Temp} / \mathrm{UV}$ & - & - & - & - & & $\begin{array}{l}0.248 \\
\text { STGE }\end{array}$ & $<0.001$ & $\begin{array}{l}0.513 \\
\text { GEN }\end{array}$ & 0.007 & 0.275 & $\begin{array}{l}0.050 \\
\text { GEN }\end{array}$ \\
\hline $\mathrm{Cu}-\mathrm{Cu}$ & - & - & - & - & - & - & 0.083 & 0.083 & $\begin{array}{l}0.102 \\
\text { GEN }\end{array}$ & 0.248 & 0.900 \\
\hline Temp/UV - No Stress & - & - & - & - & - & - & - & $\begin{array}{l}<\mathbf{0 . 0 0 1} \\
\text { STGE }\end{array}$ & $\begin{array}{c}0.554 \\
\text { STGE }\end{array}$ & $\begin{array}{l}<0.001 \\
\text { GEN }\end{array}$ & 0.007 \\
\hline Temp/UV - Temp/UV & - & - & - & - & - & - & - & - & $\begin{array}{l}<0.001 \\
\text { STGE }\end{array}$ & 0.275 & $\begin{array}{l}0.050 \\
\text { GEN }\end{array}$ \\
\hline Temp/UV - Cu & - & - & - & - & - & - & - & - & - & 0.050 & 0.076 \\
\hline Temp/UV/Cu - No Stress & - & - & - & - & - & - & - & - & - & - & $\begin{array}{r}0.077 \\
\text { STGE } \\
\end{array}$ \\
\hline Temp/UV/Cu - Temp/UV & - & - & - & - & - & - & - & - & - & - & - \\
\hline
\end{tabular}


Table 3.6 Size at day 27 pairwise comparisons. Results of post-hoc Mann-Whitney U tests performed after Kruskal-Wallis test examining the effect of treatment history (11 levels) on size of larvae at day $27(n=30)$. Each treatment history incorporates an adult (parent) treatment, named first, followed by an egg mass treatment. Differences significant at the $\alpha=0.05$ level appear in bold ( $p$-values). Pairwise comparisons are also labelled according to the type of COE that would be indicated by a significant difference ("GEN" = trans-generational COE; "STGE" = COE between egg mass and larval life stages).

No label is present where this distinction cannot be made.

\begin{tabular}{|c|c|c|c|c|c|c|c|c|c|c|c|}
\hline $\begin{array}{l}\text { Pairwise Comparisons } \\
\text { between Treatment } \\
\text { Histories } \\
\text { (parent treatment - egg } \\
\text { mass treatment) }\end{array}$ & 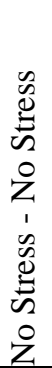 & 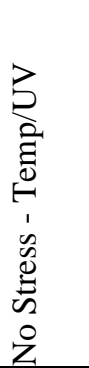 & 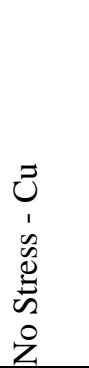 & 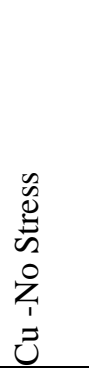 & 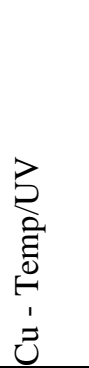 & $\begin{array}{l}\vec{J} \\
\dot{J} \\
\vec{J}\end{array}$ & 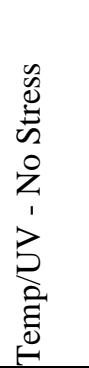 & 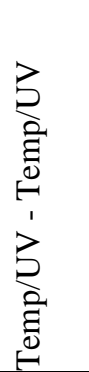 & 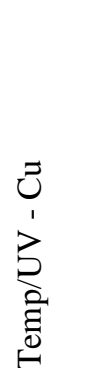 & 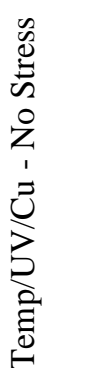 & 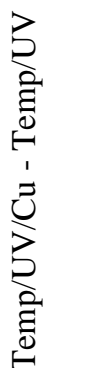 \\
\hline No Stress - No Stress & - & $\begin{array}{l}0.318 \\
\text { STGE }\end{array}$ & $\begin{array}{l}0.997 \\
\text { STGE } \\
\end{array}$ & $\begin{array}{l}0.900 \\
\text { GEN } \\
\end{array}$ & 0.720 & $<0.001$ & $\begin{array}{l}<0.001 \\
\text { GEN }\end{array}$ & 0.900 & $<0.001$ & $\begin{array}{l}0.900 \\
\text { GEN }\end{array}$ & 0.387 \\
\hline No Stress - Temp/UV & - & - & $\begin{array}{c}0.976 \\
\text { STGE } \\
\end{array}$ & 0.059 & $\begin{array}{l}<0.001 \\
\text { GEN }\end{array}$ & $<0.001$ & 0.387 & $\begin{array}{l}0.073 \\
\text { GEN } \\
\end{array}$ & $<0.001$ & 0.108 & $\begin{array}{c}<0.001 \\
\text { GEN }\end{array}$ \\
\hline No Stress - $\mathrm{Cu}$ & - & - & - & 0.890 & 0.221 & $\begin{array}{l}<0.001 \\
\text { GEN }\end{array}$ & 0.031 & 0.914 & $\begin{array}{l}<0.001 \\
\text { GEN }\end{array}$ & 0.952 & 0.076 \\
\hline $\mathrm{Cu}$ - No Stress & - & - & - & - & $\begin{array}{c}0.982 \\
\text { STGE } \\
\end{array}$ & $\begin{array}{l}<\mathbf{0 . 0 0 1} \\
\text { STGE }\end{array}$ & $\begin{array}{l}<0.001 \\
\text { GEN }\end{array}$ & 0.900 & 0.015 & $\begin{array}{l}0.900 \\
\text { GEN } \\
\end{array}$ & 0.847 \\
\hline $\mathrm{Cu}-\mathrm{Temp} / \mathrm{UV}$ & - & - & - & - & - & $\begin{array}{l}<0.001 \\
\text { STGE }\end{array}$ & $<0.001$ & $\begin{array}{l}0.973 \\
\text { GEN } \\
\end{array}$ & 0.290 & 0.943 & $\begin{array}{l}0.900 \\
\text { GEN } \\
\end{array}$ \\
\hline $\mathrm{Cu}-\mathrm{Cu}$ & - & - & - & - & - & & $<0.001$ & $<0.001$ & $\begin{array}{l}0.280 \\
\text { GEN }\end{array}$ & $<0.001$ & $<0.001$ \\
\hline Temp/UV - No Stress & - & - & - & - & - & & - & $\begin{array}{l}<0.001 \\
\text { STGE } \\
\end{array}$ & $\begin{array}{l}<0.001 \\
\text { STGE } \\
\end{array}$ & $\begin{array}{l}<0.001 \\
\text { GEN }\end{array}$ & $<0.001$ \\
\hline Temp/UV - Temp/UV & - & - & - & - & - & - & - & - & \begin{tabular}{c|}
0.012 \\
STGE \\
\end{tabular} & 0.900 & $\begin{array}{l}0.809 \\
\text { GEN } \\
\end{array}$ \\
\hline Temp/UV - Cu & - & - & - & - & - & - & - & - & - & 0.007 & 0.575 \\
\hline Temp/UV/Cu - No Stress & - & - & - & - & - & - & - & - & - & - & $\begin{array}{l}0.720 \\
\text { STGE }\end{array}$ \\
\hline Temp/UV/Cu - Temp/UV & - & - & - & - & - & - & - & - & - & - & - \\
\hline
\end{tabular}


Table 3.7 Size at day 27 CV pairwise comparisons. Results of post-hoc Mann-Whitney U tests performed after Kruskal-Wallis test examining the effect of treatment history (11 levels) on the coefficient of variation $(\mathrm{CV})$ for larval size at 27 days $(n=30)$. Each treatment history incorporates an adult (parent) treatment, named first, followed by an egg mass treatment. Differences significant at the $\alpha=0.05$ level appear in bold ( $p$-values). Pairwise comparisons are also labelled according to the type of COE that would be indicated by a significant difference ("GEN" = trans-generational COE; "STGE" = COE between egg mass and larval life stages). No label is present where this distinction cannot be made.

\begin{tabular}{|c|c|c|c|c|c|c|c|c|c|c|c|}
\hline $\begin{array}{c}\text { Pairwise Comparisons } \\
\text { between Treatment } \\
\text { Histories } \\
\text { (parent treatment - egg } \\
\text { mass treatment) }\end{array}$ & 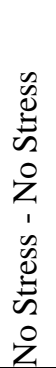 & 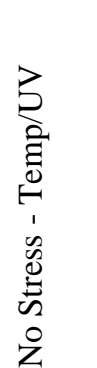 & 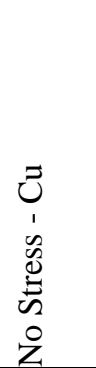 & 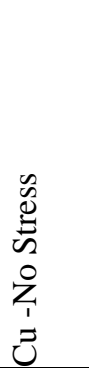 & 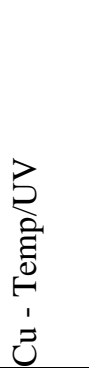 & $\begin{array}{l}\vec{U} \\
\dot{3}\end{array}$ & 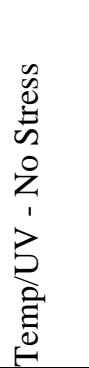 & 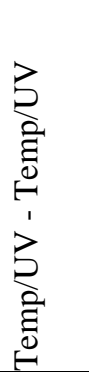 & 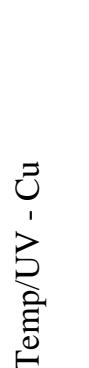 & 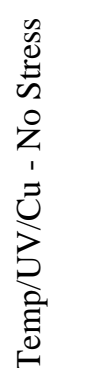 & 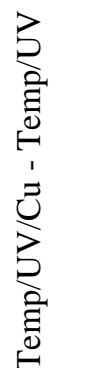 \\
\hline No Stress - No Stress & - & $\begin{array}{r}0.050 \\
\text { STGE }\end{array}$ & $\begin{array}{l}0.083 \\
\text { STGE }\end{array}$ & $\begin{array}{l}0.513 \\
\text { GEN } \\
\end{array}$ & 0.050 & 0.083 & $\begin{array}{l}0.050 \\
\text { GEN } \\
\end{array}$ & 0.050 & 0.564 & $\begin{array}{l}0.513 \\
\text { GEN }\end{array}$ & 0.127 \\
\hline No Stress - Temp/UV & - & - & $\begin{array}{r}0.050 \\
\text { STGE } \\
\end{array}$ & 0.050 & $\begin{array}{l}0.050 \\
\text { GEN } \\
\end{array}$ & 0.900 & 0.050 & $\begin{array}{l}0.127 \\
\text { GEN } \\
\end{array}$ & 0.083 & 0.050 & $\begin{array}{l}\text { 0.050 } \\
\text { GEN } \\
\end{array}$ \\
\hline No Stress - $\mathrm{Cu}$ & - & - & - & 0.248 & 0.248 & $\begin{array}{l}0.121 \\
\text { GEN }\end{array}$ & 0.564 & 0.043 & $\begin{array}{l}0.439 \\
\text { GEN } \\
\end{array}$ & 0.564 & 0.043 \\
\hline $\mathrm{Cu}$ - No Stress & - & - & - & - & $\begin{array}{c}\text { 0.050 } \\
\text { STGE } \\
\end{array}$ & $\begin{array}{l}0.083 \\
\text { STGE } \\
\end{array}$ & $\begin{array}{l}0.050 \\
\text { GEN } \\
\end{array}$ & 0.275 & 0.083 & $\begin{array}{l}0.248 \\
\text { GEN }\end{array}$ & 0.127 \\
\hline $\mathrm{Cu}-\mathrm{Temp} / \mathrm{UV}$ & - & - & - & - & -1 & $\begin{array}{c}.050 \\
\text { STGE }\end{array}$ & 0.275 & $\begin{array}{l}0.050 \\
\text { GEN }\end{array}$ & 0.083 & 0.127 & $\begin{array}{l}0.050 \\
\text { GEN }\end{array}$ \\
\hline $\mathrm{Cu}-\mathrm{Cu}$ & - & - & - & - & - & - & 0.083 & 0.564 & $\begin{array}{l}0.121 \\
\text { GEN }\end{array}$ & 0.083 & 0.083 \\
\hline Temp/UV - No Stress & - & - & - & - & - & - & - & $\begin{array}{c}0.050 \\
\text { STGE }\end{array}$ & $\begin{array}{l}0.248 \\
\text { STGE } \\
\end{array}$ & $\begin{array}{l}0.275 \\
\text { GEN }\end{array}$ & 0.050 \\
\hline Temp/UV - Temp/UV & - & - & - & - & - & - & - & - & $\begin{array}{l}0.083 \\
\text { STGE }\end{array}$ & 0.083 & $\begin{array}{l}0.127 \\
\text { GEN }\end{array}$ \\
\hline Temp/UV - Cu & - & - & - & - & - & - & - & - & - & 0.564 & 0.083 \\
\hline Temp/UV/Cu - No Stress & - & - & - & - & - & - & - & - & - & - & $\begin{array}{l}0.275 \\
\text { STGE }\end{array}$ \\
\hline Temp/UV/Cu - Temp/UV & - & - & - & - & - & - & - & - & - & - & - \\
\hline
\end{tabular}


Table 3.8 Size at death pairwise comparisons. Results of post-hoc Tukey tests performed after one-way ANOVA examining the effect of treatment history (11 levels) on mean size at death of larvae $(n=30)$.

Each treatment history incorporates an adult (parent) treatment, named first, followed by an egg mass treatment. Differences significant at the $\alpha=0.05$ level appear in bold ( $\mathrm{p}$-values). Pairwise comparisons are also labelled according to the type of COE that would be indicated by a significant difference ("GEN" = trans-generational COE; "STGE" = COE between egg mass and larval life stages). No label is present where this distinction cannot be made.

\begin{tabular}{|c|c|c|c|c|c|c|c|c|c|c|c|}
\hline $\begin{array}{l}\text { Pairwise Comparisons } \\
\text { between Treatment } \\
\text { Histories } \\
\text { (parent treatment - egg } \\
\text { mass treatment) }\end{array}$ & 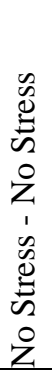 & 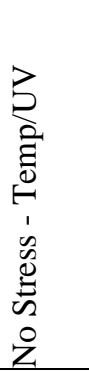 & 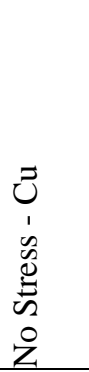 & 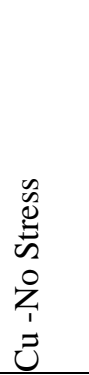 & 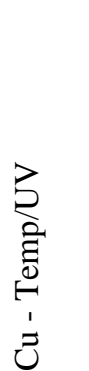 & $\begin{array}{l}\vec{J} \\
\dot{J} \\
\tilde{J}\end{array}$ & 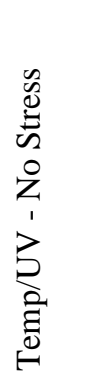 & 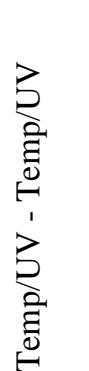 & 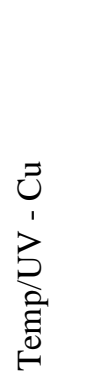 & 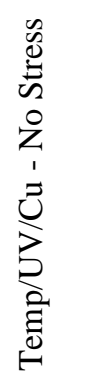 & 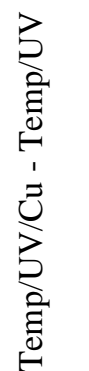 \\
\hline No Stress - No Stress & - & $\begin{array}{l}<0.001 \\
\text { STGE }\end{array}$ & $\begin{array}{l}<0.001 \\
\text { STGE }\end{array}$ & $\begin{array}{l}<0.001 \\
\text { GEN }\end{array}$ & 0.251 & $<0.001$ & $\begin{array}{l}<0.001 \\
\text { GEN }\end{array}$ & $<0.001$ & $<0.001$ & $\begin{array}{c}<\mathbf{0 . 0 0 1} \\
\text { GEN }\end{array}$ & $<0.001$ \\
\hline No Stress - Temp/UV & - & - & $\begin{array}{l}<0.001 \\
\text { STGE } \\
\end{array}$ & 0.900 & $\begin{array}{l}<0.001 \\
\text { GEN }\end{array}$ & $<0.001$ & $<0.001$ & $\begin{array}{l}<0.001 \\
\text { GEN }\end{array}$ & $<0.001$ & $<0.001$ & $\begin{array}{l}<0.001 \\
\text { GEN }\end{array}$ \\
\hline No Stress - $\mathrm{Cu}$ & - & - & 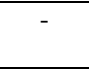 & $<0.001$ & $<0.001$ & $\begin{array}{l}<0.001 \\
\text { GEN }\end{array}$ & 0.762 & 0.538 & $\begin{array}{l}0.008 \\
\text { GEN }\end{array}$ & 0.103 & $<0.001$ \\
\hline $\mathrm{Cu}$ - No Stress & - & - & - & - & $\begin{array}{l}<0.001 \\
\text { STGE }\end{array}$ & $\begin{array}{l}<<.001 \\
\text { STGE }\end{array}$ & $\begin{array}{l}<<.001 \\
\text { GEN }\end{array}$ & $<0.001$ & $<0.001$ & $\begin{array}{l}<0.001 \\
\text { GEN }\end{array}$ & $<0.001$ \\
\hline $\mathrm{Cu}-\mathrm{Temp} / \mathrm{UV}$ & - & - & - & - & 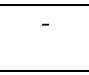 & $\begin{array}{l}<0.001 \\
\text { STGE }\end{array}$ & $<0.001$ & $\begin{array}{l}<0.001 \\
\text { GEN } \\
\end{array}$ & $<0.001$ & $<0.001$ & $\begin{array}{l}<0.001 \\
\text { GEN }\end{array}$ \\
\hline $\mathrm{Cu}-\mathrm{Cu}$ & - & - & - & - & - & 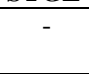 & $<0.001$ & $<0.001$ & $\begin{array}{l}<0.001 \\
\text { GEN }\end{array}$ & $<0.001$ & $<0.001$ \\
\hline Temp/UV - No Stress & - & - & - & - & - & - & - & $\begin{array}{l}<0.001 \\
\text { STGE }\end{array}$ & $\begin{array}{l}<0.001 \\
\text { STGE }\end{array}$ & $\begin{array}{l}<\mathbf{0 . 0 0 1} \\
\text { GEN }\end{array}$ & $<0.001$ \\
\hline Temp/UV - Temp/UV & - & - & - & - & - & - & - & - & $\begin{array}{l}0.681 \\
\text { STGE }\end{array}$ & 0.998 & $\begin{array}{l}0.051 \\
\text { GEN }\end{array}$ \\
\hline Temp/UV - Cu & - & - & - & - & - & - & - & - & - & 0.988 & 0.988 \\
\hline Temp/UV/Cu - No Stress & - & - & - & - & - & - & - & - & - & - & $\begin{array}{l}0.431 \\
\text { STGE } \\
\end{array}$ \\
\hline Temp/UV/Cu - Temp/UV & - & - & - & - & - & - & - & - & - & - & \\
\hline
\end{tabular}




\subsection{Discussion}

COEs between generations and between life stages are both demonstrated by these results, which show that characteristics of $S$. australis larvae can be significantly influenced by global change-type intertidal stressors experienced by progenitors and during embryonic development in egg masses. Transgenerational influences were detected slightly more often than effects between life stages. Generally however, treatment histories displayed an interaction between both types of COE, whereby transgenerational effects altered the ways in which stressors during development affected larvae, and conversely, effects from egg masses to larvae altered the ways in which stress effects from parent to offspring were manifested. Consequently, all examined larval responses, except survivorship, were highly context-dependent and based on specific parental and egg mass treatment combinations.

Hatching size of larvae showed a high degree of variation, with the smallest mean hatching size up to 20\% lower than the largest. There were clear COEs between the benthic egg mass and planktonic larval stage, as larvae from egg masses treated with $\mathrm{Cu}$ or Temp/UV tended to have smaller hatching sizes relative to unstressed egg masses for each parental treatment. Decreases in hatching size are commonly seen in metal toxicity tests (Johnson et al., 2007), as Cu decelerates embryonic growth rates in many organisms, even at concentrations lower than those used here (Bryan, 1971). In contrast, similarly high temperature is mostly associated with an increase in embryonic growth in molluscs (Spight, 1975; Caveriviere et al., 1999) and should thus be expected to yield larger hatchlings. This is not evident here, and it is likely that UVR exposure, which is highly deleterious to developing embryos at identical levels to those used here (Fisher \& Phillips, 2014) counteracted any potential positive effects of high temperature through synergistic interaction as described by Crain et al. (2008). Small hatching size is usually considered disadvantageous as it increases susceptibility to starvation and predation during later larval stages (Moloney et al., 1994). Note however, that small hatching size may confer advantages through enhanced dispersal, which would allow larvae to escape local stressors (Krug, 1998), and that small hatching size may not necessarily represent a negative COE.

No clear patterns based on parental treatment alone were found for hatching size. Instead, COEs between life stages interacted with trans-generational COEs in complex ways. For example, egg masses stressed with $\mathrm{Cu}$ had larger hatching larvae when laid by stressed adults. When parents were unstressed, developmental $\mathrm{Cu}$ exposure caused the smallest of all mean hatching sizes. Thus parental stress evidently modified how embryos coped with exposure to $\mathrm{Cu}$. Larger size may in this case be indicative of an anticipatory maternal effect (AME) that rendered offspring resistant to stress previously experienced by the parental generation and able to grow larger before hatching (Bernardo, 1996). There is support for such an interpretation, as AMEs have been recorded in response to various pollutants in diverse aquatic taxa, including cadmium in fish (Lin et al. 2000), mercury in annelid worms (Vidal \& 
Horne, 2003), and $\mathrm{Cu}$ in gastropods (Untersee \& Pechenik, 2007). Interaction between the two types of COE was widespread and the remainder of its consequences cannot easily be generalised as most treatment histories differed from most others (37 significantly different pairwise comparisons).

The coefficients of variation (CV) calculated for hatching size was on the other hand more uniform among treatments (only 25 significant pairwise differences), which means that although most treatment histories differed in mean hatching size, most showed similar degrees of variation in size. The most notable exceptions are No Stress-Cu and Temp/UV-Temp/UV, which displayed a CV twice as high or more than others, as well as the lowest mean hatching sizes. Although high within-brood offspring size variation such as this has been linked to increased maternal fitness through bet-hedging in highly stressful or variable environments (Marshall et al., 2008b), the parents of No Stress-Cu larvae were unstressed, and this interpretation can therefore not be applied in this case. It is likely that the growthdecelerating effects of $\mathrm{Cu}$ mentioned above, while reducing growth of all larvae in this treatment history when applied to egg masses, did so to a greater extent in some individuals than others. Similarly, for Temp/UV-Temp/UV larvae, some individuals may have been more heavily impacted by the growthaccelerating effects of high temperature, and some more so by the deleterious effects of UVR, causing the presence of both relatively large and somewhat stunted embryos prior to hatching. The fact that other egg masses treated with either $\mathrm{Cu}$ or Temp/UV did not show comparable size variation again serves to underline the high degree of parent-embryo stress interaction resulting in very contextdependent larval traits.

Growth rate also showed interaction between the two types of COE through high variability among treatment histories. Growth rate between days 9 and 18 was the most context-dependent, followed by that between hatching and day 9 and finally between days 18 and 27 (with 38, 33 and 26 significantly different pairwise comparisons respectively). Two notable patterns emerged through larval growth rates. Firstly, larvae from No Stress-Cu egg masses, which hatched as the smallest but became some of the largest, were distinct from other larvae stressed with $\mathrm{Cu}$ as embryos in having an extremely high growth rate between days 9 and 18. This indicates a strong response to release from stress, perhaps mediated by a form of selection. Because these larvae were the offspring of unstressed parents, no AMEs can account for this elevated growth rate. It is therefore possible that these larvae represent very robust individuals, as weak embryos may have been prevented from completing development successfully by $\mathrm{Cu}$ exposure. Subsequently, when transferred to the ambient conditions of rearing containers, these strong individuals were unimpeded and may have thus been able to exceed other larvae in growth rate, at least for the middle phase of rearing. Ritter et al. (2010), described a similar scenario in algae, where only resistant individuals survived $\mathrm{Cu}$ exposure, and suggested that this metal acts as a selective force that can lead to the formation of adaptively resistant strains. 
Secondly, the observed growth rates of larvae from Temp/UV-treated egg masses, somewhat contradict results obtained by Fisher \& Phillips (2014), who demonstrated reduced larval growth (in stressed and unstressed larvae) over the first 10 days after hatching in response to these egg mass stressors. However, larvae in the current study responded in this way only between days 9 and 18 . Relative to larvae from unstressed egg masses, their growth rates were virtually identical from hatching to day 9 , and actually tended to be greater between days 18 and 27. Additionally, size at day 27 was also similar between larvae from Temp/UV and unstressed egg masses, while Temp/UV-treated egg masses tended to produce slightly smaller hatching size. Together, these results imply that larvae were able to recover from the high impact of temperature and UVR stress during embryonic development (also shown by Fisher \& Phillips, 2014), provided that the larval phase was devoid of stress. In contrast, recovery appears not to be the case for larvae that experienced $\mathrm{Cu}$ stress during development, except for larvae of the No Stress-Cu treatment history discussed above, which reaffirms the notion that heavy metals constitute a particularly strong stressor during early development (Bryan, 1971).

By day 27, larvae from $\mathrm{Cu}$-exposed egg masses showed opposite trends to size at hatching, now being substantially smaller if their parents had been stressed. This may indicate that their initially large size at hatching may not in fact have conferred an advantage as they were overtaken in size by almost all other larvae during the rearing period. This is confirmed by their low growth rates throughout. Thus results here closely mirror those by Marshall (2008), who found bryozoan offspring to initially show positive results in response to parental $\mathrm{Cu}$ exposure, but suffer a delayed performance reduction. This is evidence not only for an interaction between both types of COE, but also for the effects of this interaction to vary as the affected organism grows.

Further, because fewer COEs of both types were found for size at day 27 than hatching size, this indicates that larvae were most strongly affected by COEs immediately upon hatching, and that this influence diminished over time. This is in contrast to "latent" responses, which are also often recorded but manifest later rather than sooner in the life history of organisms and often not at all until adulthood, particularly for effects between life stages (review by Pechenik, 2006). However, this trend remains speculative for $S$. australis as post-metamorphic stages were not examined, and it is possible that later life stages would display stronger COEs.

Overall, although the smallest and largest mean sizes varied by $\sim 30 \%$ by day 27 , larval size was more uniform than at hatching, as only 24 pairwise comparisons yielded significant differences. This is supported by the lowest growth rate context-dependency being found towards the end of the rearing period, and very low context-dependency in larval size variation at day 27 (only 17 significantly different pairwise comparisons). This means that larval sizes converged during rearing from initially disparate starting points at hatching. This is most likely the result of compensatory growth rather than 
size-selective mortality, as all treatment histories showed higher coefficients of variation at day 27 than at hatching. Although the opposite trend would be expected under size-selective mortality in surviving larvae, the mean sizes of recovered dead shells do suggest that treatments influenced size at death.

Mean size at death was partly determined by COEs between life stages, as larvae from unstressed egg masses tended to die at larger sizes than those of Temp/UV treated egg masses, followed by those exposed to $\mathrm{Cu}$, with the exception of $\mathrm{Cu}-\mathrm{Temp} / \mathrm{UV}$ larvae, which died at a very large size. They were also the result of trans-generational COEs, whereby larvae of unstressed parents died larger than those of $\mathrm{Cu}$, followed by Temp/UV and lastly Temp/UV/Cu-stressed parents. This is reminiscent of the pattern seen for embryo viability in Chapter 2, and shows that size at death decreased according to both parental and developmental influences. This illustrates again that trans-generational COEs interacted with COEs between life stages to determine size at death, as larvae died according to egg mass treatment in a similar pattern under each adult treatment, but at progressively smaller sizes. Size at death was also the larval character seemingly most influenced by this interaction as it showed the highest contextdependency with 44 significantly different pairwise comparisons.

Furthermore, control larvae from the No Stress-No Stress treatment history, as well as those from $\mathrm{Cu}$ Temp/UV, showed mean sizes at death that were almost identical to their mean size reached at day 27. Although age at death is unknown, this nonetheless suggests that in these treatment histories, large numbers of larvae probably died within a short space of time near the 27-day mark at a late stage of growth. This may be indicative of mortality due to a lack of settlement opportunity and delayed metamorphosis, since 27 days represents an unusually long larval duration for Siphonaria limpets (Hodgson, 1999). Control larvae may thus have been ready to settle sooner than most other treatment histories, for which the interaction between parental and developmental stage stress postponed their reaching of the point of competence. This is in keeping with the results of other studies, which found early life stage stress, particularly high temperature, to delay metamorphosis (Diaz-Perez \& CarpizoItuarte, 2011), and maternal stress to extend settlement-site selection periods in marine invertebrates (Marshall \& Keough, 2003). In contrast, $\mathrm{Cu}-\mathrm{Cu}$ constituted the only treatment history in which larvae tended to die at very small sizes, very close to those at which they hatched. When considered in conjunction with this treatment's poor growth rate, this shows that a combination of parental and developmental $\mathrm{Cu}$ stress represented the most deleterious of all observed COEs and that resistance was not imparted by the parental generation, again supporting Marshall (2008).

Despite the highly context-dependent responses of larva size and growth, survivorship was universally low and did not vary significantly, with most treatment histories retaining only $\sim 5 \%$ of their initial larval stock by the end of the rearing period. S. australis larvae have never been kept alive under laboratory conditions for longer, and never in numbers as high as in this study. Therefore, this high mortality may 
be explained by the relative fragility of $S$. australis larvae. However, it may also be the case that high mortality was seen in different treatment histories for different reasons, and that this can be attributed to settlement prevention in control larvae (as discussed above) and to stress-induced COEs in others, since larval mortality has been shown to increase due to developmental (Fisher \& Phillips, 2014; review by Pechenik, 2006) and parental stress (review by Marshall et al., 2008) in diverse marine taxa. However, it must be acknowledged that replication in terms of the numbers of egg masses that provided larvae for each treatment was low (2-3). Consequently, some of the variability discussed for the various larval responses may be due to genetic differences between parents rather than treatment, as maternal effects unrelated to stress exposure can also be significant determinants of larval characteristics (review by Marshall et al., 2008).

Finally, these results allow for the first assessment of the relative frequency of the two types of COE to be made. Trans-generational effects were slightly more common than effects between the egg mass and larval stage in all examined response variables. Therefore, trans-generational effects played a proportionately greater role in determining larval characteristics relating to growth and size than developmental stress. This is somewhat surprising since the literature surrounding effects between life stages is more extensive and more advanced in terms of theoretical considerations of ecological and evolutionary significance than that covering trans-generational effects (reviews by Pechenik, 2006; O'Connor et al., 2014), which remains the scene of much debate (reviews by Youngson \& Whitelaw, 2008; Bonduriansky, 2012; Bateson, 2014; Burton \& Metcalfe, 2014). The hypothesis of highly-context dependent larval characteristics due to interaction between the two types of COE was nonetheless clearly supported throughout.

Ultimately, this extends the conclusion reached in Chapter 2, namely that COEs between generations may become more common under ongoing anthropogenic change, by highlighting that the same applies to COEs between life stages. Most importantly, it is shown that both forms of COE, each triggered by multiple global change-associate stressors, interact to negatively affect the performance of an unstressed life stage in highly complex ways. Because more than one stressor, generation and life stage have not previously been employed simultaneously to demonstrate results like these, the existing literature may be underestimating the role of COEs in the persistence of marine invertebrates under ongoing global change. 


\section{CHAPTER 4 \\ General Discussion}

Global change is increasingly impacting coastal marine systems (Harley et al., 2006; Halpern et al., 2008). Of particular concern are organisms inhabiting the intertidal, which may be especially vulnerable because they are already subjected to naturally stressful, highly variable conditions that may exceed their tolerance limits when augmented by additional anthropogenic influences (Clarke, 1996; Tomanek \& Somero, 1999; Stillman, 2002). Ongoing climate change and historical ozone depletion are conspiring to routinely raise water temperature and UVR exposure in tide pools to levels that are lethal or capable of causing severe sub-lethal effects (Thompson et al., 2002). In addition, increasing human populations and activities along coastlines cause marine organisms to come into contact with pollutants more frequently, such as the heavy metal copper (Cu) (Stoffers et al., 1986).

Despite growing interest in predictive models of ecosystem responses, accurate forecasts of even singlespecies responses have so far been hampered by a dearth of realistic empirical data. In nature, organisms are invariably subjected to multiple co-occurring and interacting stressors, yet most global changerelated studies use only a single stressor (Crain et al., 2008). Further, it is now understood that organisms with complex life histories incur profound costs in a given life stage based on their performance or stress exposure in previous stages through carry-over effects (COEs) that transcend metamorphic boundaries. Yet most experiments examine the responses of only a single stage (Pechenik, 2006). Perhaps most importantly, organisms are also subjected to poorly understood, non-genetic transgenerational influences, and again, these are often ignored (Marshall, 2008). Because of these limitations, the true consequences of stress exposure for a given organism at a given point in its life history may be underestimated and much more far-reaching than generally acknowledged.

Although awareness of synergistic stressor interactions and the use of multifactorial designs is increasing (Wernberg et al., 2012), comparatively little attention has been given to how stress propagates through the often dramatically disparate life stages of marine organisms or how it's effects are passed through to successive generations, especially in a global change context. The current study examined all of these key considerations simultaneously. First, adults of the pulmonate limpet Siphonaria australis and their egg masses were subjected to different combinations of high water temperature, elevated UVR and $\mathrm{Cu}$ pollution, all at realistic levels (Chapter 2). Subsequently the hatching larvae were reared in the absence of stress in order to ascertain how they were affected by stress experienced during embryonic development and by the parental generation (Chapter 3). Through this novel approach, it was hoped that more realistic insights into COEs would be gained than have been experimentally achieved to date. 


\subsection{Summary of Findings}

Adult $S$. australis showed responses that can be directly attributed to treatment only in terms of survivor size, where those exposed to $\mathrm{Cu}$ experienced size-selective mortality favouring smaller individuals, as can occur in other taxa (Perez et al., 2006; Agatz et al., 2012). In contrast, the number of egg masses laid, the size of these egg masses, and the size of the individual eggs they contained varied in complex ways over the adult treatment period and most likely reflect maternal variability among adult limpets (Ito, 1997; Phillips, 2007; Marshall et al., 2008), while the number of adult survivors was relatively uniform. These results suggest that the parental generation suffered relatively minor direct effects due to their greater tolerance of stress compared to early life stages. Generally, low levels of stress or short exposure times (as were used here) rarely invoke strong responses in adults of most taxa (Hodson et al., 1979; Eisler, 1997; De Pirro \& Marshall, 2005). Despite minimal effects in adults, the stress levels used clearly initiated legacies of mostly impaired performance that persisted throughout the observed lives of offspring.

Although hatching time was unaffected in egg masses, they were much more vulnerable to identical stress levels than adults, and displayed strong responses in hatching success and embryo viability that are directly attributable to egg mass treatment, as described by Russell \& Phillips (2009) and Fisher \& Phillips (2014), as well as to trans-generational COEs originating in the treatment of adult limpets. All egg masses treated with extreme stress failed to hatch, $\mathrm{Cu}$ alone reduced hatching success to two thirds and, crucially, $\mathrm{Cu}$ also prevented hatching when parents experienced extreme stress, illustrating a highly specific trans-generational COE. This reaffirms the critical role of heavy metal exposure during development in egg masses (Conrad, 1988; Mayer-Pinto et al., 2010) and its capacity to interact synergistically with other stressors (Crain et al., 2008), but in this case contradicts studies that have found parental toxin exposure to impart resistance to offspring (Lin et al. 2000; Vidal \& Horne 2003; Untersee \& Pechenik, 2007). This context-dependency was mirrored by the viability of embryos, which declined according to complex interactions between egg mass and parental stressors. Here, transgenerational COEs manifested widely, since parental treatment was identified as influencing embryo viability in all 11 treatment histories. This offered strong support for the hypothesis that offspring vulnerability reflects parental experiences.

In larvae, there continued to be highly context-dependent results due to complex interaction between the two types of COE, as each treatment history performed differently from almost all others in all examined traits except survivorship. Hatching size was reduced by egg mass stress of all kinds, most likely due to synergistic interaction between high temperature and UVR for the Temp/UV treatment (Crain et al., 2008; Fisher \& Phillips, 2014), and the decelerating effects on embryonic growth of heavy 
metals for the $\mathrm{Cu}$ treatment (Bryan, 1971: Johnson et al., 2007). Importantly, the decrease in hatching size also partly depended on parental treatment. Most notably, $\mathrm{Cu}$-stressed egg masses produced larger hatchlings when parents were also under some form of stress, potentially revealing an anticipatory maternal effect similar to those observed under heavy metal stress in other taxa (Lin et al. 2000; Vidal \& Horne, 2003; Untersee \& Pechenik, 2007).

Similarly complex responses accrued throughout the larval period. By day 27, the initial advantage of large size in hatchlings of $\mathrm{Cu}$-stressed egg masses and stressed parents disappeared, as these larvae suffered low growth rates and became some of the smallest. This shows a delayed performance reduction based on parental $\mathrm{Cu}$ exposure that has previously been demonstrated in other taxa (Marshall, 2008). Overall, larval sizes differed less by day 27 than upon hatching, showing that the influence of COEs diminished during the course of the larval rearing period through strong effects on growth rate, particularly between days 9 and 18 . This does not illustrate latent effects but instead supports the notion that COEs have greater influence early in successive life stages rather than late (review by Pechenik, 2006). In the case of the anomalously high growth rate displayed by larvae from unstressed parents and copper-stressed egg masses, this may be the consequence of selective pressures acting on still developing embryos within egg masses, leading to an adaptive toxin resistance akin to that commonly found in algae (Ritter et al. 2010). Growth rate in larvae from Temp/UV-treated egg masses was surprisingly high, attaining levels equal to those of larvae from unstressed egg masses, and contradicted the high vulnerability documented by Fisher \& Phillips (2014) under identical egg mass stress. This implies that unstressed larvae are capable of recovering from certain stressors experienced during embryonic development, namely high temperature and UVR, but not others, in this case $\mathrm{Cu}$, and reaffirms this stressor's reputation as particularly harmful for the early life stages of marine invertebrates (Bryan, 1971).

Size at death closely recalled the step-like pattern first observed in embryo viability, both of which demonstrate a hierarchy of influence among the stressors. Interestingly, this hierarchy differed slightly between the two forms of COEs. Trans-generational influences were most negative when adult limpets were subjected to all stressors, followed by Temp/UV, then $\mathrm{Cu}$ and finally No Stress. COEs between life stages on the other hand, were most negative when egg masses were exposed to $\mathrm{Cu}$, and less so when treated with Temp/UV. This disparity in influence of $\mathrm{Cu}$ and Temp/UV between adult and embryonic $S$. australis is supported by the wider literature, which notes that heavy metals are disproportionately deleterious in very early life stages (Bryan, 1971; Eisler, 1997). Overall, almost all treatment histories showed smaller sizes at death than control larvae, which indicates that any form of stress experienced either by parents or during development, and not necessarily both, has negative influences on larvae and a potential propensity to increase larval duration and postpone the point of 
competence, although this remains speculative. In this respect, larvae herein emulated trends already observed in other taxa (Marshall \& Keough, 2003; Diaz-Perez \& Carpizo-Ituarte, 2011). Larvae whose parents and egg masses were exposed to copper died at sizes very close to that at which they hatched, and thus probably young. In addition, synergistic stressor interactions were observed through the low values of hatching viability and larval size at death for the parental Temp/UV/Cu treatment, and the absence of successful hatching for egg masses treated with Temp/UV/Cu. Thus when combined, climate change stress (temperature and UVR) and pollution were more deleterious than when occurring alone in these instances.

Finally, trans-generational COEs manifested more frequently than those between life stages, and were thus somewhat more influential in determining larval characteristics. Such an assessment of the relative frequency of the two types of COE has not been made before. Considering the more exhaustive and advanced literature surrounding COEs between life stages, the apparent prominence of parental influences in S. australis is surprising. However, due to the wide-spread interaction between both types of COEs observed herein, and the particularly conspicuous role of developmental $\mathrm{Cu}$ exposure in many treatment histories, effects between generations should not be described as more "important" than effects between life stages, as other authors have done (Wade, 1998). This study has demonstrated that multiple, realistic, global change-associated stressors affecting a parental generation of S. australis and its offspring's development, can continue to influence planktonic larvae in complex ways. Overall, the limpet's legacy under global change stressors is one of impaired performance. The key implication is that existing research has so far underestimated the true scope of global change-induced COEs.

\subsection{Further Directions for COE Research}

This research highlights a need for the previous history of individuals as well as that of their progenitors to be incorporated into predictions of responses to global change. While the COE literature is extensive, it is largely restricted to studies examining either COEs between life stages or between generations and experimental designs utilising only single stressors despite previous calls for a more integrative approach (Padilla \& Miner, 2006). Since consideration of both forms of COEs simultaneously and in conjunction with multiple stressors is undoubtedly a more realistic representation of the conditions under which COEs manifest in the field, this approach will need to be applied more widely in order to accurately gage the role of COEs under ongoing global change. This means applying a similar methodology as herein to more species, particularly representatives of other ecosystems and taxonomic or functional groups. Siphonarid limpets are particularly stress tolerant compared to other intertidal gastropods (Hodgson, 1999), especially to copper exposure as adults (De Pirro \& Marshall, 2005) and to UVR during development in egg masses (Wraith et al., 2006). In less tolerant species it is unknown whether the influence of COEs may be somewhat diminished by higher rates of immediate mortality, 
or on the other hand, whether COEs may be more pronounced and occur with greater severity than in S. australis. It would therefore be of interest to compare the relative importance of stress-induced COEs and direct effects between robust and fragile taxa.

More stressors will also need to be examined for their capacity to trigger COEs, especially biotic rather than abiotic factors, such as predation pressure or disease, which are rarely considered in discussions of COEs. It is also recommended that research subjects for which metamorphosis-inducing procedures have been established, such as for example abalone (Williams \& Degnan, 2009), should be used for future $\mathrm{COE}$ studies since settlement of $S$. australis larvae was unfortunately not achieved. This would allow for examination of COEs in offspring into adulthood and to reproductive maturity, and should be complemented with considerations of more diverse response variables. This is because by this time, the observed CEOs on growth or size of larvae may even out and be of little consequence, while other characters, such as size of feeding apparatus (Fisher \& Phillips, 2014), may influence individuals even late in life. Moreover, multi-generational experiments that are facilitated by such an approach are already increasing in frequency, and this likely represents the next major trend in COE research (Shama \& Wegner, 2014).

Given the strong links between global change and COEs discussed throughout, it may also be necessary in the future to discern regional patterns of $\mathrm{COE}$ susceptibility, since some areas may experience certain stressors more severely. For example, New Zealand intertidal marine organisms may be particularly prone to COEs due to high summer UVR (McKenzie et al., 1999). It is likely that COEs will in the future gain recognition as a major factor in species and population persistence in the face of anthropogenic disturbance (Chevin \& Lande, 2010), and a global context of this phenomenon will therefore need to be established. COEs, by affecting the performance of organisms, have also been suggested as capable of impacting population dynamics, community composition and ecosystem functioning (Benton et al., 2001; Emlet \& Sadro, 2006). The current study and the cited literature demonstrate that COEs do take place in laboratory settings, but in the field other factors are likely to dominate. For example, the vast majority of marine invertebrate larvae succumb to predation or poor settlement site selection (Keough \& Downes, 1982) regardless of parental and previous life stage experiences. Therefore, COEs in the real world are likely to be of lesser importance to organisms than laboratory studies may suggest. In any case, the circumstances under which COEs are negligible and under which they are significant, remains a conspicuous knowledge gap. Ultimately, the wider ecological implications of COEs are poorly understood and can only be elucidated once large-scale and long-term field studies of natural populations are attempted from a COE perspective. 
Beyond global change, a more detailed understanding of COEs, which can of course also occur in response to natural stress, nonetheless has the capacity to contribute to a wide range of fields. For example, an appreciation of COEs may become invaluable to management of marine living resources such as fisheries stocks. This is because through COEs, the vulnerability of a given organism at a given time can be linked to its own experiences at an earlier life stage, which may have occurred at a different location far away, or those of its parents, which may have lived at a different time under very different conditions. This implies that effective management may be hindered where the manifestation of COEs is not accounted for. Finally, the mechanisms behind the transmission of COEs from one generation to the next undoubtedly represents the least well understood of all facets of COE research. Advances in this fundamental aspect of COEs are currently being made in an epigenetics and gene expression context, and may in the near future contribute to paradigm shifts in an array of disciplines ranging from our understanding of evolutionary processes (Youngson \& Whitelaw, 2008; Bonduriansky \& Day, 2009; Bonduriansky, 2012; Bateson, 2014) to the ways in which heart disease risk (Ho, 2014) and the effects of nicotine consumption (Leslie, 2013) are assessed in humans. 


\section{References}

Agatz A, Hammers-Wirtz M, Gabsi F, Ratte HT, Brown CD, Preuss TG (2012) Promoting effects on reproduction increase population vulnerability of Daphnia magna. Environmental Toxicology and Chemistry, 31, 1604-1610.

Agrawal AA (2001) Transgenerational consequences of plant responses to herbivory: an adaptive maternal effect? American Naturalist, 157, 555-569.

Agrawal AA, Laforsch C, Tollrian R (1999) Transgenerational induction of defences in animals and plants. Nature, 401, 60-63.

Airoldi L (2003) The effects of sedimentation on rocky coast assemblages. Oceanography and Marine Biology: An Annual Review, 41, 161-236.

Allen JD, Zakas C, Podolsky RD (2006) Effects of egg size reduction and larval feeding on juvenile quality for a species with facultative-feeding development. Journal of Experimental Marine Biology and Ecology, 331, 186-197.

Badyaev AV, Uller T (2009) Parental effects in ecology and evolution: mechanisms, processes and implications. Philosophical Transactions of the Royal Society B, 364, 1169-1177.

Ban N, Alder J (2008) How wild is the ocean? Assessing the intensity of anthropogenic marine activities in British Columbia, Canada. Aquatatic Conservation: Marine and Freshwater Ecosystems, 18, 55-85.

Bateson P (2014) New thinking about biological evolution. Biological Journal of the Linnean Society, 112, 268-275.

Bayne BL, Gabbott PA, Widdows J (1975) Some effects of stress in the adult on the eggs and larvae of Mytilus edulis L. Journal of the Marine Biological Association of the United Kingdom, 55, 675-689.

Baynes SM, Howell BR (1996) The influence of egg size and incubation temperature on the condition of Solea solea (L.) larvae at hatching and first feeding. Journal of Experimental Marine Biology and Ecology, 199, 59-77.

Beardall J, Beer S, Raven JA (1998) Biodiversity of marine plants in an era of climate change: Some predictions based on physiological performance. Botanica Marina, 41, 113-123.

Bellas J, Beiras R, Vazquez E (2004) Sublethal Effects of Trace Metals (Cd, Cr, Cu, Hg) on Embryogenesis and Larval Settlement of the Ascidian Ciona intestinalis. Archives of Environmental Contamination and Toxicology, 46, 61-66.

Benkendorff K, Davis AR (2002) Identifying hotspots of molluscan species richness on rocky intertidal reefs. Biodiversity and Conservation, 11, 1959-1973.

Benton TG et al. (2001) Maternal effects and the stability of population dynamics in noisy environments. Journal of Animal Ecology, 70, 590-599.

Bernardo J (1996) Maternal effects in animal ecology. American Zoologist, 36, 83-105. 
Biermann C, Schinner G, Strathmann R (1992) Influence of solar radiation, microalgal fouling, and current on deposition site and survival of embryos of a dorid nudibranch gastropod. Marine Ecology progress Series, 86, 205-215.

Billick I, Case TJ (1994) Higher-order interactions in ecological communities - what are they and how can they be detected. Ecology, 75, 1529-1543.

Bonduriansky R (2012) Rethinking heredity, again. Trends in Ecology and Evolution, 27, 330-336.

Bonduriansky R, Day T (2009) Nongenetic inheritance and its evolutionary implications. Annual Review of Ecology, Evolution, and Systematics, 40, 103-125.

Brown RJ, Lowe D, Browne MA, Dissanayake A, Jones M, Galloway T, Depledge MH (2004) Differential sensitivity of three invertebrate species to copper assessed using biomarkers of exposure and effect. Aquatic Toxicology, 66, 267-278.

Bryan GW (1971) The effects of heavy metals (other than mercury) on marine and estuarine organisms. Proceedings of the Royal Society of London (Series B, Biological Sciences), 177, $389-410$.

Bryan GW, Langston WJ (1992) Bioavailability, accumulation and effects of heavy metals in sediments with special reference to United Kingdom estuaries: a review. Environmental Pollution, 76, 89-131.

Burgess SC, Marshall DJ (2011) Temperature-induced maternal effects and environmental predictability. The Journal of Experimental Biology, 214, 2329-2336.

Burton T, Metcalfe NB (2014) Can environmental conditions experienced in early life influence future generations? Proceedings of the Royal Society B: Biological Sciences, 281: 20140311. DOI: $10.1098 / \mathrm{rspb} .2014 .0311$

Byrne M (2011) Impact of ocean warming and ocean acidification on marine invertebrate life history stages: vulnerabilities and potential for persistence in a changing ocean. Oceanography and Marine Biology: An Annual Review, 49, 1-42.

Byrne M, Wong E, Soars NA et al. (2010) Unshelled abalone and corrupted urchins: development of marine calcifiers in a changing ocean. Proceedings of the Royal Society B: Biological sciences, 278, 2376-2383.

Cartwright SR, Coleman RA, Browne MA (2006) Ecologically relevant effects of pulse application of copper on the limpet Patella vulgate. Marine Ecology Progress Series, 326, 187-194.

Caveriviere A, Francois D, Diallo A (1999) Observations on the influence of temperature on the length of embryonic development in Octopus vulgaris (Senegal). Aquatic Living Resources, 12, 151-154.

Chaffee C, Strathmann RR (1984) Constraints on egg masses, I. Retarded development within thick egg masses. Journal of Experimental Marine Biology Ecology, 84, 73-83.

Chambers RC, Leggett WC (1996) Maternal influences on variation in egg size in temperate marine fishes. American Zoologist, 36, 180-196.

Chambers RJ, McQuaid CD (1994) A Review of Larval Development in the Intertidal Limpet Genus Siphonaria (Gastropoda: Pulmonata). Journal of Molluscan Studies, 60, 415-423. 
Chan HY, Xu WZ, Shin PK, Cheung SG (2008) Prolonged exposure to low dissolved oxygen affects early development and swimming behaviour in the gastropod Nassarius festivus (Nassariidae). Marine Biology, 153, 735-743.

Chen Z, Mayer LM, Weston DP, Bock MJ, Jumars PA (2002) Inhibition of digestive enzyme activities by copper in the guts of various marine benthic invertebrates. Environmental Toxicology and Chemistry, 21, 1243-1248.

Chevin LM, Lande R (2010) When do adaptive plasticity and genetic evolution prevent extinction of a density-regulated population? Evolution, 64, 1143-1150.

Clarke A (1996) The influence of climate change on the distribution and evolution of organisms. In: Animals and Temperature: Phenotypic and Evolutionary Adaptation, Society for Experimental Biology Seminar Series 59 (eds. Johnston IA \& Bennett AF), pp. 377-407, Cambridge University Press, Cambridge UK.

Conrad GW (1988) Heavy-metal effects on cellular shape-changes, cleavage and larval development of the marine gastropod mollusk Ilyanassa obsoleta. Bulletin of Environmental Contamination and Toxicology, 41, 79-85.

Cossa D, Bourget E, Pouliot D, Piuze J, Chanut JP (1980) Geographical and Seasonal Variations in the Relationship Between Trace Metal Content and Body Weight in Mytilus edulis. Marine Biology, 58, 7-14.

Costanza R, d'Arge R, de Groot R, Farber S et al. (1997). The value of the world's ecosystem services and natural capital. Nature, 387, 253-260.

Cox EF, Ward S (2002) Impact of elevated ammonium on reproduction in two Hawaiian scleractinian corals with different life history patterns. Marine Pollution Bulletin, 44, 1230-1235.

Crain CM (2008) Interactions between marsh plant species vary in direction and strength depending on environmental and consumer context. Journal of Ecology, 96, 166-173.

Crain MC, Kroeker K, Halpern BS (2008) Interactive and cumulative effects of multiple human stressors in marine systems. Ecology Letters, 11, 1304-1315.

Crean AJ, Dwyer JM, Marshall DJ (2013) Adaptive paternal effects? Experimental evidence that the paternal environment affects offspring performance. Ecology, 94, 2575-2582.

Crean AJ, Monro K, Marshall JD (2011) Fitness consequences of larval traits persist across the metamorphic boundary. Evolution, 65, 3079-3089.

Creese RG (1980) Reproductive Cycles and Fecundities of Two Species of Siphonaria (Mollusca: Pulmonata) in South-eastern Australia. Australian Journal of Marine and Freshwater Research, 31, 37-47.

Davis AR, Coleman D, Broad A, Byrne M, Dworjanyn SA, Przeslawski R (2013) Complex Responses of Intertidal Molluscan Embryos to a Warming and Acidifying Ocean in the Presence of UV Radiation. PLOS ONE, 8: e55939.

Day TA, Neale PJ (2002) Effects of UV-B radiation on terrestrial and aquatic primary producers. Annual Review of Ecology, Evolution, and Systematics, 33, 371- 396.

De Block M, Stoks R (2005) Fitness effects from egg to reproduction: bridging the life history transition. Ecology, 86, 185-197. 
Dehnel PA, Kong DC (1979) The effect of temperature on development rates in the nudibranch Cadlinna luteomarginilata. Canadian Journal of Zoology, 57, 1835-1844.

Delorme NJ, Sewell MA (2014) Temperature and salinity: two climate change stressors affecting early development of the New Zealand sea urchin Evechinus chloroticus. Marine Biology, 161, 1999-2009

De Pirro M, Marshall DJ (2005) Phylogenetic differences in cardiac activity, metal accumulation and mortality of limpets exposed to copper: A prosobranch-pulmonate comparison. Journal of Experimental Marine Biology and Ecology, 322, 29-37.

Depledge MH, Billinghurst Z (1998) Ecological significance of endocrine disruption in marine invertebrates. Marine Pollution Bulletin, 39, 32-38.

Diaz-Perez L, Carpizo-Ituarte E (2011) Effect of thermal stress on survival and delay of metamorphosis in larvae of the purple sea urchin Strongylocentrotus purpuratus. Ciencias Marinas, 37, 403-414.

Dytham C (2011) Choosing and using statistics, a biologist's guide. John Wiley and Sons Ltd, UK.

Eisler R (1997) Copper hazards to fish, wildlife, and invertebrates: a synoptic review. U.S. Geological Survey, Biological Resources Division, Biological Science Report USGS/BRD/BSR-19970002, pp.98.

Emlet RB, Sadro SS (2006) Linking stages of life history: How larval quality translates into juvenile performance for an intertidal barnacle (Balanus glandula). Integrative and Comparative Biology, 46, 334-346.

Fields PA, Graham JB, Rosenblatt RH, Somero GN (1993). Effects of expected global climate change on marine faunas. Trends in Ecology and Evolution, 8, 361-367.

Fisher J, Phillips NE (2014) Carry-over effects of multiple stressors on benthic embryos are mediated by larval exposure to elevated UVB and temperature. Global Change Biology, 20, 21082116.

Folt CL, Chen CY, Moore MV, Burnaford J (1999) Synergism and antagonism among multiple stressors. Limnology and Oceanography, 44, 864-877.

Fox CW, Thakar MS, Mousseau TA (1997) Egg size plasticity in a seed beetle: an adaptive maternal effect. American Naturalist, 149, 149-163.

Franzke A, Reinhold K (2012) Transgenerational effects of diet environment on life-history and acoustic signals of a grasshopper. Behavioral Ecology, 21, 734-739.

Ganning B (1971) Studies on chemical, physical and biological conditions in Swedish rockpool ecosystems. Ophelia, 9, 51-105.

Garcia LV (2004) Escaping the Bonferroni Iron Claw in Ecological Studies. Oikos, 105, 657-663.

George SB, Lawrence JM, Fenaux L (1991) The effect of food ration on the quality of eggs of Luidia clathrata (Say) (Echinodermata: Asteroidea). Invertebrate Reproduction and Development, 20, 237-242. 
Gimenez L, Anger K (2001) Relationships among salinity, egg size, embryonic development and larval biomass in the estuarine crab Chasmagnathus granulata, Dana 1851. Journal of Experimental Marine Biology and Ecology, 260, 241-257.

Guisande C, Sanchez J, Maneiro I, Miranda A (1996) Trade-off between offspring number and offspring size in the marine copepod Euterpina acutifrons at different food concentrations. Marine Ecology Progress Series, 143, 37-44.

Hader DP, Kumar HD, Smithe RC, Worrest RC (2007) Effects of solar UV radiation on aquatic ecosystems and interactions with climate change. Photochemical and Photobiological Sciences, 6, 267-285.

Halpern B, Selkoe K, Micheli F, Kappel C (2007) Evaluating and ranking the vulnerability of global marine ecosystems to anthropogenic threats. Conservation Biology, 21, 1301-1315.

Halpern BS, Walbridge S, Selkoe et al. (2008) A global map of human impact on marine ecosystems. Science, 319, 948-952.

Harley CDG, Hughes AR, Hultgren KM et al. (2006) The impacts of climate change in coastal marine systems. Ecology Letters, 9, 228-241.

Harrison XA, Blount JD, Inger R, Norris DR, Bearhop S (2011) Carry-over effects as drivers of fitness differences in animals. Journal of Animal Ecology, 80, 4-18.

Hart MW (1995) What are the costs of small egg size for marine invertebrate with feeding planktonic larvae. American Naturalist, 146, 415-426.

Heath DD, Blouw DM (1998) Are maternal effects in fish adaptive or merely physiological side effects? In Maternal Effects as Adaptations (eds. Mousseau TA, Fox CW), pp. 178-201, Oxford University Press, Oxford, UK.

Heintz RA, Rice SD, Wertheimer AC, Bradshaw RF, Thrower FP, Joyce JE, Short JW (2000) Delayed effects on growth and marine survival of pink salmon Oncorhynchus gorbuscha after exposure to crude oil during embryonic development. Marine Ecology Progress Series, 208, $205-216$.

Helmuth B, Harley SDG, Halpin PM, O'Donnell M, Hofmann EG, and Blanchette CA (2002) Climate change and latitudinal patterns of intertidal thermal stress. Science, 298, 1015-1017.

Helmuth B, Mieszkowska N, Moore P, Hawkins SJ (2006) Living on the Edge of Two Changing Worlds: Forecasting the Responses of Rocky Intertidal Ecosystems to Climate Change. Annual Review of Ecology, Evolution and Systematics, 37, 373-404.

Ho DH (2014) Transgenerational Epigenetics: The Role of Maternal Effects in Cardiovascular Development. Integrative and Comparative Biology, 54, 43-51.

Hodgson AN (1999) The biology of Siphonariid limpets (Gastropoda: Pulmonata). Oceanography and Marine Biology: an Annual Review, 37, 245-314.

Hodson PV, Borgmann U, Shear H (1979) Toxicity of copper to aquatic biota. In: Copper in the environment. Part 2: health effects (ed. Nriagu JO), pp. 307-372, John Wiley, New York.

Hoffman JR, Hansen LJ, Klinger T (2003) Interactions between UV radiation and temperature limit inferences from single-factor experiments. Journal of Phycology, 39, 268-272. 
Hofmann DJ, Pyle JA (1999) Prediction future ozone change and detection of recovery. In: Scientific Assessment of Ozone Depletion 1998. World Meteorological Organization Global Ozone Research and Monitoring Project - Report No. 44. Geneva: World Meteorological Organization.

Holeski LM, Jander G, Agrawal AA (2012) Transgenerational defence induction and epigenetic inheritance in plants. Trends in Ecology and Evolution, 27, 618-626.

Isomura N, Nishimura M (2001) Size variation of planulae and its effect on the lifetime of planulae in three pocilloporid corals. Coral Reefs, 20, 309-315.

Ito K (1997) Egg size and number variations related to maternal size and age, and the relationship between egg size and larval characteristics in and annual marine gastropod, Haloa japonica (Opisthobranchia; Cephalaspidea). Marine Ecology Progress Series, 152, 187-195.

Johnson A, Carew E, Sloman KA (2007) The effects of copper on the morphological and functional development of zebrafish embryos. Aquatic Toxicology, 84, 431-438.

Johnson DW, Christie MR, Moye J (2010) Quantifying evolutionary potential of marine fish larvae: heritability, selection, and evolutionary constraints. Evolution, 64, 2614-2628.

Johnston EL, Keough MJ, Qian PY (2002) Maintenance of species dominance through pulse disturbances to a sessile marine invertebrate assemblage in Port Shelter, Hong Kong. Marine Ecology Progress Series, 226, 103-114.

Jones HL, Todd CD, Lambert WJ (1996) Intraspecific variation in embryonic and larval traits of the dorid nudibranch mollusc Adalaria proxima (Alder and Hancock) around the northern coasts of British Isles. Journal of Experimental Marine Biology and Ecology, 202, 29-47.

Kemp JOG (2009) Effects of Temperature and Salinity on Resting Metabolism in Two South African Rock Pool Fish: The Resident Gobiid Caffrogobius caffer and the Transient Sparid Diplodus sargus capensis. African Zoology, 44, 151-158.

Keough MJ, Downes BJ (1982) Recruitment of Marine Invertebrates: the Role of Active Larval Choices and Early Mortality. Oecologia, 54, 348-352.

Kirkpatrick M, Lande R (1989) The evolution of maternal characters. Evolution, 43, 485-503.

Krueger DA, Dodson SI (1981) Embryological induction and predation ecology in Daphnia pulex. Limnology and Oceanography, 26, 219-223.

Krug PJ (1998) Poecilogony in an estuarine opisthobranch: planktotrophy, lecithotrophy, and mixed clutches in a population of the ascoglossan Alderia modesta. Marine Biology, 132, 483-494.

Kurihara H (2008) Effects of CO2-driven ocean acidification on the early developmental stages of invertebrates. Marine Ecology Progress Series, 373, 275-284.

Lau JA, Peiffer J, Reich PB, Tiffin P (2008) Transgenerational effects of global environmental change: long-term $\mathrm{CO} 2$ and nitrogen treatments influence off spring growth response to elevate CO2. Oecologia, 158, 141-150.

Lacey EP (1998) What is an adaptive environmentally induced parental effect? In Maternal Effects as Adaptations (eds. Mousseau TA, Fox CW), pp. 54-66, Oxford University Press, Oxford, UK. 
Leslie FM (2013) Multigenerational epigenetic effects of nicotine on lung function. BMC Medicine, 11:27, http://www.biomedcentral.com/1741-7015/11/27.

Lin HC, Hsu SC, Hwang PP (2000) Maternal transfer of cadmium tolerance in larval Oreochromis mossambicus. Journal of Fish Biology, 57, 239-249.

Lof M, Welander NT (2000) Carry-over effects on growth and transpiration in Fagus sylvatica seedlings after drought at various stages of development. Canadian Journal of Forest Research, 30, 468-475.

Lubchenco J, Navarrete SA, Tissot BN, Castilla JC (1993) Possible ecological responses to global climate change: nearshore benthic biota of Northeastern Pacific coastal ecosystems. In: Earth System Responses to Global Climate Change: Contrasts between North and South America (eds. Mooney HA, Fuentes ER, Kronberg BI), pp. 147-166, Academic Press, San Diego, CA.

Marchan S, Davies MS, Fleming S, Jones HD (1999) Effects of copper and zinc on the heart rate of the limpet Patella vulgata L. Comparative Biochemistry and Physiology Part A, 123, 89-93.

Marshall DJ (2008) Transgenerational Plasticity in the Sea: Context-Dependent Maternal Effects Across the Life History. Ecology, 89, 418-427.

Marshall DJ, Allen RM, Crean AJ (2008) The ecological and evolutionary importance of maternal effects in the sea. Oceanography and Marine Biology: An Annual Review, 46, 203-250.

Marshall DJ, Bonduriansky R, Bussiere LF (2008b) Offspring size variation within broods as a bethedging strategy in unpredictable environments. Ecology, 89, 2506-2517.

Marshall DJ, Bolton TF, Keough MJ (2003) Offspring size affects the post-metamorphic performance of a colonial marine invertebrate. Ecology, 84, 3131-3137.

Marshall DJ, Bolton TF (2007) Effects of egg size on the development time of non-feeding larvae. Biological Bulletin, 212, 6-11.

Marshall DJ, Keough MJ (2003) Variation in the dispersal potential of non-feeding invertebrate larvae: the desperate larva hypothesis and larval size. Marine Ecology Progress Series, 255, $145-153$.

Marshall DJ, Keough MJ (2004) When the going gets rough: effect of maternal size manipulation on offspring quality. Marine Ecology Progress Series, 272, 301-305.

Marshall DJ, Keough MJ (2008) The evolutionary ecology of offspring size in marine invertebrates. Advances in Marine Biology, 53, 1-60.

Marshall DJ, Morgan SG (2011) Ecological and evolutionary consequences of linked life history stages in the sea. Current Biology, 21, 718-725.

Marshall DJ, Uller T (2007) When is a maternal effect adaptive? Oikos, 116, 1957-1963.

Massamba-N'Siala G, Prevedelli D, Simonini R (2014) Trans-generational plasticity in physiological thermal tolerance is modulated by maternal pre-reproductive environment in the polychaete Ophryotrocha labronica. Journal of Experimental Biology, 217, 2004-2012.

Mayer-Pinto M, Underwood AJ, Tolhurst T, Coleman RA (2010) Effects of metals on aquatic assemblages: What do we really know? Journal of Experimental Marine Biology and Ecology, 391, 1-9. 
McCormick MI (2006) Mothers matter: crowding leads to stressed mothers and smaller offspring in marine fish. Ecology, 87, 1104-1109.

McEdward LR (1996) Experimental manipulation of parental investment in echinoid echinoderms. American Zoologist, 36, 169-179.

McKenzie RL, Bjorn LO, Bais A, Ilyas M (2003) Changes in biologically active ultraviolet radiation reaching the Earth's surface. Photochemical and Photobiological Sciences, 2, 5-15.

McKenzie R L, Connor B, Bodeker G (1999) Increased summertime UV radiation in New Zealand in response to ozone loss. Science, 285, 1709-1711.

McLusky DS, Bryant V, Campbell R (1986) The effects of temperature and salinity on the toxicity of heavy metals to marine and estuarine invertebrates. Oceanography and Marine Biology Annual Review, 24, 481-520.

Miller BA, Emlet RB (1999) Development of newly metamorphosed juvenile sea urchins (Strongylocentrotus franciscanus and S.purpuratus): morphology, the effects of temperature and larval food ration, and a method for determining age. Journal of Experimental Marine Biology and Ecology, 235, 67-90.

Moloney CL, Botsford LW, Largier JL (1994) Development, survival and timing of metamorphosis of planktonic larvae in a variable environment: the Dungeness crab as an example. Marine Ecology Progress Series, 113, 61-79.

Mondor EB, Tremblay MN, Lindroth RL (2004) Transgenerational phenotypic plasticity under future atmospheric conditions. Ecology Letters, 7, 941-946.

Moran AL (1994) Adaptation and constraint in the complex life-cycles of animals. Annual Review of Ecology, Evolution, and Systematics, 25, 573-600.

Moran AL, Allen JD (2007) How does metabolic rate scale with egg size? An experimental test with sea urchin embryos. Biological Bulletin, 212, 143-150.

Moran AL, Emlet RB (2001) Offspring size and performance in variable environments: field studies on a marine snail. Ecology, 82, 1597-1612.

Morillo J, Usero J, Gracia I (2005) Biomonitoring of trace metals in a mine-polluted estuarine system (Spain). Chemosphere, 58, 1421-1430.

Morris S, Taylor AC (1983) Diurnal and seasonal variation in physico-chemical conditions within intertidal rock pools. Estuarine, Coastal and Shelf Science, 17, 339-355.

Mousseau TA, Dingle H (1991) Maternal effects in insect life histories. Annual Review of Entomology, 36, 511-534.

Mousseau TA, Fox CW (1998) The adaptive significance of maternal effects. Trends in Ecology and Evolution, 13, 403-407.

Munday PL, Leis JM, Lough JM, Paris CB, Kingsford MJ, Berumen ML, Lambrechts J (2009) Climate change and coral reef connectivity. Coral Reefs, 28, 379-395.

Ng TYT, Keough MJ (2003) Delayed effects of larval exposure to $\mathrm{Cu}$ in the bryozoan Watersipora subtorquata. Marine Ecology Progress Series, 257, 77-85. 
Nixon SW (1995) Coastal marine eutrophication - a definition, social causes, and future concerns. Ophelia, 41, 199-219.

Norris DR (2005) Carry-over effects and habitat quality in migratory animals. Oikos, 109, 178-186.

Ocana TMJ, Emson RH (1999) Maturation, spawning and development in Siphonaria pectinata Linnaeus (Gastropoda: Pulmonata) at Gibraltar. Journal of Molluscan Studies, 65, 185-193.

O'Connor CM, Norris DR, Crossin GT, Cooke SJ (2014) Biological carryover effects: linking common concepts and mechanisms in ecology and evolution. Ecosphere, 5, 28.

Olla BL, Estelle VB, Swartz RC, Braun G, Studholme AL (1988) Responses of polychaetes to cadmium contaminated sediment: comparison of uptake and behavior. Evironmental Toxicology and Chemistry, 7, 587-592.

Padilla DK, Miner BG (2006) Legacies in Life Histories. Integrative and Comparative Biology, 46, 217-223.

Pahkala M, Laurila A, Merila J (2001) Carry-over effects of ultraviolet-B radiation on larval fitness in Rana temporaria. Proceedings of the Royal Society B: Biological Sciences, 268, 1699-1706.

Pahkala M, Laurila A, Merila J (2003) Effects of ultraviolet-B radiation on behaviour and growth of three species of amphibian larvae. Chemosphere, 51, 197-204

Parichy DM (1998) Experimental analysis of character coupling across a complex life cycle: pigment pattern metamorphosis in the tiger salamander, Ambystoma tigrinum tigrinum. Journal of Morphology, 237, 53-67.

Parker LM, Ross PM, O'Connor WA (2009) The effect of ocean acidification and temperature on the fertilization and embryonic development of the Sydney rock oyster Saccostrea glomerata (Gould 1850). Global Change Biology, 15, 2123-2136.

Parker LM, Ross PM, O'Connor WA (2010) Comparing the effect of elevated pCO(2) and temperature on the fertilization and early development of two species of oysters. Marine Biology, 157, 2435-2452.

Parker LM, Ross PM, O'Connor WA, Borysko L, Raftos DA, Portner H (2012) Adult exposure influences offspring response to ocean acidification in oysters. Global Change Biology, 18, 82-92.

Paul N D, Gwynn-Jones D (2003) Ecological roles of solar UV radiation: towards an integrated approach. Trends in Ecology and Evolution, 18, 48-55.

Pechenik JA (1979) Role of Encapsulation in Invertebrate Life Histories. The American Naturalist, 114, 859-870.

Pechenik JA (2006) Larval experience and latent effects - metamorphosis is not a new beginning. Integrative and Comparative Biology, 46, 323-333.

Pechenik JA, Estrella MS, Hammer K (1996) Food limitation stimulates metamorphosis of competent larvae and alters postmetamorphic growth rate in the marine prosobranch gastropod Crepidula fornicata. Marine Biology, 127, 267-75. 
Pechenik JA, Gleason T, Daniels D, Champlin D (2001) Influence of larval exposure to salinity and cadmium stress on juvenile performance of two marine invertebrates (Capitella sp I and Crepidula fornicata). Journal of Experimental Marine Biology and Ecology, 264, 101-114.

Pechenik JA, Marsden ID, Pechenik O (2003) Effects of temperature, salinity, and air exposure on development of the estuarine pulmonate gastropod Amphibola crenata. Journal of Experimental Biology, 292, 159-176.

Pelletier E, Sargian P, Payet J, Demers S (2006) Ecotoxicological effects of combined UVB and organic contaminants in coastal waters: a review. Photochemistry and Photobiology, 82, 981993.

Perez P, Estevez-Blanco P, Beiras , Fernandez E (2006) Effect of copper on the photochemical efficiency, growth, and chlorophyll a biomass of natural phytoplankton assemblages. Environmental Toxicology and Chemistry, 25, 137-143.

Peterson CH (2001) The 'Exxon Valdez' oil spill in Alaska: acute, indirect and chronic effects on the ecosystem. Advances in Marine Biology, 39, 1-103.

Phillips NE (2002) Effects of nutrition-mediated larval condition on juvenile performance in a marine mussel. Ecology, 83, 2562-2574.

Phillips NE (2004) Variable timing of larval food has consequences for early juvenile performance in a marine mussel. Ecology, 85, 2341-2346.

Phillips NE (2007) High Variability in Egg Size and Energetic Content Among Intertidal Mussels. The Biological Bulletin, 212, 12-19.

Pías B, Matesanz S, Herrero A, Gimeno TE, Escudero A, Valladares F (2010) Transgenerational effects of three global change drivers on an endemic Mediterranean plant. Oikos, 119, 14351444, 2010. DOI: 10.1111/j.1600-0706.2010.18232.x

Pipe RK, Coles JA, Carissan FMM, Ramanathan K (1999) Copper induced immunomodulation in the marine mussel, Mytilus edulis. Aquatic Toxicology, 46, 43-54.

Plautz SC, Guest T, Funkhouser MA, Salice SJ (2013) Transgenerational cross-tolerance to stress: parental exposure to predators increases offspring contaminant tolerance. Ecotoxicology, 22, 854-861.

Podolsky RD, Hoffmann GE (1998) Embryo development during tide-related thermal stress, evidence of a protective role for heat-shock proteins. American Naturalist, 38, 186.

Podolsky RD, Moran AL (2006) Integrating function across marine life cycles. Integrative and Comparative Biology, 46, 577-586.

Przeslawski R (2004) A review of the effects of environmental stress on embryonic development within intertidal gastropod egg masses. Molluscan Research, 24, 43-63.

Przeslawski R, Ahyong S, Byrne M, Worheide G, Hutchings P (2008) Beyond corals and fish: the effects of climate change on non-coral benthic marine invertebrates of tropical reefs. Global Change Biology, 14, 2773-2795.

Przeslawski R, Byrne M, Mellin C (2015) A review and meta-analysis of the effects of multiple abiotic stressors on marine embryos and larvae. Global Change Biology, 21, 2122-2140. 
Przeslawski R, Davis AR, Benkendorff K (2005) Synergistic effects associated with climate change and the development of rocky shore molluscs. Global Change Biology, 11, 515-522.

Qian PY, Pechenik JA (1998) Effects of larval starvation and delayed metamorphosis on juvenile survival and growth of the tube-dwelling polychaete Hydroides elegans (Haswell). Journal of Experimental Marine Biology and Ecology, 227, 169-85.

Qiu JW, Qian PY (1999) Tolerance of the barnacle Balanus amphitrite amphitrite to salinity and temperature stress: effects of previous experience. Marine Ecological Progress Series, 188, 123-132.

Ramos-Jiliberto R, Garay-Narvaez L, Medina MH (2012) Retrospective qualitative analysis of ecological networks under environmental perturbation: a copper-polluted intertidal community as a case study. Ecotoxicology, 21, 234-243.

Rawlings TA (1990) Associations between Egg Capsule Morphology and Predation among Populations of the Marine Gastropod, Nucella emarginata. Biological Bulletin, 179, 312-325.

Rawlings TA (1996) Shields against ultraviolet radiation: an additional protective role for the egg capsules of benthic marine gastropods. Marine Ecology Progress Series, 136, 81-95.

Reusch TBH (2014) Climate change in the oceans: evolutionary versus phenotypically plastic responses of marine animals and plants. Evolutionary Applications, 7, 104-122.

Ricciardi A, Bourget E (1999) Global patterns of macroinvertebrate biomass in marine intertidal communities. Marine Ecology Progress Series, 185, 21-35.

Ritchie H, DJ Marshall (2013) Fertilisation is not a new beginning: sperm environment affects offspring developmental success. The Journal of Experimental Biology, 216, 3104-3109.

Ritter A, Ubertini M, Romac S et al. (2010) Copper stress proteomics highlights local adaptation of two strains of the model brown alga Ectocarpus siliculosus. Proteomics, 10, 2074-2088.

Rivest BR (1983) Development and the influence of nurse egg allotment on hatching size in Searlesia dira (Reeve, 1846) (Prosobranchia: Buccinidae). Journal of Experimental Marine Biology and Ecology, 69, 217-241.

Roach DA, Wulff RD (1987) Maternal effects in plants. Annual Review of Ecology and Systematics 18, 209-235.

Rossiter MC (1996) Incidence and consequences of inherited environmental effects. Annual Review of Ecology and Systematics, 27, 451-476.

Rothman KJ (1990) No adjustments are needed for multiple comparisons. Epidemiology, 1, 43-46.

Roughgarden J, Gaines S, Possingham H (1988) Recruitment Dynamics in Complex Life Cycles. Science, 241, 1460-1466.

Russell J, Phillips N (2009) Synergistic effects of ultraviolet radiation and conditions at low tide on egg masses of limpets (Benhamina obliquata and Siphonaria australis) in New Zealand. Marine Biology, 156, 579-587.

Russell J, Phillips N (2009b) Species-Specific Vulnerability of Benthic Marine Embryos of Congeneric Snails (Haminoea spp.) to Ultraviolet Radiation and Other Intertidal Stressors. Biological Bulletin, 217, 65-72. 
Sakai S, Harada Y (2001) Why do large mothers produce large offspring? Theory and a test. American Naturalist, 157, 348-359.

Sala OE, Chapin FS, Armesto JJ et al. (2000) Biodiversity - global biodiversity scenarios for the year 2100. Science, 287, 1770-1774.

Salinas S, Munch SB (2012) Thermal legacies: transgenerational effects of temperature on growth in a vertebrate. Ecology Letters, 15, 159-163.

Sanderson EW, Jaiteh M, Levy MA, Redford KH, Wannebo AV, Woolmer G (2002) The human footprint and the last of the wild. Bioscience, 52, 891-904.

Savitz DA, Olshan AF (1995) Multiple comparisons and related issues in the interpretation of epidemiologic data. American Journal of Epidemiology, 142, 904-908.

Schluter D, Price TD, Rowe L, (1991) Conflicting selection pressures and life history trade offs. Proceedings of the Royal Society B: Biological Sciences, 246, 11-17.

Searle CL, Belden LK, Bancroft BA, Han BA, Biga LM, Blaustein AR (2010) Experimental examination of the effects of ultraviolet-B radiation in combination with other stressors on frog larvae. Oecologia, 162, 237-245.

Segers FHID, Taborsky B (2012) Juvenile exposure to predator cues induces a larger egg size in fish. Proceedings of the Royal Society B: Biological Sciences, 279, 1241-1248.

Shama LNS, Wegner KM (2014) Grandparental effects in marine sticklebacks: transgenerational plasticity across multiple generations. Journal of Evolutionary Biology, 27, 2297-2307.

Shick JM, Dunlap WC (2002) Mycosporine-like amino acids and related gadusols: biosynthesis, accumulation, and UV-protective functions in aquatic organisms. Annual Review of Physiology, 64, 223-262.

Sinha RP, Hader DP (2002) UV-induced DNA damage and repair: A review. Photochemical and Photobiological Sciences, 1, 225-236.

Solomon S (2004) The hole truth. What's news (and what's not) about the ozone hole. Nature, 427, 289-291.

Somero GN (2002) Thermal physiology and vertical zonation of intertidal animals: optima, limits, and costs of living. Integrative and Comparative Biology, 42, 780-789.

Strathmann MF (1987) General Procedures. In: Reproduction and development of marine invertebrates of the northern Pacific coast: Data and methods for the study of eggs, embryos, and larvae (ed. Strathmann MF), pp. 3-43, University of Washington Press, Seattle USA.

Strathmann R, Hess HC (1999) Two designs of marine egg masses and their divergent consequences for oxygen supply and desiccation in air. American Zoologist, 39, 253-260.

Spight TM (1975) Factors extending gastropod embryonic development and their selective cost. Oecologia, 21, 1-16.

Stearns SC (1992) The evolution of life histories. Oxford University Press, Oxford, UK, pp.249.

Stillman JH (2002) Causes and consequences of thermal tolerance limits in rocky intertidal porcelain crabs, genus Petrolisthes. Integrative and Comparative Biology, 42, 790-796. 
Stoffers P, Glasby GP, Wilson CJ, Davis KR, Walter P (1986) Heavy metal pollution in Wellington Harbour. New Zealand Journal of Marine and Freshwater Research, 20, 495-512.

Susser E, Kirkbride JB, Heijmans BT, Kresovich JK, Lumey LH, Stein AD (2012) Maternal prenatal nutrition and health in grandchildren and subsequent generations. Annual Review of Anthropology, 41, 577-610.

Talmage SC, Gobler CJ (2011) Effects of elevated temperature and carbon dioxide on the growth and survival of larvae and juveniles of three species of northwest Atlantic bivalves. PLOS ONE, 6: e26941.

Thompson RC, Crowe TP, Hawkins SJ (2002) Rocky intertidal communities: past environmental changes, present status and predictions for the next 25 years. Environmental Conservation, 29, 168-191.

Thompson TE (1958) The influence of temperature on spawning in Aldaria proxima (A. and H.) (Gastropoda: Nudibranchia). Oikos, 9, 246-252.

Thorson G (1950) Reproductive and larval ecology of marine bottom invertebrates. Biological Reviews, 25, 1-45.

Tomanek L, Somero GN (1999) Evolutionary and acclimation-induced variation in the heat-shock responses of congeneric marine snails (genus Tegula) from different thermal habitats: implications for limits of thermotolerance and biogeography. Journal of Experimental Biology, 202, 2925-2936.

Trivers RL (1974) Parent-offspring conflict. American Zoologist, 14, 249-264.

Underwood AJ (1979) The ecology of intertidal gastropods. Advances in marine Biology, 16, 111210.

Underwwod AJ (2000) Experimental ecology of rocky intertidal habitats: what are we learning? Journal of Experimental Marine Biology and Ecology, 250, 51-76.

Untersee S, Pechenik JA (2007) Local adaptation and maternal effects in two species of marine gastropod (genus Crepidula) that differ in dispersal potential. Marine Ecology Progress Series, 347, 79-85.

Van Allen BG, Rudolf VHW (2013) Ghosts of Habitats Past: Environmental Carry-Over Effects Drive Population Dynamics in Novel Habitat. American Naturalist, 181, 596-608.

Vehmaa A, Brutemark A, Engstrom-Ost J (2012) Maternal Effects May Act as an Adaptation Mechanism for Copepods Facing pH and Temperature Changes. PLOS ONE, 7, e48538. DOI:10.1371/journal.pone.0048538

Vermeij GJ (1971) Temperature relations of some tropical Pacific intertidal gastropods. Marine Biology, 10, 308-314.

Vinebrooke RD, Cottingham KL, Norberg J, et al. (2004). Impacts of multiple stressors on biodiversity and ecosystem functioning: the role of species co-tolerance. Oikos, 104, 451457.

Vidal DE, Horne AJ (2003) Inheritance of mercury tolerance in the aquatic oligochaete Tubifex tubifex. Environmental Toxicology and Chemistry, 22, 2130-2135. 
Wade MJ (1998) The evolutionary genetics of maternal effects. In: Maternal effects as adaptations (eds. Mousseau TA, Fox CW) Oxford University Press, Oxford, UK, 5-21.

Wallenstein S, Fisher AC (1977) The analysis of the two-period repeated measurements crossover design with application to clinical trials. Biometrics, 33, 261-269.

Weber RE, De Zwaan A, Bang A (1992) Interactive effects of ambient copper and anoxic, temperature and salinity stress on survival and hemolymph and muscle tissue osmotic effectors in Mytilus edulis. Journal of Experimental Marine Biology and Ecology, 159, 135156.

Wernberg T, Smale DA, Thomsen MS (2012) A decade of climate change experiments on marine organisms: procedures, patterns and problems. Global Change Biology, 18, 1491-1498.

Wilbur HM (1980) Complex life cycles. Annual Review of Ecology, Evolution, and Systematics, 11, 67-93.

Williams EA, Degnan SM (2009) Carry-over effect of larval settlement cue on postlarval gene expression in the marine gastropod Haliotis asinine. Molecular Ecology, 18, 4434-4449.

Wolf JB, Wade MJ (2009) What are maternal effects (and what are they not)? Philosophical Transactions of the Royal Society B, 364, 1107-1115.

Wraith J, Przeslawski R, Davis AR (2006) UV-Induced Mortality in Encapsulated Intertidal Embryos: Are Mycosporine-Like Amino Acids an Effective Sunscreen? Journal of Chemical Ecology, 32, 993-1004.

Wulff A, Wangberg SA, Sundback K, Nilsson C, Underwood GJC (2000) Effects of UVB radiation on a marine microphytobenthic community growing on a sand-substratum under different nutrient conditions. Limnology and Oceanography, 45, 1144-1152.

Yeom DH, Lee SA, Kang GS, Seo J, Lee SK (2007) Stressor identification and health assessment of fish exposed to wastewater effluents in Miho Stream, South Korea. Chemosphere, 67, 2282 2292.

Youngson NA, Whitelaw E (2008) Transgenerational Epigenetic Effects. Annual Review of Genomics and Human Genetics, 9, 233-257. 